\title{
Engineered genetic tools for directed gene regulation
}

\author{
PhD Thesis
}

\author{
in partial fulfilment of the requirements \\ for the degree "Doctor of Philosophy (PhD)" \\ in the Neuroscience Program \\ at the Georg August University Göttingen, \\ Faculty of Biology
}

submitted by

Rafael Rinaldi Ferreira

born in

Piraju, Brazil 
2019 
Thesis committee members

Jens Gruber Ph.D.

Junior Research Group Medical RNA Biology

German Primate Center, Göttingen

\section{Camin Dean Ph.D.}

Trans-synaptic Signalling Group

European Neuroscience Institute, Göttingen

Prof. Dr. Tobias Moser

Institute for Auditory Neuroscience

Göttingen University Medical Center (UMG), Göttingen

\section{Extended thesis committee members}

\section{Dr. Alexander Hahn}

Junior Research Group Herpesviruses

German Primate Center, Göttingen

\section{Prof. Dr. Ralf Heinrich}

Cellular Neurobiology Department

Schwann-Schleiden Research Center, Göttingen

\section{Prof. Dr. Manuela Schmidt}

Somatosensory Signalling Group

Max Planck Institute for Experimental Medicine, Göttingen 
Date of oral examination: 25.04.2019

\section{Affidavit}

Herewith I declare, that I prepared this thesis "Engineered genetic tools for directed gene regulation" independently and with no other sources and aids than quoted.

Göttingen, 08.03.2019

Rafael Rinaldi Ferreira 


\section{Original Publications}

\section{Published}

Böker KO, Lemus-Diaz N, Rinaldi Ferreira R, Schiller LT, Schneider S, Gruber J. The impact of the tetraspanin CD9 on exosome secretion and lentivirus infectivity. Mol Ther. 2018 Feb 7;26(2):634-647. doi: 10.1016/j.ymthe.2017.11.008.

Lara Schiller, Nicolás Lemus-Diaz, Kai Oliver Böker, Rafael Rinaldi Ferreira, Jens Gruber. Enhancing exo-AAV production by CD9 over-expression. Mol Ther Methods Clin Dev. 2018 Mar 29;9:278-287. doi: 10.1016/j.omtm.2018.03.008.

Lemus-Diaz N, Rinaldi Ferreira R, Bohnsack KE, Gruber J, Bohnsack MT. The human box C/D snoRNA U3 is a miRNA source and miR-U3 regulates expression of sortin nexin 27. Nucleic Acids Research, Volume 48, Issue 14, 20 August 2020, Pages 80748089, https://doi.org/10.1093/nar/gkaa549

\section{In Preparation}

Nicolas Lemus-Diaz*, Rafael Rinaldi Ferreira*, Stefan Schneider, Markus Bohnsack, Jens Gruber. The $5^{\prime}$-end of the C/D box snoRNA U3 is an evolutionary young miRNA. (in preparation, * for equal contributions)

Kai O. Böker, Stefan Schneider, Nicolas Lemus-Diaz, Daniela Lazzarini, Daniel B. Hoffmann, Lara Schiller, Rafael Rinaldi Ferreira, Wolfgang Lehmann, Arnd F. Schilling, Jochen Gaedcke, Jens Gruber. Chitosan Hydrogels efficiently release viral and nonviral gene-therapy vectors in vitro and in vivo. (in preparation)

Kai O. Böker, Nicolas Lemus-Diaz, Rafael Rinaldi Ferreira, Jochen Gaedcke, Stefan Schneider, Jens Gruber. Exosome purification, sRNA profiles and horizontal transfer of siRNAs between human cells (in preparation). 


\section{Abbreviations}

aa

AAV

$a b$

Ad

Amp

$A U$

bp

$\mathrm{Ca}$

CMV

CNS

CRLF3

$\mathrm{Da}$

DIV

DMEM

DMSO

DNA

dsRNA

dNTP

E. coli

ECL

EDTA

EF1a

Epo

EpoR

Exo-AAV

FACS

FCS

FIV

fuHA

GFP

GMO

GOI amino acid

Adeno-associated virus

antibody

Adenovirus

ampicillin

arbitrary unit

base pair

calcium

cytomegalovirus promoter

central nervous system

cytokine receptor-like factor 3

Dalton

days in vitro

Dulbecco's modified Eagle's medium

dimethysulfoxide

deoxyribonucleic acid

double-stranded RNA

desoxynucleotide triphosphate

Escherichia coli

enhanced chemiluminescence

ethylendiamine tetraacetate

elongation factor $1 \alpha$

Erythropoietin

Erythropoietin receptor

exosome-associated AAV

fluorescence-activated cell sorting

Foetal calf serum

feline immunodeficiency virus

fusogenic hemagglutinin

Green fluorescent protein

genetic modified organism

gene of interest 
Abbreviations cont.

\begin{tabular}{|c|c|}
\hline $\mathrm{HA}$ & hemagglutinin \\
\hline HIV & human immunodeficiency virus \\
\hline Her2/neu & human epidermal growth factor receptor 2 \\
\hline $\mathrm{k}$ & kilo \\
\hline $\mathrm{kDa}$ & kilo Dalton \\
\hline LTR & long terminal repeats \\
\hline LV & lentivirus \\
\hline MCS & multiple cloning site \\
\hline $\min$ & minute(s) \\
\hline $\mathrm{m}$ & milli \\
\hline$\mu$ & micro \\
\hline $\mathrm{Mg}$ & magnesium \\
\hline mRNA & messenger RNA \\
\hline miRNA & micro RNA \\
\hline miRNP & miRNA ribonucleoproteins \\
\hline MW & relative molecular weight \\
\hline ncRNA & non-coding RNA \\
\hline NeuN & neuronal nuclear antigen \\
\hline NGS & next generation sequencing \\
\hline PAM & protospacer adjacent motif \\
\hline PBS & phosphate buffered saline \\
\hline PCR & polymerase chain reaction \\
\hline PEG & polyethylene glycol \\
\hline PFA & paraformaldehyde \\
\hline PGK1 & phosphoglycerate kinase 1 \\
\hline RISC & RNA-induced silencing complex \\
\hline RFP & red fluorescent protein \\
\hline RNA & ribonucleic acid \\
\hline RPMI & Roswell Park Memorial Institute \\
\hline rRNA & ribosomal ribonucleic acid \\
\hline scFv & single-chain antibody variable fraction \\
\hline
\end{tabular}


SIV simian immunodeficiency virus

Abbreviations cont.

$\begin{array}{ll}\text { ss } & \text { single stranded } \\ \text { ds } & \text { double stranded } \\ \text { rpm } & \text { revolutions per minute } \\ \text { s } & \text { second(s) } \\ \text { sgRNA } & \text { single guide RNA } \\ \text { siRNA } & \text { small interfering RNA } \\ \text { snoRNA } & \text { small nucleolar RNA } \\ \text { Tris } & \text { Tris(hydroxymethyl)-aminomethane } \\ \text { TrkB } & \text { tyrosine receptor kinase B } \\ \text { U } & \text { unit } \\ \text { VSV-G } & \text { vesicular stomatitis virus glycoprotein } \\ \text { wt } & \text { wild type } \\ \text { x g } & \text { x-fold gravity }\end{array}$




\section{Acknowledgements}

First, I would like to thank my supervisor Jens Gruber for allowing me to be a part of his team, his guidance and patience.

I thank my family, specially my mother Cassia and my grandmother Irene who have always been my biggest inspirations and supporters. I love you both.

Special thanks to my lab mates Dr. Stefan Schneider for scientific support, countless cups of coffee and Pokémon adventures; Dr. Lara Schiller for bringing a tranquil and organized vibe to our work group; Dr. Kai Böker for his help with lab work, experiments and his family for taking in this weird foreigner (thank you Annika, Lars and Marlene); Dr. Nicolás Lemus for incredible support and friendship, this journey would certainly not be the same without your help.

Many thanks to our lab technicians Angelina Schuder, Astrid Backhaus and Ellen Eckermann-Felkl who provided outstanding technical support. I also thank Daniela Lazzarini for her friendship and technical advice.

I thank Dr. Ralf Heinrich and Nina Hahn from the Cellular Neurobiology Department at the Schwann-Schleiden Research Center for allowing me to collaborate with their work group.

I am thankful to the members of my advisory committee for the guidance during this project and extended committee members for accepting to be a part of this.

Finally, I would like to thank the University of Göttingen, the Göttingen Graduate School for Neurosciences, Biophysics, and Molecular Biosciences and the Neurosciences program for helping to fund me since the master's and allow a smooth integration of foreigner students like me in the German educational system. I specially thank the members of the Neurosciences program coordination team Sandra Drube for her exceptional help in absolutely all matters regarding the graduation program and Prof. Dr. Michael Hörner, who unfortunately is not with us anymore; your advices and kind words will always be remembered.

My gratitude to the German Primate Center for providing me the physical conditions to conclude this thesis. 
I thank the Brazilian National Council for Scientific and Technological Development Conselho Nacional de Desenvolvimento Científico e Tecnológico (CNPq) that funded me for the entirety of my PhD through the Science without Borders program - Ciência sem Fronteiras. 
LIST OF FIGURES

1. INTRODUCTION

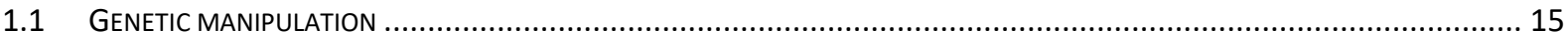

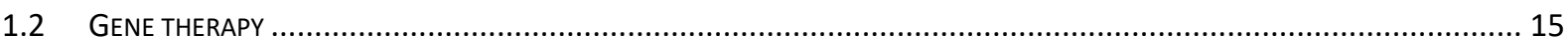

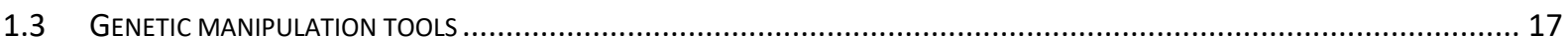

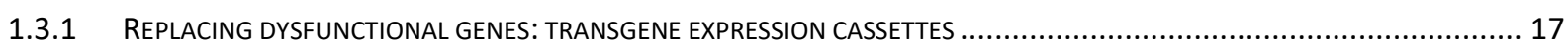

1.3.2 INHIBITING GENE EXPRESSION AT THE POST-TRANSLATIONAL LEVEL: RNA INTERFERENCE (RNAI) ................................19

1.3.2.1 Gene silencing on the study of biological function of new molecules: the CRLF3 receptor question . 20

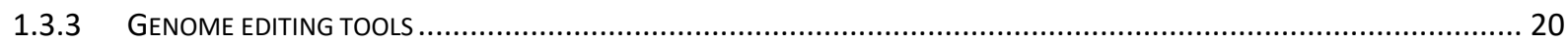

1.3.3.1 Clustered regularly interspaced short palindromic repeats (CRISPR)-Cas9 (CRISPR associated nuclease 9) 21

1.3.3.2 Further CRISPR applications: activation and inhibition of gene expression ....................................... 22

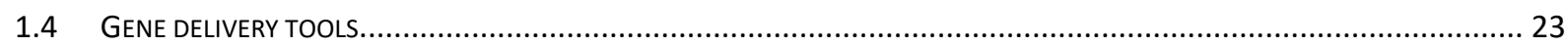

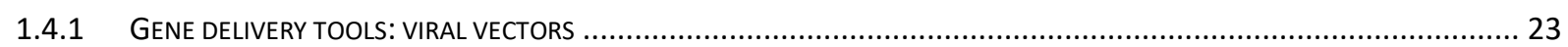

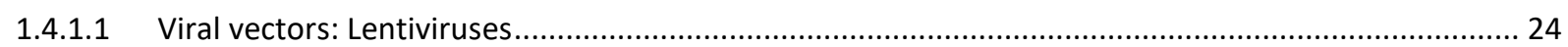

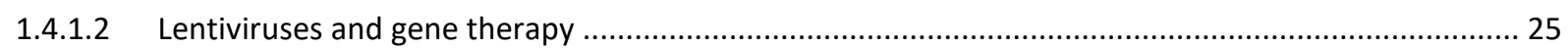

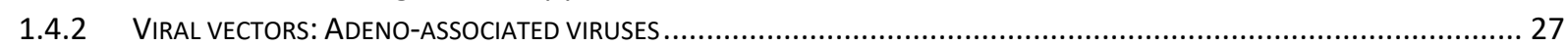

1.5 GENE EXPRESSION REGULATION: THE SMALL NUCLEOLAR RNA U3 AND MICRO RNA BIOGENESIS ....................................28

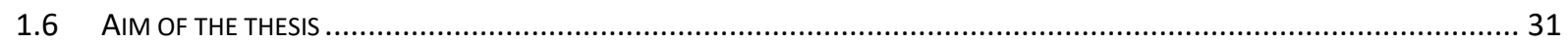

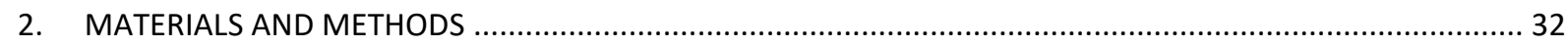

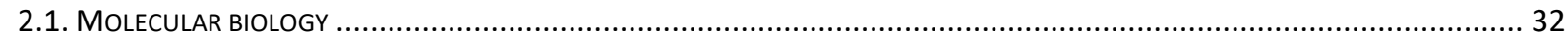

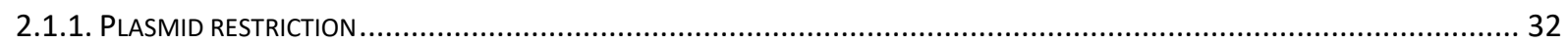

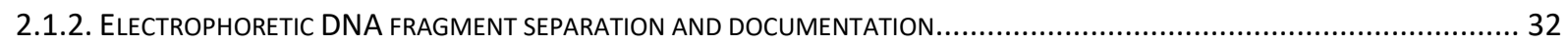

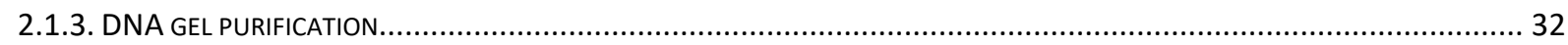

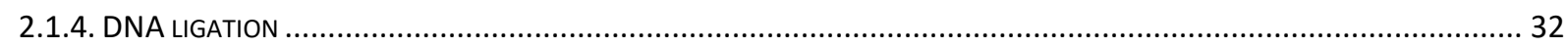

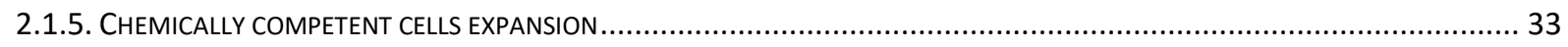

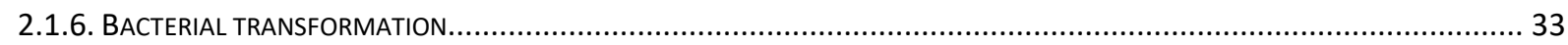

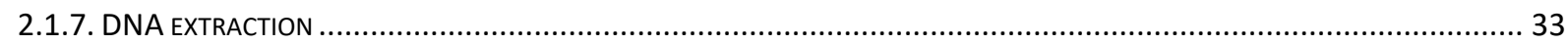

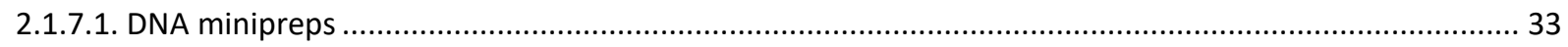

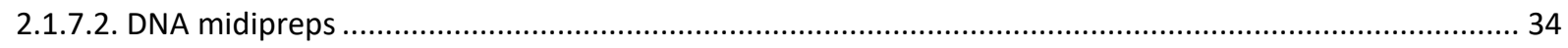

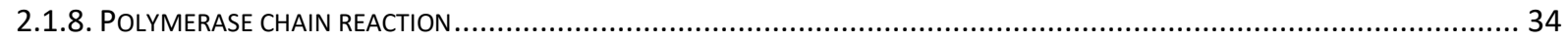

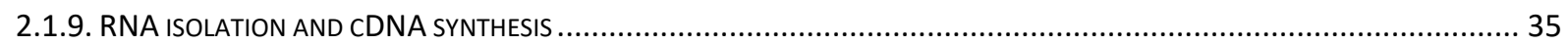

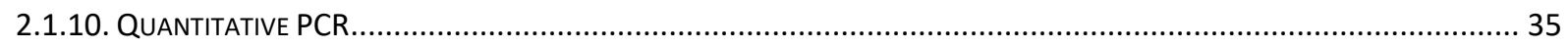

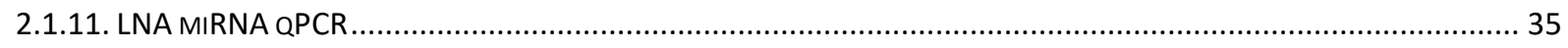

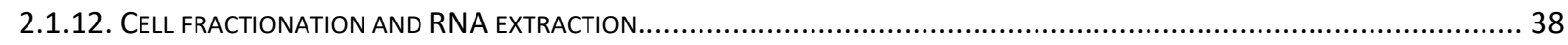

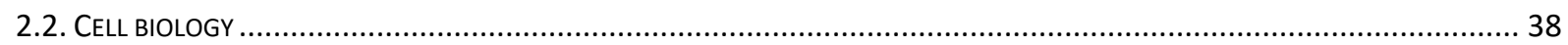

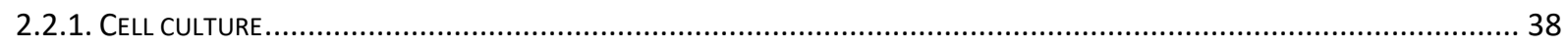

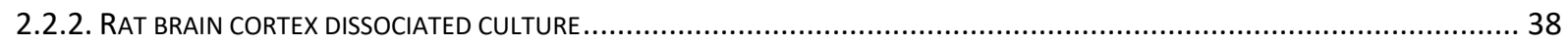

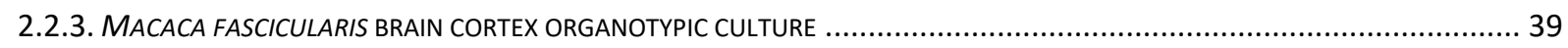

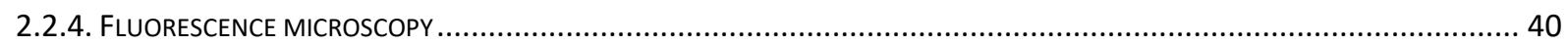

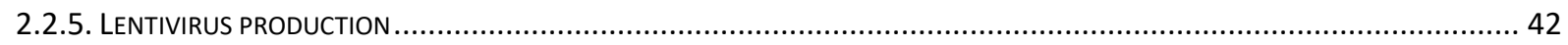

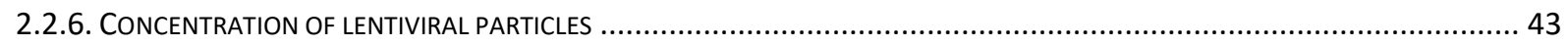

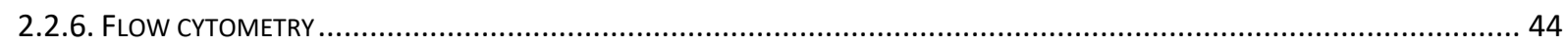

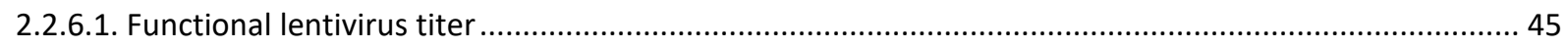

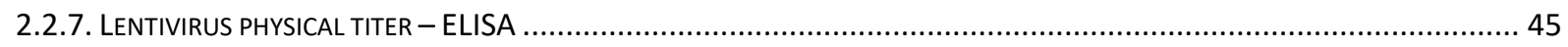




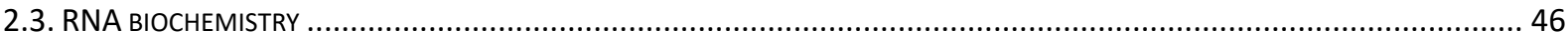

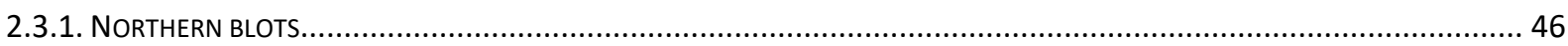

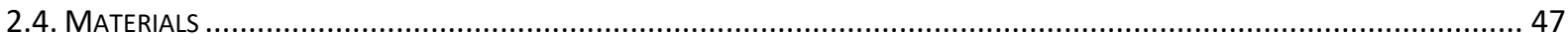

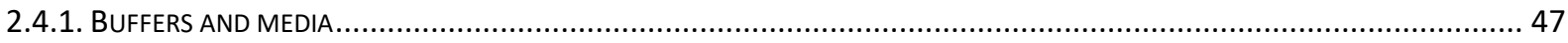

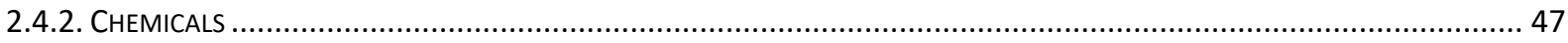

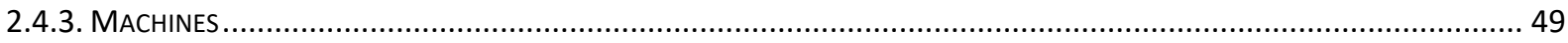

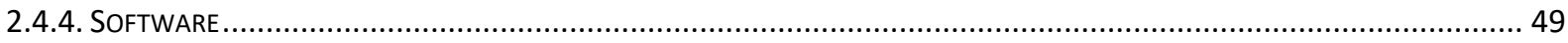

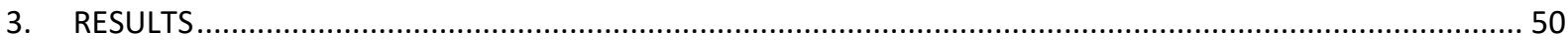

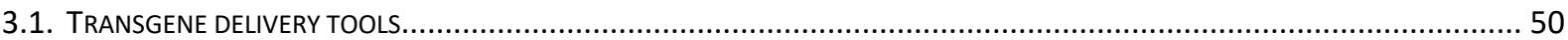

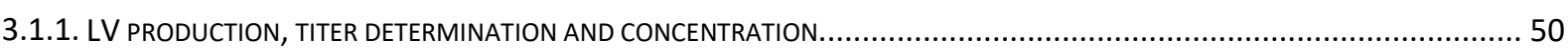

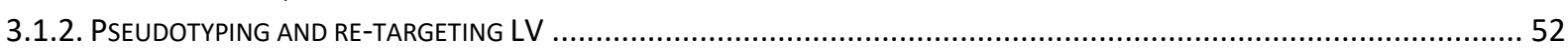

3.1.3. PSEUDOTYPED LV SUCCESSFULLY EXPRESS TRANSGENES IN MAMMALIAN TARGET CELL LINES.........................................5

3.1.4. PSEUDOTYPED LV LEADS TO SUCCESSFUL TRANSGENE EXPRESSION IN RAT BRAIN DISSOCIATED CULTURE............................ 55

3.1.5. PSEUDOTYPED LV LEADS TO SUCCESSFUL TRANSGENE EXPRESSION IN EX VIVO NON-HUMAN PRIMATES ORGANOTYPIC BRAIN

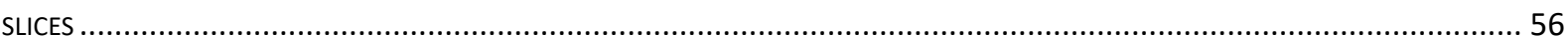

3.1.6. RE-TARGETED LV: NARROWING VIRAL TROPISM BY EXPRESSION OF SINGLE CHAIN ANTIBODIES AND FUSOGENIC MOLECULE....57

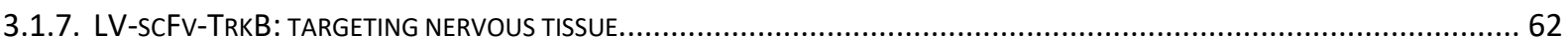

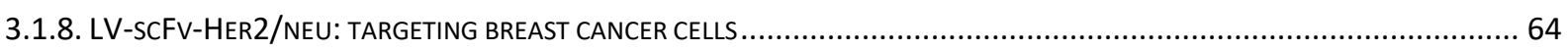

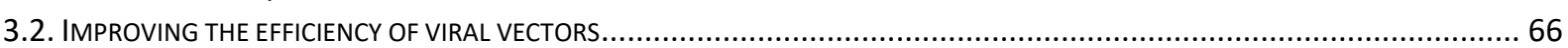

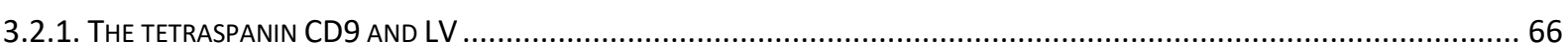

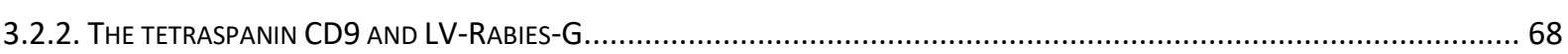

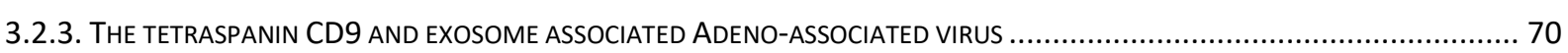

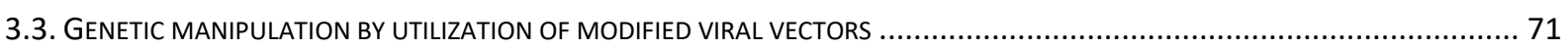

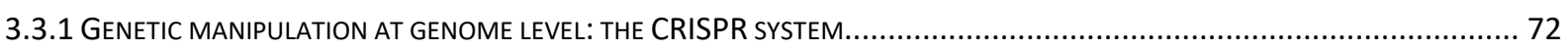

3.3.2 GENETIC MANIPULATION AT THE MRNA LEVEL: GENE SILENCING THROUGH RNA INTERFERENCE.................................... 73

3.3.3. GENETIC MANIPULATION AT THE POST-TRANSCRIPTIONAL LEVEL: SNORNA U3 AS A SOURCE OF MICRORNA .................... 77

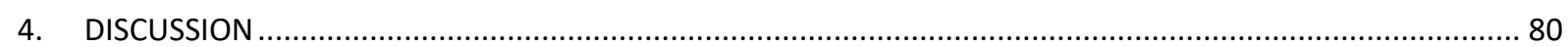

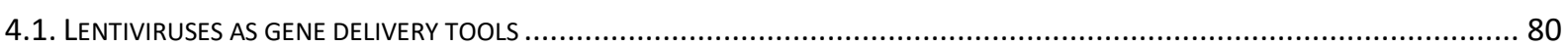

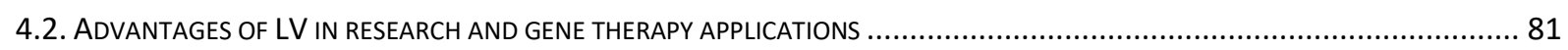

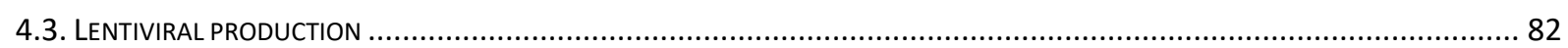

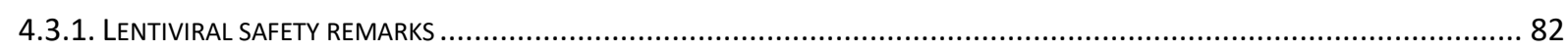

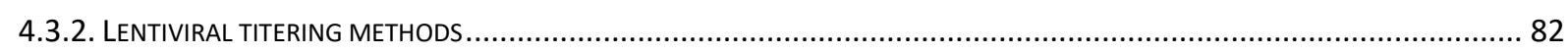

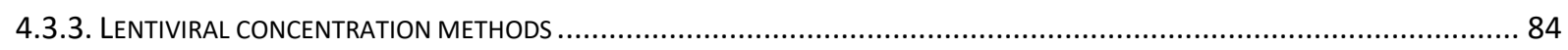

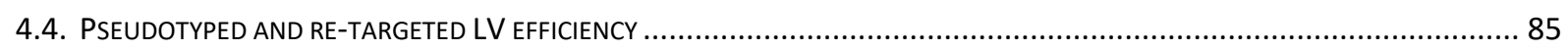

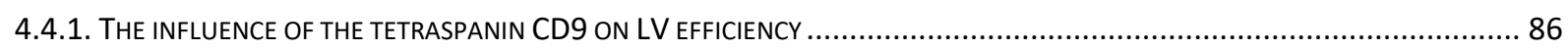

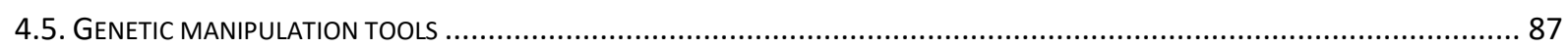

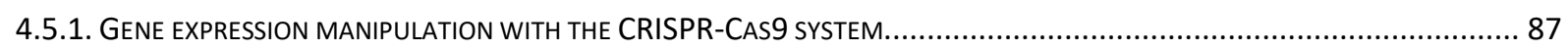

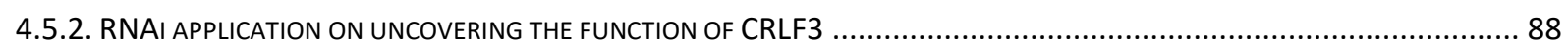

4.5.3. GENETIC MANIPULATION AT A POST-TRANSCRIPTIONAL LEVEL: UNTANGLING THE BIOLOGY OF A SNORNA ........................89

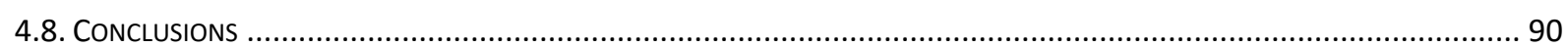

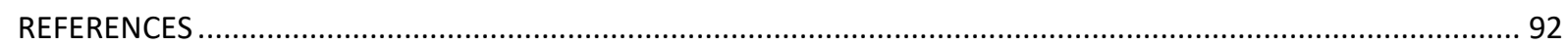

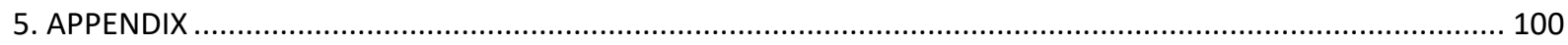

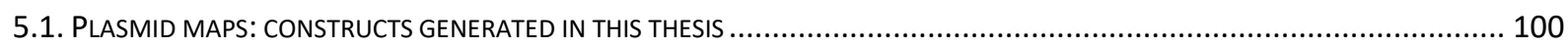

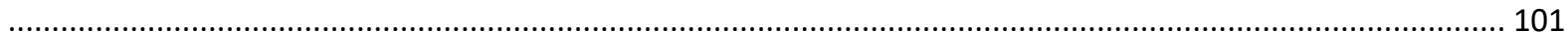

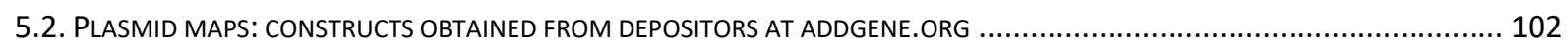

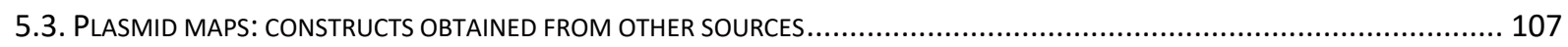




\section{List of figures}

Figure 1. Number of approved clinical trials involving gene therapy in humans from 1989 to $2018 \ldots . .17$

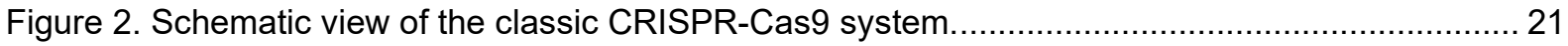

Figure 3. Schematic view of nuclease-deactivated Cas9 (dCas9) .................................................. 22

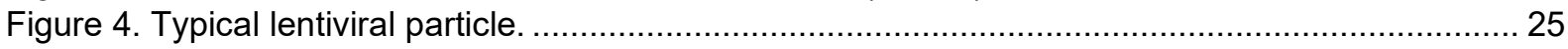

Figure 5. Schematic representation of HIV genome and packaging construct. ................................. 26

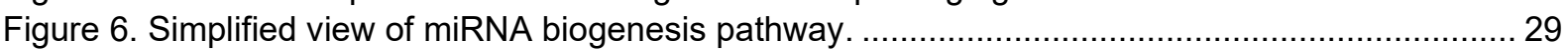

Figure 7. Dual fluorescence assay for assessment of miRNA functionality at single-cell level. ........... 30

Figure 8. Second generation lentivirus production workflow...................................................... 51

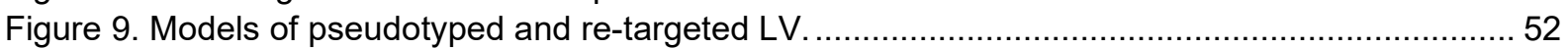

Figure 10. LV-VSV-G transduction pattern in HEK293 and Hela cells. ......................................... 53

Figure 11. LV-Rabies-G transduction pattern in HEK293, Hela and differentiated SH-SY5Y cells...... 54

Figure 12. LV-VSV-G and LV-Rabies-G transduction pattern in Wistar rat brain dissociated culture. . 56

Figure 13. LV-VSV-G and LV-Rabies-G transduction pattern in Macaca fascicularis organotypic brain

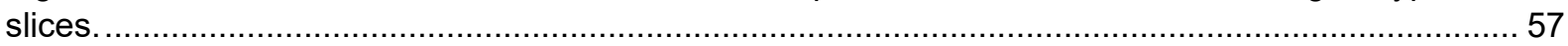

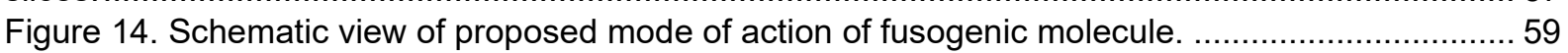

Figure 15. Construct for expression of molecules on mammalian cell membranes............................. 60

Figure 16. Histogram of immunoassay for detection of protein on the outer cell membrane in HEK293

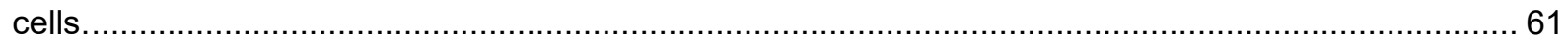

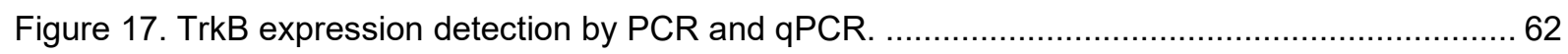

Figure 18. Neuroblastoma derived SH-SY5Y cells morphology upon differentiation. .......................... 63

Figure 19. LV-fuHA and LV-scFv-TrkB-fuHA transduction pattern in differentiated SH-SY5Y............63

Figure 20. LV-scFv-TrkB-fuHA transduction pattern in HEK293 and Hela. ......................................6 64

Figure 21. Her2/neu expression detection by qPCR in several cell lines. .......................................65

Figure 22. LV-Her2/neu-fuHA transduction pattern in SKBR3 and HEK293. ................................... 65

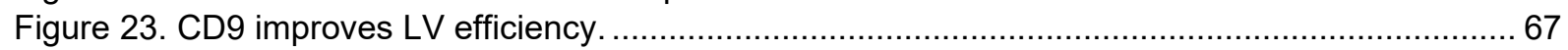

Figure 24. Physical titer comparison LV-Rabies-G vs LV-Rabies-G-CD9. …................................. 68

Figure 25. Transduction pattern and fluorescence quantification of LV-Rabies-G and LV-Rabies-G-

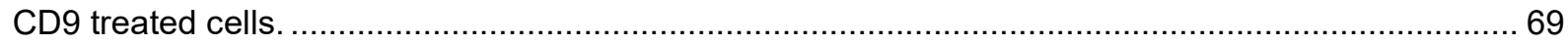

Figure 26. CD9 boosts exosome production and exo-AAV efficiency............................................. 71

Figure 27. GFP expression disruption by CRISPR-Cas9 in HEK293 and SH-SY5Y .......................... 73

Figure 28. Relative expression of CRLF3 in HEK293 cells as assessed by qPCR. …......................... 75

Figure 29. Relative expression of CRLF3 in SH-SY5Y and differentiated SH-SY5Y under hypoxia as

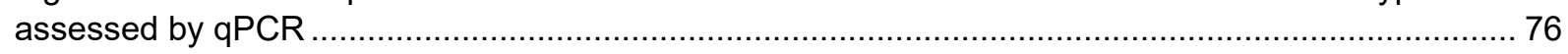

Figure 30. Expression of CRLF3 in different cell lines measured by qPCR $\ldots \ldots \ldots \ldots \ldots \ldots \ldots \ldots \ldots \ldots \ldots \ldots . . . . \ldots 77$

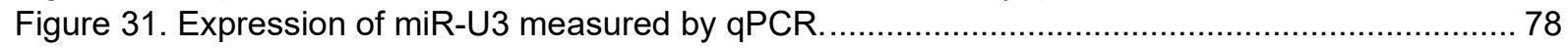

Figure 32. Northern blot of nuclear and cytoplasmic expression of U3........................................ 79

Figure 33. Expression of U3 in nuclear and cytoplasmic fractions measured by qPCR.................... 79

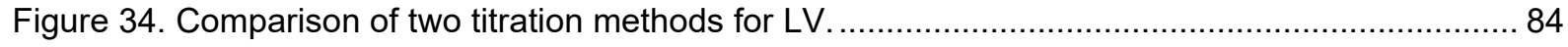




\section{List of tables}

Table 1: PCR reaction mix general protocol ......................................................................... 34

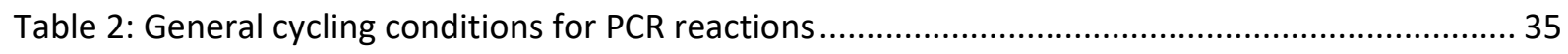

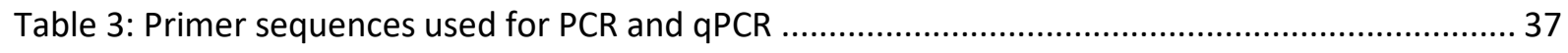

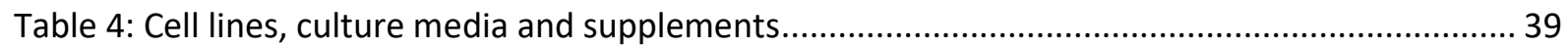

Table 5: Plasmid vectors used for cloning ....................................................................... 41

Table 6: Plasmids used for lentiviral production.................................................................... 43

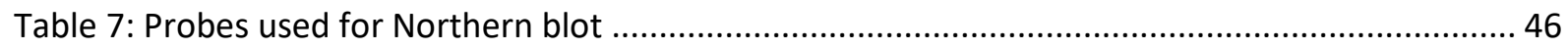

Table 8: Buffers and bacterial media composition.......................................................... 47

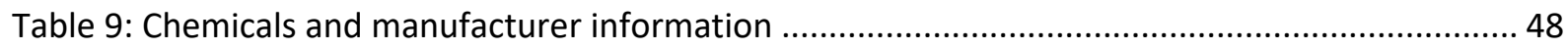

Table 10: Machines, models and manufacturer information ..................................................49

Table 11: Transduction efficiency of pseudotyped LV .......................................................... 55 


\section{Introduction}

\subsection{Genetic manipulation}

Genetic manipulation or genetic engineering is the ability to modify the behaviour of a gene or group of genes. In biological research, since nucleic acids were shown to be responsible for control of cellular functions and transfer of biological information, the urge to understand how genetic material works led to the development of tools in order to manipulate gene expression.

By observing the phenotype of an organism upon enhancing, inhibiting or disrupting gene expression it is possible to understand how a gene works and how it influences a target organism.

Transgenic or genetic modified organisms (GMO) are organisms that express genes originally expressed by different organisms. They are invaluable tools for research, agriculture, industrial and biomedical applications for they allow the generation of new research models and tools for production of important biomolecules such as hormones, drugs and enzymes.

Transgenic animal models are key components on biomedical research. The advancements on understanding and treating genetic disorders on the past decades is due to the ability of mimicking genetic conditions on target organisms that would otherwise be impossible to be studied. However, the generation of transgenic or knock-out animal models, especially complex organisms such as nonhuman primates is laborious, time consuming and expensive (Racay, 2002).

The refinement and development of genetic manipulation techniques such as genome editing tools are thought to be the key for a new era of GMO production, leading to easier, more controlled alteration of gene expression on a genomic level.

\subsection{Gene therapy}

The generation of GMO led to a greater understanding of genetic diseases. Changes in the expression profile of a single gene or group of genes is the cause of most incurable genetic disorders, such as neurodegenerative diseases. 
Gene therapy aims to try and correct dysfunctional genes by manipulation of their expression through transgene expression or gene expression suppression. For successful gene therapy, the correct foreign genes need to be delivered to the dysfunctional cells where they can be expressed and lead to an effect. There are several gene manipulation tools and gene delivery tools that have been developed and some of them are already in use in the clinics. These tools will be described in greater detail in this text.

One of the greatest concerns regarding gene therapy in humans is the safety of the procedure. A lot of effort has been put on developing and improving gene engineering tools and gene delivery tools regarding their safety and efficiency. Several clinical trials have been performed with different degrees of success (Sheridan, 2011). The first reported gene therapy study was performed by Blaese and colleagues in 1990 aiming to rescue the expression of an enzyme (adenosine deaminase - ADA) in T cells, to limited success (Blaese et al., 1995). Ten years later, Cavazzana-Calvo and colleagues were able to replace a defective cytokine receptor subunit that prevented $T$ and natural killer lymphocyte differentiation. Even though a causality was reported, that study was considered the first successful trial involving gene therapy (Cavazzana-Calvo, 2000). Since the 1990's a variety of gene therapy clinical trials have been approved worldwide (figure 1). 


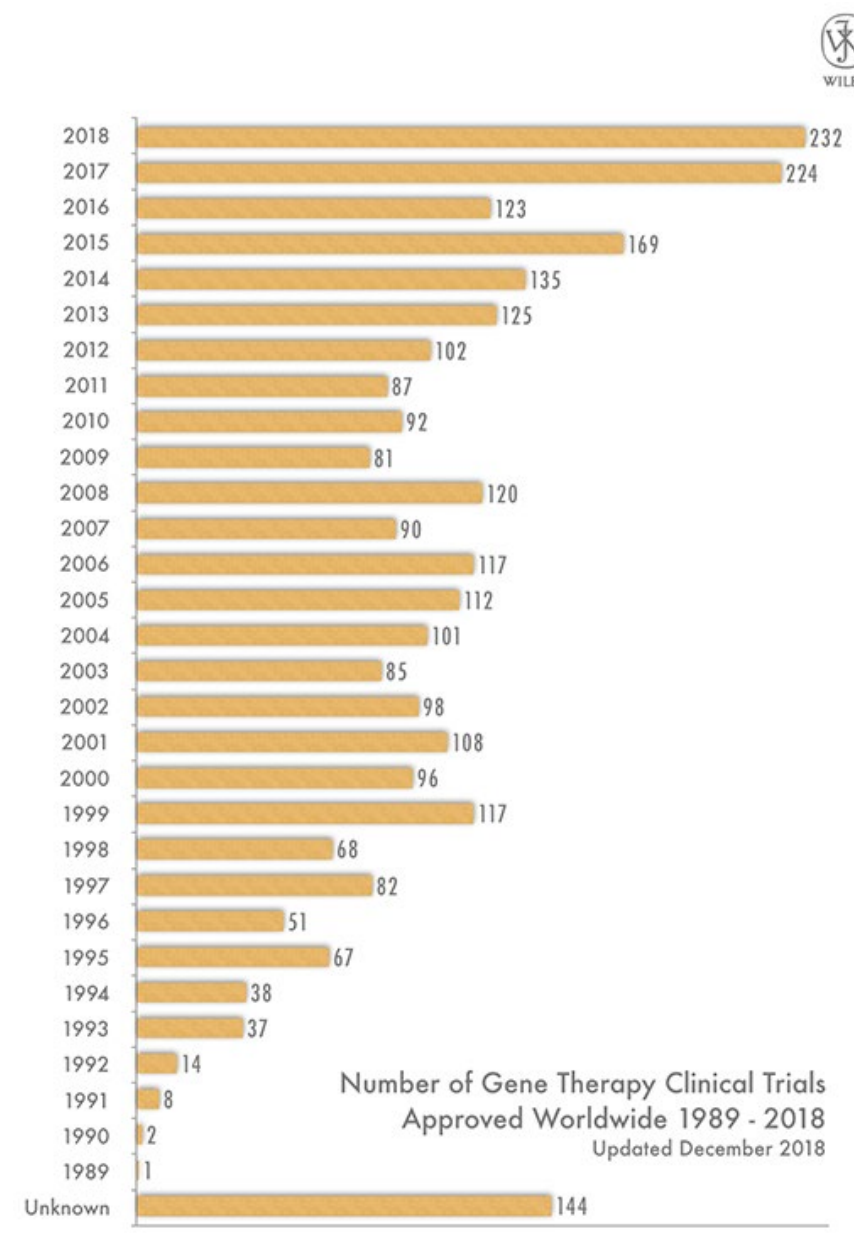

Figure 1. Number of approved clinical trials involving gene therapy in humans from 1989 to 2018. The development of new genetic manipulation and gene delivery tools led to a substantial increase in the number of approved gene therapy clinical trials worldwide. Source: The Journal of Gene Medicine.

\subsection{Genetic manipulation tools}

A genetic disorder can be caused by a single gene or pool of genes that are malfunctioning by either lack of expression or overexpression of its products. Gene therapy aims to correct the disfunctions by introducing specific transgenes that can replace, inhibit or activate a faulty gene function.

\subsubsection{Replacing dysfunctional genes: transgene expression cassettes}

A commercially available gene therapy treatment is sold under the name Glybera and aims to replace the function of a defective lipoprotein lipase (LPL) caused by a singlegene defect (Stroes et al., 2008). 
Genetic disorders caused by a single gene or monogenic disorders such as haemophilia and muscular dystrophy are better understood and where the focus of most gene therapy trials to date have been put on. Most disorders are caused by lack of expression of a gene that can be counterfeited by insertion of a transgene expression cassette containing a copy of the faulty gene into the patient cells, usually in the form of a complementary DNA (cDNA) paired with a promoter.

The choice of the promoter to drive transgene expression needs to be careful and lead to long term expression. For in vitro and some in vivo applications, viral-based promoters are widely used for they lead to strong expression of the transgene and have a reduced size, which facilitates its packing into delivery tools. The cytomegalovirus (CMV) promoter is one of the most common promoters used for transgene expression but it was shown to elicit a higher immune response to the transgene product and lead to a shorter-term expression (Papadakis et al., 2004), possibly because the mammalian cells evolved to detect and countereffect viral components.

Eukaryotic-based promoters are a better choice when it comes to human gene therapy. They provide in general weaker transgene expression and have longer sequences when compared to viral promoters but allow for longer term expression. Furthermore, the possibility of tissue-specific promoters adds an additional layer of safety for the transgene expression can be directed to a population of cells.

The elongation factor $1 \alpha(E F 1 \alpha)$ and the human phosphoglycerate kinase 1 (PGK1) promoters are non-tissue specific promoters that were found to lead to the strongest transgene expressions when compared to CMV promoter (Fan et al., 2000), (Ramezani et al., 2000). The reduced size of EF1a promoter makes it an interesting choice for gene therapy.

The use of a cell-specific promoter is indicated for gene therapy for a variety of studies showed that expression of transgenes in antigen presenting cells (APC) can lead to immune response (Hartigan-O'Connor et al., 2001), (Pastore et al., 1999), (Weeratna et al., 2001). Tissue-specific driven expression also leads to lower risks of cell toxicity and adverse effects caused by transgene expression. A comprehensive summary of tissue-specific promoters for use in gene therapy, including central nervous system (CNS) and cancer cells can be found at (Papadakis et al., 2004). 


\subsubsection{Inhibiting gene expression at the post-translational level: RNA interference (RNAi)}

RNA interference methods allow for gene expression repression at the posttranslational level by interfering with messenger RNA (mRNA) biogenesis. The introduction of double-stranded RNA containing specific complementary sequences to target mRNAs can lead to inhibition of mRNA activity through cleavage of the complex by the RNA interference silencing ribonucleoprotein complex (RISC) (figure 6).

In 1998 Fire and colleagues used double-stranded RNA (dsRNA) to drive strong gene silencing in the nematode Caenorhabditis elegans. They discovered that the silencing mechanism was due to the interaction of the antisense strand of the dsRNA with the complementary target mRNA (Fire et al., 1998). The synthetic dsRNA is also known as small interfering RNA (siRNA).

Short hairpin RNA (shRNA) are single-stranded RNA molecules that naturally form a hairpin like structure. These molecules are synthesised by RNA polymerase 3 and therefore need a vector containing a suitable promoter (such as U6) to be properly expressed in cells (Cullen, 2005). Both RNAi systems act by interaction with mRNA inhibiting the translation step.

A commercially available treatment consisting of RNAi under the name Patisiran aims to treat hereditary transthyretin-mediated amyloidosis by decreasing the expression of transthyretin (TTR) and therefore the hepatic accumulation of misfolded TTR (Kristen et al., 2019).

Although strong levels of gene silencing can be achieved through RNAi techniques, these tools are not without flaws. Off-target effects are an issue and therefore the target sequences need to be carefully chosen. The shRNA needs to be delivered as a construct in combination with a pol 3 suitable promoter, which is known to not allow for a tight controlled regulation of expression (Cullen, 2005). 


\subsubsection{Gene silencing to study of biological function of new molecules}

The cytokine receptor-like factor 3 (CRLF3) is an orphan receptor whose function in mammalian organisms has yet to be uncovered. It is part of a family of receptors known to interact with type I cytokines.

Erythropoietin (Epo) is a type I cytokine that increases the amount of red blood cells by inhibiting apoptosis (Fisher, 2003). Besides its classical role in erythropoiesis, Epo has been shown to also act on development of nervous tissue (Masuda et al., 1994), (Konishi et al., 1993) and induce neuroprotection (Morishita et al., 1996), (Sakanaka et al., 1998), (Brines et al., 2000).

Leist and colleagues demonstrated that modified Epo molecules without hematopoietic activity were still able to drive protector effects through interactions with receptors other than the classic Epo receptor (EpoR) (Leist et al., 2004). The search for neuroprotective Epo receptors then began in invertebrates and in 2017 Hahn and colleagues showed that an insect ortholog of CRLF3 was involved in Epo mediated neuroprotection (Hahn et al., 2017). These findings bring the question of whether the human CRLF3 conserve the same function as its counterpart in insects. Gene silencing is a powerful tool to help answer questions regarding unknown biological functions of emergent molecules and therefore presents itself as a method to be utilised in order to better understand CRLF3 biology.

\subsubsection{Genome editing tools}

Targeted genome editing techniques take advantage of the ability of engineered nucleases to promote double-strand breaks (DSB) in the DNA molecule leading to activation of the DNA self-repair mechanism by homologous recombination allowing insertion of exogenous sequences or non-homologous end-joining, which can lead to small insertions or deletions and consequent loss of function mutations (González et al., 2014). It allows modifications in the genome such as insertions, replacement or removal of specific DNA sequences, thus enabling specific, controlled genome editing. The currently most used techniques are Zinc finger nucleases (ZFN), Transcription activator-like effector nucleases (TALENs) and Clustered regularly interspaced short palindromic repeats (CRISPR)/Cas9 (CRISPR associated nuclease 9). The latter system has attracted much attention on the past years for it is an extremely versatile tool that allows for DBS, activation or inhibition of gene expression on a genomic level. 


\subsubsection{Clustered regularly interspaced short palindromic repeats (CRISPR)- Cas9 (CRISPR associated nuclease 9)}

CRISPR-Cas9 is a system derived from an RNA-guided eukaryotic defence system. It consists in a region of bacterial genome containing short DNA sequences copied from exogenous organisms such as virus and phages intercalated within palindromic repeats in the host genome. When associated with Cas endonucleases it acts as a primitive adaptative immune system (Mojica et al., 2005), (Pourcel et al., 2005).

The specificity of the cleavage by Cas is driven by a CRISPR RNA (crRNA) transcribed from a locus in the CRISPR sequence which associates to a transactivating RNA (tracrRNA) to target invader organism's genomes in a specific manner (Deltcheva et al., 2011). For a straight forward schematic of the system see figure 2. A simpler version of the system has been developed in which the complex crRNA+tracrRNA has been put together into a single guide RNA (sgRNA) (Gasiunas et al., 2012).

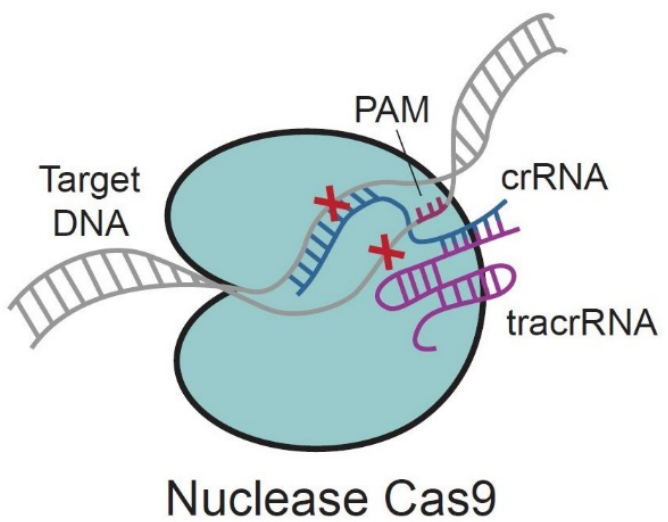

Figure 2. Schematic view of the classic CRISPR-Cas9 system. Figure depicts the association of a CRISPR RNA (crRNA) with transactivating RNA (tracrRNA) to form a single guide RNA (sgRNA) which in combination with a nuclease Cas9 targets a specific genome sequence adjacent to a protospacer adjacent motif (PAM). The Cas9sgRNA complex leads to a specific DBS dictated by the sgRNA sequence complementary to the genome. Source: (La Russa and Qi, 2015).

In 2013 the first reports of successful translation of the prokaryotic system for use in human cells were published (Cong et al., 2013), (Mali et al., 2013a). Since then, several alterations and improvements have been implemented aiming to broaden the 
application of the CRISPR system and overcome its disadvantages, such as off-target effects and possible immune response against Cas9 for in vivo applications.

\subsubsection{Further CRISPR applications: activation and inhibition of gene expression}

By preventing Cas9 from its nuclease activity, the utility of the CRISPR-Cas9 system can be further extended. Several studies describe a method to disrupt Cas 9 nuclease activity, turning it into an RNA guided DNA binding protein (Qi et al., 2013), (Mali et al., 2013b), (La Russa and Qi, 2015). By mutating its nuclease active domains, a nuclease- defective Cas9 or dead Cas9 (dCas9) was generated, see figure 3.

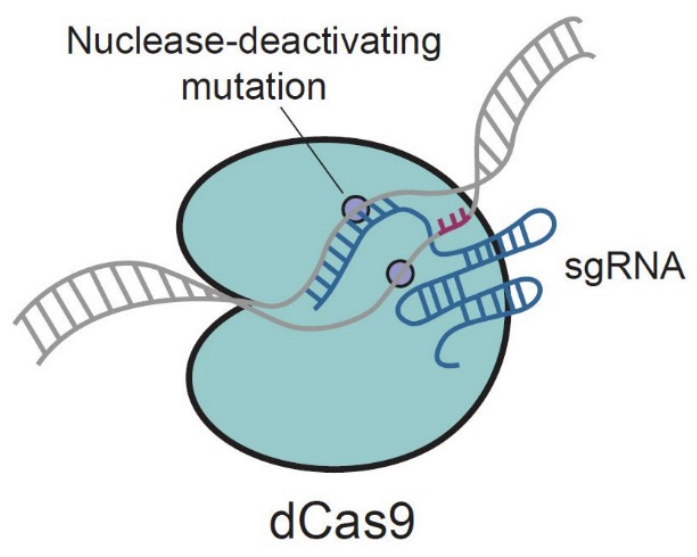

Figure 3. Schematic view of nuclease-deactivated Cas9 (dCas9). Mutations on the nuclease activity domain of Cas9 leads to a molecule incapable of inducing DSB. The protein will still interact with an sgRNA and be targeted to a specific genomic region where it will sit and diminish the availability of this region to the transcription machinery. Source: (La Russa and Qi, 2015).

The new dCas 9 protein can be used as a transcription factor-like molecule. By appending factors to dCas 9 the transcription machinery can be attracted to a specific promoter region activating gene transcription. This method is known as CRISPR activation or CRISPRa.

Several studies report fusing different activators to dCas 9 in order to achieve enhanced expression such as VP64, p65, Rta and arrays of combined activators (SunTag, SAM, 
VPR) for stronger effect. See (Mali et al., 2013b), (Gilbert et al., 2013), (Maeder et al., 2013), (Perez-Pinera et al., 2013), (Tanenbaum et al., 2014), (Chavez et al., 2014), (Konermann et al., 2015).

Additionally, dCas9 can be fused to transcription inhibitors factors that once driven to a promoter genomic region will prevent the transcription machinery to reach a specific gene, leading to gene repression. This method is known as CRISPR interference or CRISPRi. Although it has been shown that dcas9 alone when guided to DNA can decrease gene expression (Gilbert et al., 2013), (Qi et al., 2013), when inhibitor factors are fused to dCas9 the repression efficiency is more accentuated (Konermann et al., 2013), (Gilbert et al., 2014).

\subsection{Gene delivery tools}

All gene manipulation techniques described above have a common treat: the necessity of expression of a foreign gene in the target cell. To do so, gene delivery tools that can effectively deliver the desired genetic material into the adequate systems are necessary.

The most used techniques to insert transgenes into organisms in vitro are physical techniques such as electroporation, where a brief electric current will open pores on the cell wall or membrane allowing the diffusion of genetic material into the cell. Chemical methods based on cationic lipids and DNA precipitation with salts are also commonly used for they are simple to use and effective.

\subsubsection{Gene delivery tools: viral vectors}

When it comes to in vivo and gene therapy applications, these methods prove to be inadequate due to difficulty of assessment of targeted regions and possible toxicity. Viral vectors are the tool of choice because they exploit the natural role of viral particles as organisms that invade and use cell machinery for replication of their genetic material.

Adenoviruses (Ad), adeno-associated viruses (AAV), retroviruses and lentiviruses (LV) are amongst the most commonly used gene delivery tools for in vivo applications. They 
have been engineered to be replication deficient and deliver solely the gene of interest (GOI) into host cells. Every viral type has its own applications, depending on which organisms they can transduce, the packaging limit, if it can transduce dividing or nondividing cells, if it elicits an immune response among others.

All the afore mentioned viral vectors are currently being tested or have been tested on clinical trials. For an overview on which viruses are being used for different clinical purposes, see (Sheridan, 2011). For the purposes of this thesis LV and AAV will be described in greater details.

\subsubsection{Viral vectors: Lentiviruses}

Lentiviruses are enveloped single-stranded RNA viruses from the Retroviridae family. Once inside the host cell the viral genome is reverse transcribed through a reverse transcriptase enzyme producing cDNA that can be integrated into the host genome. Several LV are mammalian pathogens known to cause immunodeficiency-like diseases i.e. Simian immunodeficiency virus (SIV), Feline immunodeficiency virus (FIV) and human immunodeficiency virus (HIV).

HIV is an important pathogen that causes an acquired immunodeficiency syndrome (AIDS) in humans by targeting immune cells such as CD4+, macrophages and dendritic cells. There are two main subtypes known as HIV-1, the most common and virulent and HIV-2, restricted to Africa and with apparent lower virulence.

Since the outbreak of AIDS in the early 1980s, extensive research efforts have been made in order to understand HIV biology. Although there is no cure for HIV infection to date, those efforts were crucial for the development of prevention strategies and treatment programs, as well as the advent of utilizing the virus as a biotechnological tool that could be used in researches advantage.

The genome of the virus is comprised of several genes for expression of structural viral elements as well as enzymes and products for nuclear trafficking, which allows the viral genes to be transported into the cell nuclei. These genes are flanked by 5 'and 3' long terminal repeats (LTR) regions which act as promoter for viral gene expression and polyadenylation and contains a packaging signal to drive encapsulation of newly produced viral genome during viral replication cycle (figure 5). 


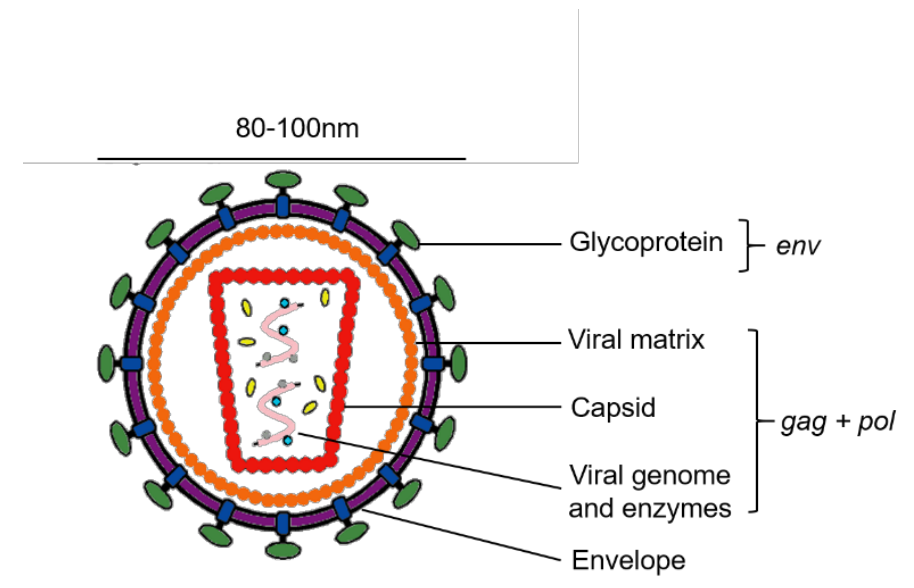

Figure 4. Typical lentiviral particle. Scheme shows the main viral components and the viral genes responsible for expression. Lentivirus are around $80-100 \mathrm{~nm}$ in diameter. When shedding from the host cell they are coated with a patch of membrane that will become the viral envelope and determine viral tropism. Adapted from https://library.med.utah.edu/WebPath/TUTORIAL/AIDS/AIDS004.html

\subsubsection{Lentiviruses and gene therapy}

As research tools for gene delivery, SIV, FIV and HIV-1 based viral particles have been engineered to deliver genes of interest into host cells in a controlled and safer manner when compared to their wt versions.

HIV-1 based LV are efficient gene delivery tools for both in vitro and in vivo gene therapy. The main advantages of this system are rooted in the biology of the virus itself: the ability to infect non-dividing cells which makes them useful tools for neurosciences applications;

- The fact that the viral genome is integrated into the host genome, leading to long term, stable transgene expression;

- The high yields of viral particles by producer cells;

- The relatively high packing capacity in the range of $\sim 8.5 \mathrm{~kb}$ which allows for the incorporation of longer constructs consisting of an adequate promoter and $\mathrm{GOI}$;

- The possibility of altering the viral tropism by manipulating the expression of proteins on the viral envelope (figure 4).

Perhaps the most striking feature of HIV based LV is the straightforward manipulation of the viral tropism. When exiting the host cell, each viral particle is coated with a patch 
of the cell membrane that will become the viral envelope. The tropism of the viruses is dictated by the molecules expressed on the envelope (figure 4). Pseudotyping LV is a procedure by which glycoproteins from other virus types are incorporated into the LV envelope, providing the new viral particles with the targeting affinity of the original virus type. The vesicular stomatitis virus glycoprotein (VSV-G) is widely used to pseudotype LV for research purposes. It gives rise to viral particles with a broad tropism, greatly increasing viral transduction efficiency.

The use of a pathogenic virus such as HIV as vectors for gene therapy is of course source of concern. On the past decades HIV was thoroughly studied and the role of each component from the viral genome was assessed.

Nowadays, only three out of nine wt HIV genes are present in constructs used to produce pseudotyped LV: gag, rev and pol responsible for expression of the viral capsid, nuclear export element and viral enzymes (reverse transcriptase and integrase), respectively (figure 5).
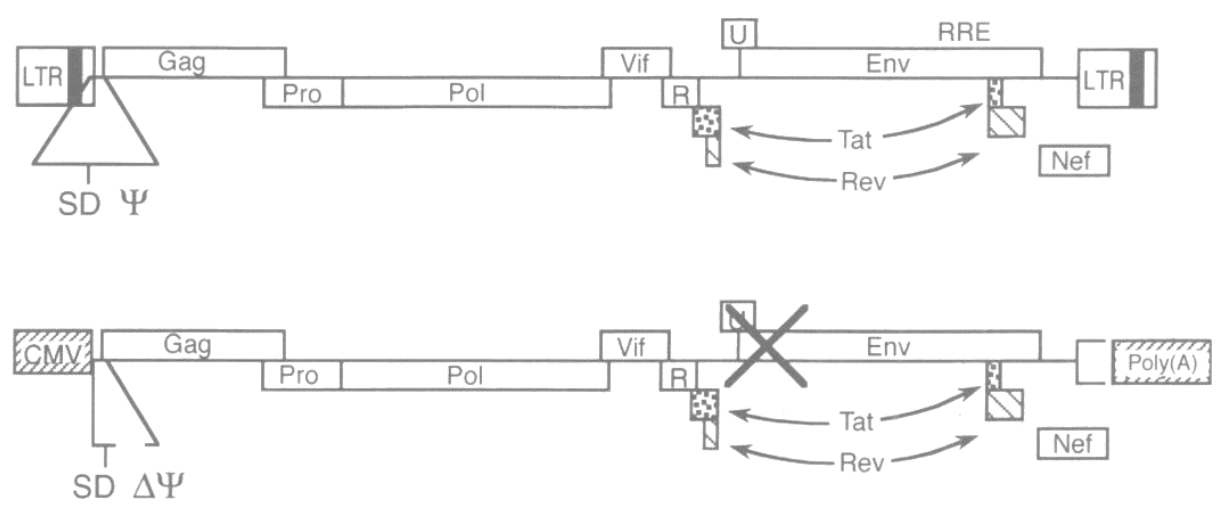

Figure 5. Schematic representation of HIV genome and packaging construct. Upper panel shows wt viral genome flanked by the two long terminal repeat (LTR) regions. On modern LV expression cassettes only gag, pol and rev are present under expression of a constitutive promoter (CMV) lower panel. Source: (Naldini et al., 1996)

Zufferey and colleagues (Zufferey et al., 1998) further improved the LV system by engineering self-inactivating LV particles. Deletions on the promoter region of the LTR 
lead to viruses that will deliver a GOI and will not enter a replication cycle inside the cell.

HIV-1 based pseudotyped viruses are produced in high protein producing cell lines modified to express a Simian vacuolating virus (SV40) large T antigen (Ali and DeCaprio, 2001) by transient transfection of plasmids containing viral components (gag, pol, rev), GOI flanked by LTR and an envelope protein (second generation method). Advancing a step further regarding the safety of the system, third generation lentiviral production method separates the rev element in another plasmid. This decreases the chances of viral components recombination. New viral particles bud from the producer cells carrying a patch of the cell membrane as envelope and are secreted into the culture medium. Supernatant containing viral particles can be used directly for transduction after clarification by centrifugation and filtration. Additionally, the $\mathrm{SN}$ can be concentrated to increase the viral titer and facilitate inoculation into organisms.

In 2003 Carl June and colleagues (Levine et al., 2006) performed the first clinical trial using HIV-1 based LV for gene therapy. Ironically the target of the trials was the treatment of chronic HIV infected patients. The subjects had CD4+ cells treated ex vivo with LV containing an antisense gene against wt HIV envelope. The cells were later reinfused into the patients. Immune function improved in four out of five subjects. Other clinical trials using LV for gene therapy followed including a $\beta$-thalassemia treatment (Thompson et al., 2016) and Parkinson's disease (Palfi et al., 2014) (Palfi et al., 2018) showing that although in need of efficiency improvements, the LV system is safe for use in patients.

\subsubsection{Viral vectors: Adeno-associated viruses}

Adeno-associated virus (AAV) are single-stranded DNA viruses from the Parvoviridae family. They are small non-enveloped particles $(20-25 \mathrm{nM})$ that are not known to be pathogenic. To date twelve different human AAV serotypes have been reported (AAV1 to AAV-12). Its replication is dependent on co-infection with other viruses such as adenoviruses (Carter, 2004).

AAVs are widely used in gene therapy for they can transduce non-dividing cells, have a broad range of tropism (dependent on the serotype) and are replicant deficient in the 
absence of associated viruses (Naso et al., 2017). Since the first clinical trial in the early 1990s involving AAV by Flotte and colleagues (Flotte et al., 2008), a number of studies were published on the subject (Carter, 2004). Recently, positive effects on AAV efficiency were reported upon association with extracellular vesicles, namely exosomes (Maguire et al., 2012). The so called exo-AAV are an interesting new tool for gene therapy, because in theory these particles can be pseudotyped by altering the molecules expressed by the exosomes.

\subsection{Gene expression regulation: the small nucleolar RNA U3 and micro RNA biogenesis}

microRNA (miRNA) are small non-coding RNA composed of 22nt that play a role in mRNA expression regulation. They are abundant in the in the mammalian cell and are also present in plants and even viruses. Their biogenesis is regulated by an intricated machinery that starts in the nuclei and ends the process in the cytoplasm. Notably in the nucleus the nascent miRNA molecule is processed by Drosha and DGCR8 and then exported to the cytoplasm by Exportin-5 (XPO5), where it is further cleaved by a RNAse called Dicer (Bartel, 2004) (figure 6). 


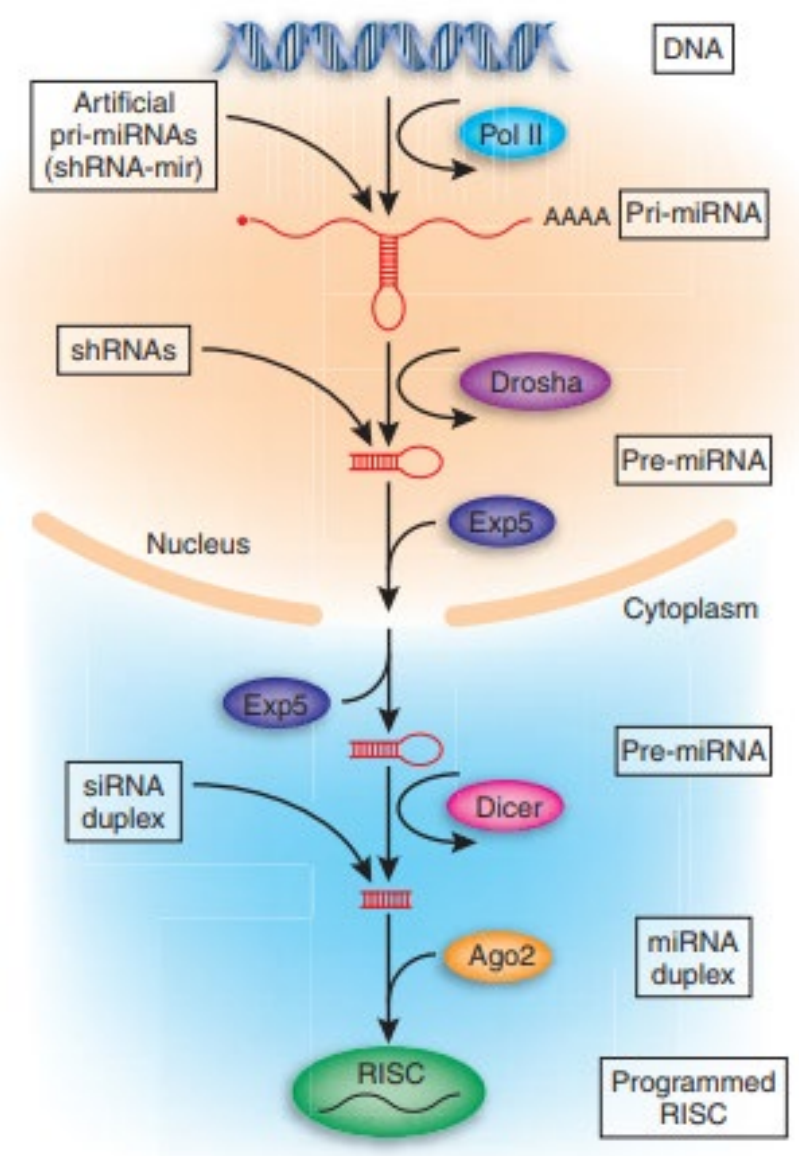

Figure 6. Simplified view of miRNA biogenesis pathway. Schematic depiction of miRNA biogenesis from transcription by Polymerase II and processing by Drosha in the nucleus. Upon transport to the cytosol by Exportin-5 (Exp5) the pre-miRNA is further processed by Dicer. Source: (Cullen, 2005)

Small nucleolar RNA (snoRNA) are small RNA molecules that are believed to be exclusively in the nuclei where it participates in ribosomal biogenesis (Bachellerie et al., 2002) (Watkins et al., 2007). U3 is a snoRNA that is independently transcribed and unlike other snoRNA is believed to localize exclusively in the nucleus (Cléry et al., 2007). However, some studies suggested the processing of snoRNA into miRNA (Ender et al., 2008), (Brameier et al., 2011), which would require cytosolic presence of snoRNA.

Dr. Nicolás Lemus, during his PhD studies, found strong evidence that the $5^{\prime}$ domain of snoRNA U3 may indeed be further processed into a functional miRNA. Through NGS data analysis it was found out that U3-derived miRNA interacts with microRNA ribonucleoprotein complex (miRNP), which indicates processing into miRNA. Also, using a dual fluorescence reporter assay that allows for the detection of miRNA activity 
at a single cell level (Lemus-Diaz et al., 2017), it was shown that snoRNA U3 derived miRNA may play a role as a functional miRNA (figure 7).

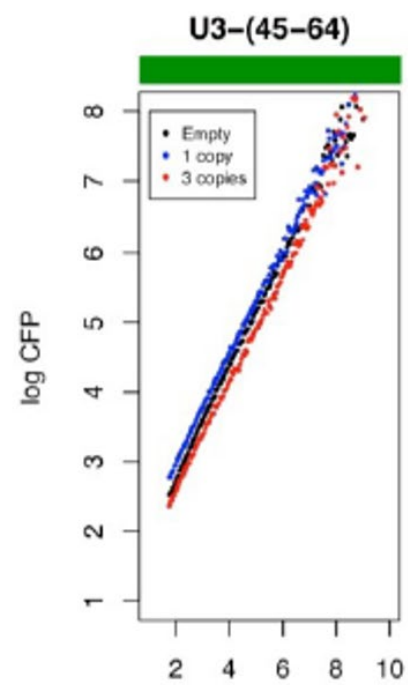

$\log$ YFP

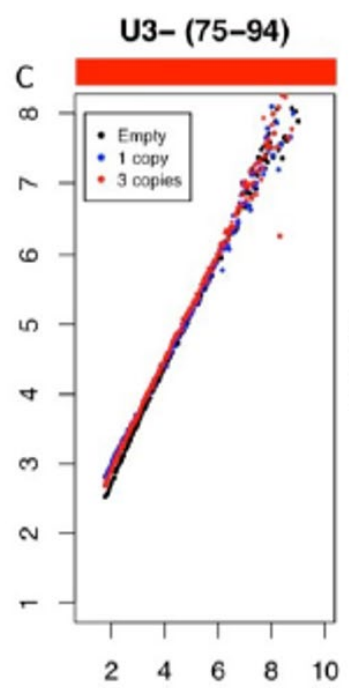

$\log$ YFP

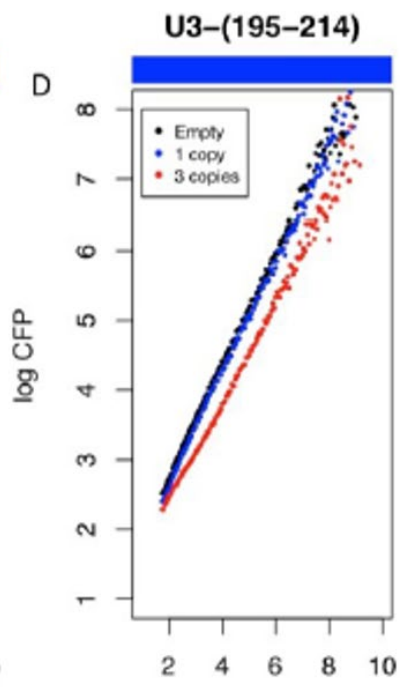

$\log$ YFP

Figure 7. Dual fluorescence assay for assessment of miRNA functionality at single-cell level. Cells are transfected with a dual fluorescence construct for expression of yellow fluorescent protein (YFP) and cyan fluorescent protein (CFP) (Lemus-Diaz et al., 2018). On CFP 3'untranslated region a small complementary miRNA sequence is fused. Upon binding of fitting endogenous miRNA, translation of CFP is diminished, while YFP is not affected and remains constant, as a control. Fluorescence is analysed by fluorescence-activated cell sorting (FACS). Three different U3 sequences were used and the effects of fusing one or three copies of the same sequence were analysed. Red dots represent the effects of three copies of U3 complementary sequences on CFP expression. Decreased CFP expression indicates low miRNA functionality of U3 derived complementary sequences. Source: (LemusDiaz, 2017). 


\subsection{Aim of the thesis}

Genetic manipulation is a powerful tool for biological research and the clinics. The improvement and development of gene manipulation techniques as well as gene delivery tools is crucial for the success and advancements of the field.

In this thesis, we aimed to produce gene delivery tools that are more specific and efficient on delivering a gene of interest.

We also aimed to utilise our delivery tools to test effective gene manipulation techniques to assist us on answering interesting scientific questions:

Is the CRLF3 receptor linked to Epo mediated neuroprotection in mammals?

Does a snoRNA derived miRNA behave as a classical miRNA? 


\section{Materials and Methods}

\subsection{Molecular biology}

All buffers and media compositions are listed on table 8 . A list of vectors used for cloning and LV production can be found on tables 5 and 6 . Plasmid maps are shown in the Appendix section.

\subsubsection{Plasmid restriction}

DNA constructs were digested using appropriate restriction enzymes from New England Biolabs (USA) or Thermo Fisher Scientific (Germany) according to manufacturer's instructions. In brief, plasmids were mixed with appropriated buffers, purified $\mathrm{H}_{2} \mathrm{O}$ and enzymes and incubated at $37^{\circ} \mathrm{C}$ for at least $1 \mathrm{~h}$ or overnight when there was no star activity described for the enzyme.

\subsubsection{Electrophoretic DNA fragment separation and documentation}

Digested constructs were mixed with 6X DNA loading dye (Thermo Fisher Scientific, Germany) and $10 \mu \mathrm{L}$ were loaded into a 1 or $2 \%$ w/v Agarose gel (Carl Roth, Germany). DNA fragments were separated by applying $130 \mathrm{~V}$ for $45 \mathrm{~min}$ in TAE buffer. Bands were visualized by incubation in Ethidium bromide staining $10 \mu \mathrm{g} / \mathrm{mL}$ in $\mathrm{H}_{2} \mathrm{O}$ (Carl Roth, Germany) for 15min. DNA bands were documented on an INTAS Ge liX20 Imager (INTAS, Germany) under UV light.

\subsubsection{DNA gel purification}

Digested DNA fragments or PCR products were excised from the agarose gel with a clean scalp. Gel purification was carried out using a QIAquick Gel Extraction Kit (QIAGEN, Germany). Agarose gel slices were melted at $50^{\circ} \mathrm{C}$ with appropriate buffer under agitation for 10min according to manufacturer's instructions. DNA content of purified products was obtained by spectrometry on a Synergy 2 Multi-Mode Microplate reader (BioTek, USA) using $\mathrm{H}_{2} \mathrm{O}$ as blank. Purified DNA was stored at $-20^{\circ} \mathrm{C}$.

\subsubsection{DNA ligation}

DNA fragments were ligated with T4 DNA ligase (New England Biolabs, USA) according to manufacturer's instructions. In summary DNA fragments were mixed with 
T4 DNA ligase buffer, purified $\mathrm{H}_{2} \mathrm{O}$ and ligase and incubated for 10min at room temperature or at $16^{\circ} \mathrm{C}$ overnight.

\subsubsection{Chemically competent cells expansion}

Competent E. coli were expanded using the Mix \& Go! E. coli Transformation Kit (Zymo Research, Germany) according to manufacturer's protocol. In brief, competent bacteria were inoculated in appropriate buffer and incubated $\mathrm{t} 37^{\circ} \mathrm{C}$ under agitation of $180 \mathrm{rpm}$ overnight. Cells were harvested by centrifugation, aliquoted and stored at $-80^{\circ} \mathrm{C}$.

\subsubsection{Bacterial transformation}

One Shot TOP10 chemically competent E. coli or One Shot Stbl3 Chemically competent cells were thawed on ice for $10 \mathrm{~min}$ and $1-5 \mu \mathrm{L}$ plasmid or ligation product was added. The transformation reaction was incubated on ice for $5 \mathrm{~min}$ and transformed bacteria were inoculated on a LB-agar plate with either $100 \mu \mathrm{g} / \mathrm{mL}$ Ampicillin (Carl Roth, Germany) or $50 \mu \mathrm{g} / \mathrm{mL}$ Kanamycin (Applichem, Germany). For plasmids conferring Kanamycin resistance, an additional step was performed after incubation on ice: $400 \mu \mathrm{L}$ of SOC medium was added and cells were incubated for $30 \mathrm{~min}$ at $37^{\circ} \mathrm{C}$ under mild agitation before being inoculated. Inoculated LB-agar plates were incubated at $37^{\circ} \mathrm{C}$ overnight.

\subsubsection{DNA extraction}

Individual bacterial colonies grown on LB-agar plates were picked with a sterile micropipette tip (Sarstedt, Germany) and transferred to tubes or flasks containing appropriate amounts of LB medium with appropriate antibiotic. Tubes were then incubated at $37^{\circ} \mathrm{C}$ for at least $8 \mathrm{~h}$ under $180 \mathrm{rpm}$ agitation.

\subsubsection{DNA minipreps}

Bacterial suspension ( $2 \mathrm{~mL}$ ) were centrifuged on a Heraeus Fresco21 microcentrifuge (Thermo Fisher scientific, USA) at $15.000 x \mathrm{x}$ for $1 \mathrm{~min}$. Bacterial pellet was resuspended in $200 \mu \mathrm{L}$ by agitation with buffer P1 containing $100 \mu \mathrm{g} / \mathrm{mL}$ RNAse (Sigma Aldrich, USA). $200 \mu \mathrm{L}$ of a mixture of buffer P2a+P2b was added and the contents mixed. $200 \mu \mathrm{L}$ of buffer P3 was added and the tubes were centrifuged at $15.000 \mathrm{xg}$ at $4^{\circ} \mathrm{C}$ for $10 \mathrm{~min}$. Supernatant was transferred to clean $1.5 \mathrm{~mL}$ tubes (Sarstedt, Germany) and $350 \mu \mathrm{L}$ 
Isopropanol (Carl Roth, Germany) was added. The contents were centrifuged at $15.000 \mathrm{xg}$ at $4^{\circ} \mathrm{C}$ for $30 \mathrm{~min}$. Supernatant was discarded, and DNA pellet was washed with $70 \%$ Ethanol v/v. Pellets were spun down at $12.000 \times \mathrm{xg}$ at $4^{\circ} \mathrm{C}$ for $15 \mathrm{~min}$. Supernatant was discarded, and pellets could air dry and later be resuspended in $50 \mu \mathrm{L}$ purified $\mathrm{H}_{2} \mathrm{O}$ and stored at $-20^{\circ} \mathrm{C}$.

\subsubsection{DNA midipreps}

DNA midipreps were prepared using a ZymoPURE Plasmid Midiprep Kit (Zymo Research, Germany) according to manufacturer's instructions. The extracted DNA was column purified and eluted with $200 \mu \mathrm{L}$ purified $\mathrm{H}_{2} \mathrm{O}$. Minipreps were stored at $-20^{\circ} \mathrm{C}$.

\subsubsection{Polymerase chain reaction}

PCR reactions were carried out using appropriate primers synthesized by Sigma Aldrich (Germany). Either Taq DNA polymerase (Biotherm, Germany) or Phusion Highfidelity DNA Polymerase (Thermo Fisher Scientific, Germany). The protocols and thermocycling programs were adjusted for each reaction, but general protocols for the PCR reaction mix and cycling program are described in table 1 and 2 respectively.

Table 1: PCR reaction mix general protocol

\begin{tabular}{lll}
\hline Component & Volume & \\
\hline & Taq & Phusion \\
\hline DNA template (50-100ng) & X $\mu \mathrm{L}(100 \mathrm{ng})$ & $\mathrm{X} \mu \mathrm{L}(50 \mathrm{ng})$ \\
\hline Reaction buffer $(5-10 \mathrm{X})$ & $3 \mu \mathrm{L}(10 \mathrm{X})$ & $4 \mu \mathrm{L}(5 \mathrm{X})$ \\
dNTPs $(10 \mathrm{mM})$ & $0.2 \mu \mathrm{L}$ & $0.4 \mu \mathrm{L}$ \\
Forward primer $(10 \mu \mathrm{M})$ & $1 \mu \mathrm{L}$ & $1 \mu \mathrm{L}$ \\
Reverse primer $(10 \mu \mathrm{M})$ & $1 \mu \mathrm{L}$ & $1 \mu \mathrm{L}$ \\
Polymerase & $0.2 \mu \mathrm{L}$ & $0,2 \mu \mathrm{L}$ \\
RNAse free $\mathrm{H}_{2} \mathrm{O}$ & $\mathrm{up} \mathrm{to} 30 \mu \mathrm{L}$ & $\mathrm{up} \mathrm{to} 20 \mu \mathrm{L}$ \\
DMSO & $\mathrm{NA}$ & $0.6 \mu \mathrm{L}$ \\
TOTAL & $30 \mu \mathrm{L}$ & $20 \mu \mathrm{L}$ \\
\hline
\end{tabular}

PCR reactions were performed on a thermocycler Labcycler (Sensoquest, Germany) in $200 \mu \mathrm{L}$ PCR SoftTubes (Biozym, Germany). Primer sequences are depicted in table 3. 
Table 2: General cycling conditions for PCR reactions

\begin{tabular}{|c|c|c|c|c|c|}
\hline & Taq & & Phusion & & \\
\hline Cycle step & Temperature & Time & Temperature & Time & Cycles \\
\hline $\begin{array}{l}\text { Initial } \\
\text { denaturation }\end{array}$ & $95^{\circ} \mathrm{C}$ & $5 \mathrm{~min}$ & $98^{\circ} \mathrm{C}$ & $30 s$ & 1 \\
\hline Denaturation & $95^{\circ} \mathrm{C}$ & $1 \mathrm{~min}$ & $98^{\circ} \mathrm{C}$ & $5-10 s$ & \\
\hline Annealing & $56^{\circ} \mathrm{C}$ & $1 \mathrm{~min}$ & $\leq 69^{\circ} \mathrm{C}$ & $10-30 s$ & 30 \\
\hline Extension & $72^{\circ} \mathrm{C}$ & $1 \mathrm{~min}$ & $72^{\circ} \mathrm{C}$ & $15-30 \mathrm{~s} / \mathrm{kb}$ & \\
\hline Final extension & $72^{\circ} \mathrm{C}$ & $2 \min$ & $72^{\circ} \mathrm{C}$ & $5-10 \mathrm{~min}$ & 1 \\
\hline Hold & $4^{\circ} \mathrm{C}$ & $\infty$ & $4^{\circ} \mathrm{C}$ & $\infty$ & NA \\
\hline
\end{tabular}

\subsubsection{RNA isolation and cDNA synthesis}

Culture medium was discarded, and cells were homogenized with Trizol reagent (Thermo Fisher Scientific, USA). Total RNA was isolated according to manufacturer's instructions. Isolated RNA was resuspended in RNAse free $\mathrm{H}_{2} \mathrm{O}$ and quantified on an Eppendorf BioSpectrometer basic (Eppendorf, Germany). Total RNA was reverse transcribed using the Sensifast cDNA Synthesis Kit (Bioline, UK) using 1000ng of total RNA. cDNA was stored at $-20^{\circ} \mathrm{C}$.

\subsubsection{Quantitative PCR}

In general, 20ng of cDNA template was used for qPCR on an ABI StepOnePlus system (Applied Biosystems, USA) using a SensiMix SYBR Hi-ROX Kit (Bioline, UK) according to manufacturer's protocol. Relative quantification was calculated through $\Delta \Delta \mathrm{Ct}$ method using the StepOnePlus Systems software (Applied Biosystems, USA). GAPDH and $\beta 2 \mathrm{M}$ expression were used as controls. A list of primers and sequences can be found in table 3. Comparison between nuclear and cytoplasmic expression of U3, U6, GAPDH and U1 was assessed as "fraction of total" by determining the square of the Ct values of fractions subtracted from Ct values of total RNA.

\subsubsection{LNA miRNA qPCR}


Total RNA was reverse transcribed using the miRCURY LNA RT Kit (QIAGEN, Germany) according to manufacturer's instructions and obtained CDNA was used for LNA miRNA expression detection using a miRCURY LNA SYBR Green PCR Kit (QIAGEN, Germany) on an ABI StepOnePlus system (Applied Biosystems, USA). Relative expression was calculated by $\triangle \Delta C t$-method using $U 6$ as reference. Resulting amplified sequences were visualized by electrophoresis using the E-Gel Precast Agarose Electrophoresis System (Thermo Fischer Scientific, USA) in a $4 \% \mathrm{E}-\mathrm{Gel}$ Precast Agarose Gel. Probes complementary to targets U3, U6 and miR-34a were synthesized by QIAGEN (Germany). 
Table 3: Primer sequences used for PCR and qPCR

\begin{tabular}{|c|c|c|}
\hline Primer & Purpose & Sequence \\
\hline$\beta 2 \mathrm{M}$ forward & \multirow{2}{*}{ Housekeeping } & TGTGCTCGCGCTACTCTCTCT \\
\hline$\beta 2 \mathrm{M}$ reverse & & CGGATGGATGAAACCCAGACA \\
\hline GAPDH forward & \multirow{2}{*}{ Housekeeping } & AGGTCGGAGTCAACGGAT \\
\hline GAPDH reverse & & TCCTGGAAGATGGTGATG \\
\hline TrkB forward & \multirow{2}{*}{$\begin{array}{l}\text { TrkB expression } \\
\text { quantification }\end{array}$} & GGGACACCACGAACAGAAGT \\
\hline TrkB reverse & & GACGCAATCACCACCACAG \\
\hline Her2/neu forward & $\begin{array}{l}\text { Her2/neu } \\
\text { expression }\end{array}$ & CCTCTGACGTCCATCGTCTC \\
\hline Her2/neu reverse & quantification & CGGATCTTCTGCTGCCGTCG \\
\hline CRLF3 forward & $\begin{array}{l}\text { CRLF3 } \\
\text { expression }\end{array}$ & AAACCTGGAGGCATCATTGT \\
\hline CRLF3 reverse & quantification & GCGCAGACTCTGAACTGGTA \\
\hline $\begin{array}{l}\text { Her2/neu out } \\
\text { forward }\end{array}$ & $\begin{array}{l}\text { Her2/neu } \\
\text { cloning }\end{array}$ & CCCGGGATGGCTCAGGTTCAGTTGGT \\
\hline $\begin{array}{l}\text { Her } 2 / \text { neu out } \\
\text { reverse }\end{array}$ & & CCGCGGACCCAAAACAGTCAACTTAG \\
\hline $\begin{array}{l}\text { shRNA-CRLF3 \#1 } \\
\text { forward }\end{array}$ & $\begin{array}{l}\text { Annealing for } \\
\text { insertion into } \\
\text { shRNA }\end{array}$ & $\begin{array}{l}\text { CCGGGCTGTGTGCATTAGTACAAATCT } \\
\text { CGAGATTTGTACTAATGCACACAGCTTTTT } \\
\text { G }\end{array}$ \\
\hline shRNA-CRLF3 \#1 & expression & AATTCAAAAAGCTGTGTGCATTAGTACA \\
\hline reverse & vector & AATCTCGAGATTTGTACTAATGCACACAGC \\
\hline $\begin{array}{l}\text { sgRNA-GFP } \\
\text { forward }\end{array}$ & $\begin{array}{l}\text { Annealing for } \\
\text { insertion into }\end{array}$ & CACCGGGGCGAGGAGCTGTTCACCG \\
\hline $\begin{array}{l}\text { sgRNA-GFP } \\
\text { reverse }\end{array}$ & $\begin{array}{l}\text { sgRNA } \\
\text { expression } \\
\text { cassette }\end{array}$ & AAACCGGTGAACAGCTCCTCGCCCC \\
\hline CRLF3 out forward & CRLF3 cloning & GTCGACATGAGGGGGGCGATGGAGCT \\
\hline CRLF3 out reverse & snoRNA U6 & СТАAАACACTAACACTTTCCGCGGCCGC \\
\hline U6 forward & $\begin{array}{l}\text { expression } \\
\text { quantification }\end{array}$ & CTCGCTTCGGCAGCACA \\
\hline U6 reverse & snoRNA U1 & AACGCTTCACGAATTTGCGT \\
\hline U1 forward & $\begin{array}{l}\text { expression } \\
\text { quantification }\end{array}$ & CCATGATCACGAAGGTGGTTT \\
\hline U1 reverse & snoRNA U3 & ATGCAGTCGAGTTTCCCACAT \\
\hline U3 forward & $\begin{array}{l}\text { expression } \\
\text { quantification }\end{array}$ & CGAAAACCACGAGGAAGAGA \\
\hline U3 reverse & & САСТCCCCAATACGGAGAGA \\
\hline
\end{tabular}




\subsubsection{Cell fractionation and RNA extraction}

Cytoplasmic and nuclear RNA fractions were obtained using a Cytoplasmic \& Nuclear RNA Purification Kit (Norgen Biotek Corp., Canada) according to manufacturer's instructions. RNA was eluted from purification columns and quantified on an Eppendorf BioSpectrometer basic (Eppendorf, Germany). RNA samples were kept at $-80^{\circ} \mathrm{C}$.

\subsection{Cell biology}

\subsubsection{Cell culture}

All cell lines were kept under standard conditions in humidified incubator at $37^{\circ} \mathrm{C}$ and $5 \% \mathrm{CO}_{2}$. For routine maintenance cells were harvested with Trypsin $0.05 \%$ /EDTA 0.02 $\%$ in PBS, w/o: Ca and Mg (PAN Biotech, Germany) and split accordingly. Cell lines and their respective culture media and supplements are summarized in table 4. HCT116 cells and knock-out variants were obtained from Korean Collection for Type Cultures (KCTC) KCTC-No BP1230983 to BP1230988 where they were deposited by Narry Kim (Kim et al., 2016). HEK293FT were purchased from Thermo Fisher Scientific, USA. All other cell lines were obtained from the American type culture collection - ATCC.

\subsubsection{Rat brain cortex dissociated culture}

Wistar rat brains were obtained from Markus Stahlberg (Trans-synaptic Signaling group - European Neuroscience Institute, Göttingen) in ice cold OptiMEM (Thermo Fisher Scientific, USA). Brains were processed as soon as possible by removing the meninges and isolating the cortex with appropriate tweezers. Isolated cortex was then sliced in small pieces with Surgical Disposable Scalpels (Braun, USA) and digested with Trypsin/EDTA solution (PAN Biotech) for $45 \mathrm{~min}$ at $37^{\circ} \mathrm{C}$. Digested tissue was gently dissociated by several passages through disposable pipette tips (Sarstedt, Germany) in DMEM supplemented with 10\% heat inactivated FCS (Thermo Fisher Scientific, USA), 1\% Penicillin/streptomycin and GlutaMAX-I (Thermo Fisher Scientific, USA). The cell suspension obtained was then seeded in 24-well plates containing glass cover-slips coated with 0,5\% polyethylenimine (PEI) (Sigma Aldrich, Germany). 24 hours later the supernatant was changed by Neurobasal medium (Invitrogen) 
supplemented with100mM GlutaMAX-I, $10.000 \mathrm{U}$ Penicillin+10mg Streptomycin $/ \mathrm{mL}$ (PAN Biotech) and 2\% B-27 Serum Free Supplement (Thermo Fisher Scientific, USA).

Table 4: Cell lines, culture media and supplements

\begin{tabular}{|c|c|c|c|}
\hline Cell lines & Media & Supplement & Provider \\
\hline HEK293 & DMEM & $10 \% \mathrm{FCS}$ & ATCC CRL-1573 \\
\hline HEK293FT & DMEM & $\begin{array}{l}10 \% \text { FCS }+1 \mathrm{mM} \\
\text { sodium pyruvate + } \\
1 \mathrm{mM} \mathrm{L-glutamine} \mathrm{+} \\
1 \mathrm{mM} \mathrm{NEAA} \mathrm{+} \\
1 \mathrm{mg} / \mathrm{mL} \text { Geneticin }\end{array}$ & $\begin{array}{l}\text { Thermo Fisher } \\
\text { Virapowertm } \\
\text { System }\end{array}$ \\
\hline Hela & RPMI & $10 \% \mathrm{FCS}$ & ATCC CCL-2 \\
\hline SH-SY5Y & DMEM-F12 & $10 \%$ FCS & ATCC CRL-2266 \\
\hline Raji & RPMI & $10 \%$ FCS & $\begin{array}{l}\text { ATCC CCL-86 } \\
\text { ATCC TIB-152 }\end{array}$ \\
\hline Jurkat & RPMI & $10 \%$ FCS & Clone E6-1 \\
\hline SKBR3 & DMEM & $10 \%$ FCS & ATCC HTB-30 \\
\hline MCF7 & DMEM & $10 \%$ FCS & ATCC HTB-22 \\
\hline HTC116 & McCoy's 5A & $10 \%$ FCS & $\begin{array}{l}\text { Korean } \\
\text { Collection for } \\
\text { Type Cultures } \\
\text { (KCTC) KCTC- } \\
\text { No BP1230983 } \\
\text { to BP1230988 }\end{array}$ \\
\hline
\end{tabular}

* All media and supplements were manufactured by

Thermo Fisher Scientific, USA

NEAA - non-essential aminoacids

\subsubsection{Macaca fascicularis brain cortex organotypic culture}

Macaca fascicularis brains were obtained from the Infection Biology group from the German Primate Center in Göttingen, Germany in ice cold OptiMEM (Thermo Fisher Scientific, USA). Brains were processed as soon as possible by removing the 
meninges and isolating the cortex with appropriate tweezers. Slices $300 \mu \mathrm{m}$ thick were obtained by using a tissue slicer (Stoelting, Germany) equipped with double edges razor blades (Astra, Italy). Slices were kept in HBSS - Hank's Balanced Salt solution (Thermo Fisher Scientific, USA) supplemented with 10mM HEPES (Carl Roth, Germany) and $5 \mathrm{mg} / \mathrm{mL}$ Glucose (Carl Roth, Germany) during slicing process. Afterwards, cortex slices were laid onto filter membranes - cell culture inserts (Millicel - Millipore, USA) and transferred to 6-well culture plates in a way that the slices would be in contact with atmospheric air on the top and with the medium, without soaking, on the bottom. Three slices were kept in each filter membrane. Medium used was a mixture of the following components: $50 \%$ Minimun Essential Media (Thermo Fisher Scientific, USA), 25\% HBSS (Thermo Fisher Scientific, USA), 25\% FBS (Thermo Fisher Scientific, USA), 1\% GlutaMAX-I (Thermo Fisher Scientific, USA), 1\% Penicillin/streptomycin (PAN Biotech, Germany) and $5 \mathrm{mg} / \mathrm{mL}$ Glucose. Medium was changed every 48 hours. All animal handling was carried out in accordance to approved ethical protocols.

\subsubsection{Fluorescence microscopy}

All fluorescent images were acquired in an Axio Vert.A1 epifluorescence microscope equipped with a blue LED for GFP excitation, a green LED for RFP excitation, an AxioCam ICm 1 and the AxioCam IC - ZEN 2 lite software (Zeiss Germany). 
Table 5: Plasmid vectors used for cloning

\begin{tabular}{|c|c|c|c|}
\hline Vector & Description & Function & Origin \\
\hline pDisplay & $\begin{array}{l}\text { Mammalian expression } \\
\text { vector that allows display } \\
\text { of proteins on the cell } \\
\text { surface. Proteins } \\
\text { expressed from pDisplay } \\
\text { are fused at the N- } \\
\text { terminus to the murine Ig } \\
\text { K-chain leader sequence, } \\
\text { which directs the protein to } \\
\text { the secretory pathway, and } \\
\text { at the C-terminus to the } \\
\text { platelet derived growth } \\
\text { factor receptor (PDGFR) } \\
\text { transmembrane domain, } \\
\text { which anchors the protein } \\
\text { to the plasma membrane, } \\
\text { displaying it on the } \\
\text { extracellular side. }\end{array}$ & $\begin{array}{l}\text { To direct } \\
\text { expression } \\
\text { of scFv } \\
\text { constructs } \\
\text { on the cell } \\
\text { membrane }\end{array}$ & $\begin{array}{l}\text { Gift from Dr. Michael Winkler } \\
\text { (Infection Biology Unit - } \\
\text { German Primate Center, } \\
\text { Göttingen, Germany) }\end{array}$ \\
\hline lentiGuide-puro & $\begin{array}{l}\text { Expresses S. pyogenes } \\
\text { CRISPR chimeric RNA } \\
\text { element with customizable } \\
\text { sgRNA from U6 promoter } \\
\text { and puromycin resistance } \\
\text { from EF-1a promoter. 3rd } \\
\text { generation lentiviral } \\
\text { backbone. }\end{array}$ & $\begin{array}{l}\text { Scaffold } \\
\text { for } \\
\text { expression } \\
\text { of sgRNA }\end{array}$ & $\begin{array}{l}\text { Gift from Feng Zhang } \\
\text { (Addgene plasmid \# 52963 ; } \\
\text { http://n2t.net/addgene:52963 } \\
\text {; RRID:Addgene_52963) }\end{array}$ \\
\hline pLKO.1 Puro & $\begin{array}{l}\text { 3rd gen lentiviral backbone } \\
\text { for cloning and expression } \\
\text { of new shRNA sequences. } \\
\text { Uses puromycin for } \\
\text { selection. }\end{array}$ & $\begin{array}{l}\text { Vector for } \\
\text { expression } \\
\text { of shRNA } \\
\text { under U6 } \\
\text { promoter }\end{array}$ & $\begin{array}{l}\text { Gift from Bob Weinberg } \\
\text { (Addgene plasmid \# } 8453 \text {; } \\
\text { http://n2t.net/addgene:8453; } \\
\text { RRID:Addgene_8453) }\end{array}$ \\
\hline $\begin{array}{l}\text { pPICZaA- } \\
\text { Her2neu- } \\
\text { Streptavidin }\end{array}$ & $\begin{array}{l}\text { Construct for expression of } \\
\text { scFv-Her2/neu in Pichia }\end{array}$ & $\begin{array}{l}\text { Template } \\
\text { for cloning } \\
\text { of svFv- } \\
\text { Her2/neu }\end{array}$ & $\begin{array}{l}\text { Gift from Dr. Stefan } \\
\text { Schneider (Infection Biology } \\
\text { Unit - German Primate } \\
\text { Center, Göttingen, } \\
\text { Germany) }\end{array}$ \\
\hline
\end{tabular}




\subsubsection{Lentivirus production}

HEK293FT cells were passaged 2 to 4 times prior to use. Only cultures with viability higher than $90 \%$ were used. Each experimental unit correspond to a $75 \mathrm{~cm}^{2}$ cell culture

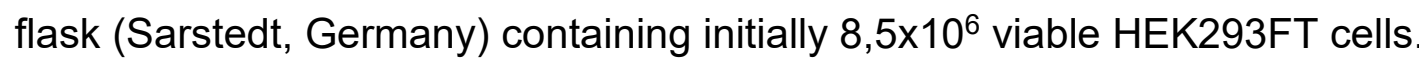

Day 1: DNA constructs amounts used for co-transfection of viral components, GOI and envelope protein were calculated based on the molar fraction represent in the mix according to their lengths in base-pairs (bp). For each experimental unit, a total amount of $30 \mu \mathrm{g}$ of DNA was mixed with $300 \mu \mathrm{L} 2.5 \mathrm{M} \mathrm{CaCl}_{2}$ (Carl Roth, Germany) in a $50 \mathrm{~mL}$ Cellstar tube (Greiner Bio-one) and sterile $\mathrm{H}_{2} \mathrm{O}$ up to $1500 \mu \mathrm{L}$. Afterwards, $1500 \mu \mathrm{L} 2 \mathrm{X}$ HEPES buffered saline was added and the contents bubbled 15 times with a $5 \mathrm{~mL}$ serological pipette (Sarstedt, Germany). The solution was incubated at room temperature for 20min to allow calcium phosphate formation. In the meanwhile, HEK293FT cells seeded previously were detached, counted in a Neubauer improved chamber (Superior Marienfeld, Germany) and a suspension containing $8,5 \times 10^{5} \mathrm{cells} / \mathrm{mL}$ was prepared. $10 \mathrm{~mL}$ of this suspension was added to $75 \mathrm{~cm}^{2}$ culture flasks for each experimental unit. DNA-calcium phosphate mix was added slowly to the cells in suspension and mixed well. Cells were then incubated under standard conditions over night. The plasmids used for LV production are listed in table 6.

Day 2: From this step on all procedures were carried out under S2 lab safety conditions. Any material/surface that might have had contact with infective material was rinsed with Optisept 7\% (Dr. Schuemacher, Germany) before proper discarding. Since the GOI constructs contained either GFP or RFP transfection efficiency could be evaluated through fluorescence microscopy. Only experimental units showing $80 \%$ or more fluorescent cells (qualitative analysis) were used for further steps. The supernatant from each flask was collected to a $50 \mathrm{~mL}$ tube and stored at $4^{\circ} \mathrm{C}$. Fresh HEK293FT keeping medium (see table 4) supplemented with 10mM Sodium butyrate (Sigma-Aldrich, Germany) were added to the flasks. After $8 \mathrm{~h}$ of incubation, the supernatant containing sodium butyrate was transferred to the corresponding tube containing the supernatant recovered before and stored at $4^{\circ} \mathrm{C}$. Fresh HEK293FT medium was added to each flask.

Day 3 and 4: The supernatant containing the viral particles was recovered and transferred to the corresponding tubes with supernatant from the day before. Fresh HEK293FT medium was added. 
Day 5: The supernatant containing viral particles was collected from the flasks and transferred to the corresponding tubes. The pool of viral containing SN was centrifuged at $2000 \mathrm{xg}$ for $15 \mathrm{~min}$ at $4^{\circ} \mathrm{C}$ on a Heraeus Megafuge $8 \mathrm{R}$ (Thermo Fisher Scientific, USA). The cleared supernatant was filtered through a $0.45 \mu \mathrm{m}$ Minisart NML Syringe Filter (Sartorius Stedim Biotech, Germany) into a fresh $50 \mathrm{~mL}$ tube and kept at $4^{\circ} \mathrm{C}$.

\subsubsection{Concentration of lentiviral particles}

$20 \mathrm{~mL}$ viral SN were added to Vivaspin 20 centrifugal concentrator - MWCO $30 \mathrm{kDa}$ (Thermo Fisher Scientific, USA) and centrifuged at maximum speed at $4^{\circ} \mathrm{C}$ for $60 \mathrm{~min}$. The final volume obtained was around $200 \mu \mathrm{L}$ and was transferred to cryotubes and stored at $-80^{\circ} \mathrm{C}$.

Table 6: Plasmids used for lentiviral production

\begin{tabular}{|c|c|c|c|}
\hline Vector & Description & Function & Origin \\
\hline psPAX2 & $\begin{array}{l}\text { 2nd generation } \\
\text { lentiviral } \\
\text { packaging } \\
\text { plasmid. Can be } \\
\text { used with 2nd or } \\
\text { 3rd generation } \\
\text { lentiviral vectors } \\
\text { and envelope } \\
\text { expressing } \\
\text { plasmid }\end{array}$ & $\begin{array}{l}\text { Expression of viral } \\
\text { structural } \\
\text { components. } \\
\text { Contains gag, pol } \\
\text { and rev }\end{array}$ & $\begin{array}{l}\text { Gift from Didier Trono } \\
\text { (Addgene plasmid \# } 12260 \text {; } \\
\text { http://n2t.net/addgene:12260 } \\
\text {; RRID:Addgene_12260) }\end{array}$ \\
\hline pCMV-VSV-G & $\begin{array}{l}\text { Envelope protein } \\
\text { for producing } \\
\text { lentiviral and } \\
\text { MuLV retroviral } \\
\text { particles. }\end{array}$ & $\begin{array}{l}\text { Envelope plasmid. } \\
\text { Expression of VSV-G } \\
\text { on viral envelope }\end{array}$ & $\begin{array}{l}\text { Gift from Bob Weinberg } \\
\text { (Addgene plasmid \# } 8454 \text {; } \\
\text { http://n2t.net/addgene:8454 ; } \\
\text { RRID:Addgene_8454) }\end{array}$ \\
\hline pLenti-CMV-GFP-Neo & $\begin{array}{l}\text { 3rd gen lentiviral } \\
\text { eGFP expression } \\
\text { vector, CMV } \\
\text { promoter, } \\
\text { Neomycin } \\
\text { resistence }\end{array}$ & $\begin{array}{l}\text { Contains GFP as } \\
\text { GOI flanked by LTR } \\
\text { driven by CMV } \\
\text { promoter. Drive } \\
\text { expression of GFP } \\
\text { on transduced cells }\end{array}$ & $\begin{array}{l}\text { Gift from Eric Campeau \& } \\
\text { Paul Kaufman (Addgene } \\
\text { plasmid \# 17447; } \\
\text { http://n2t.net/addgene:17447 } \\
\text {; RRID:Addgene_17447) }\end{array}$ \\
\hline pLemiR-NS & $\begin{array}{l}\text { Lentiviral shRNA } \\
\text { expression } \\
\text { plasmid. Contains } \\
\text { Turbo RFP as } \\
\text { reporter gene } \\
\text { Puromycin } \\
\text { resistence. }\end{array}$ & $\begin{array}{l}\text { Contains Turbo RFP } \\
\text { and a non-specific } \\
\text { shRNA as GOI } \\
\text { flanked by LTR . } \\
\text { Drive expression of } \\
\text { RFP on transduced } \\
\text { cells }\end{array}$ & $\begin{array}{l}\text { Gift from Jerry Crabtree } \\
\text { (Addgene plasmid \# } 32809 \text {; } \\
\text { http://n2t.net/addgene:32809 } \\
\text {; RRID:Addgene_32809) }\end{array}$ \\
\hline
\end{tabular}




\begin{tabular}{|c|c|c|c|}
\hline pHCMV-Rabies-G & $\begin{array}{l}\text { Rabies-G } \\
\text { expression } \\
\text { cassette under } \\
\text { CMV promoter }\end{array}$ & $\begin{array}{l}\text { Envelope plasmid. } \\
\text { Drives Rabies-G } \\
\text { expression on viral } \\
\text { envelope. }\end{array}$ & $\begin{array}{l}\text { Gift from Miguel Sena- } \\
\text { Esteves (Addgene plasmid \# } \\
15785 \text {; } \\
\text { http://n2t.net/addgene:15785 } \\
\text {; RRID:Addgene_15785) }\end{array}$ \\
\hline pTargeT-fuHA & $\begin{array}{l}\text { A fuHA was } \\
\text { cloned into } \\
\text { pTargeT } \\
\text { mammalian } \\
\text { expression vector } \\
\text { system } \\
\text { (Promega, } \\
\text { Germany) }\end{array}$ & $\begin{array}{l}\text { Envelope plasmid. } \\
\text { Drives expression of } \\
\text { a fusogenic molecule } \\
\text { on the plasma } \\
\text { membrane under } \\
\text { CMV promoter }\end{array}$ & $\begin{array}{l}\text { Construct was generated on } \\
\text { previous study: Lentiviral re- } \\
\text { targeting for in vivo neuro- } \\
\text { optogenetics applications. } \\
\text { Rafael Rinaldi Ferreira } \\
\text { Master's thesis }\end{array}$ \\
\hline pDisplay-scFvTrkB & $\begin{array}{l}\text { A scFv-TrkB was } \\
\text { cloned into the } \\
\text { pDisplay vector } \\
\text { (Thermo Fisher } \\
\text { Scientific, USA) } \\
\text { for expression on } \\
\text { cell membrane }\end{array}$ & $\begin{array}{l}\text { Envelope plasmid. } \\
\text { Drives expression of } \\
\text { svFv-TrkB on viral } \\
\text { envelope. }\end{array}$ & $\begin{array}{l}\text { Construct was generated on } \\
\text { previous study: Lentiviral re- } \\
\text { targeting for in vivo neuro- } \\
\text { optogenetics applications. } \\
\text { Rafael Rinaldi Ferreira } \\
\text { Master's thesis }\end{array}$ \\
\hline pDisplay-scFv-Her2/neu & $\begin{array}{l}\text { A scFv-Her2/neu } \\
\text { was cloned into } \\
\text { the pDisplay } \\
\text { vector (Thermo } \\
\text { Fisher Scientific, } \\
\text { USA) for } \\
\text { expression on } \\
\text { cell membrane }\end{array}$ & $\begin{array}{l}\text { Envelope plasmid. } \\
\text { Drives expression of } \\
\text { svFv-Her2/neu on } \\
\text { viral envelope. }\end{array}$ & $\begin{array}{l}\text { scFv-Her2/neu was cloned } \\
\text { from pPICZaA-Her2neu- } \\
\text { Streptavidin and inserted } \\
\text { into pDisplay }\end{array}$ \\
\hline pLKO-shRNA-CRLF3 & $\begin{array}{l}\text { Vector for } \\
\text { lentiviral } \\
\text { expression of } \\
\text { shRNA under U6 } \\
\text { promoter. } \\
\text { Puromycin } \\
\text { resistence }\end{array}$ & $\begin{array}{l}\text { Contains shRNA- } \\
\text { CRLF3 as GOI } \\
\text { flanked by LTR } \\
\text { driven by U6 } \\
\text { promoter }\end{array}$ & $\begin{array}{l}\text { shRNA against CRLF3 } \\
\text { was cloned into the } \\
\text { pLKO.1 Puro vector }\end{array}$ \\
\hline
\end{tabular}

\subsubsection{Flow cytometry}

Cells were harvested with Trypsin-EDTA and centrifuged at $500 \mathrm{xg}$ for $5 \mathrm{~min}$. Cell pellets were washed twice with $1 \mathrm{~mL}$ 1X PBS (PAN Biotech, Germany) and incubated with $2 \%$ paraformaldehyde in PBS (Carl Roth) for $30 \mathrm{~min}$ at $4^{\circ} \mathrm{C}$ for fixation. After centrifugation

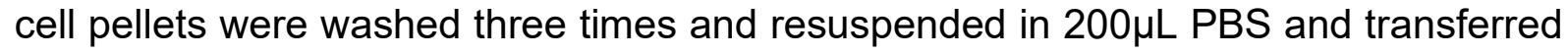
to $5 \mathrm{~mL}$ Falcon Round-Bottom Polypropylene Tubes (Omnilab, Germany). Cell suspensions were analysed on a BD LSR II flow cytometer (BD Biosciences, USA) using forward scattering and side-scattering to exclude cell debris and clumps. 
Fluorescence was detected using PE 550LP- BP575/26 filter set for RFP and 505LP BP530/30 filter set for GFP detection. Data was analysed using the Flowing Software 2 and GraphPad Prism 6.

\subsubsection{Functional lentivirus titer}

Functional LV titer was assessed according to (Kutner et al., 2009). In brief, cells were seeded in 24-well plates and transduced with serial dilutions of viral supernatant or concentrated viral SN. They were harvested 48-72h after and prepared for FACS analyses as described in section 2.6.6. 10.000 events were acquired per sample and gates were applied in order to exclude populations of cells showing aberrant fluorescence intensity and size. Non-transduced cells were used as negative control. The final data obtained were expressed as percentage of fluorescent cells per sample.

Data was analysed using Microsoft Excel 2010 software (Microsoft Corporation). Functional titer was calculated as the average amount of transducive units (TU) per $\mathrm{mL}$ using the following formula: $\mathrm{TU}=(\mathrm{F} \times \mathrm{N} \times \mathrm{D} \times 1000) / \mathrm{V}$, where $\mathrm{F}=$ percentage of fluorescent cells, $N=$ number of cells at the time of transduction, $D=$ fold dilution of vector sample used for transduction and $V=$ volume $(\mu \mathrm{L})$ of diluted vector sample added into each well for transduction.

\subsubsection{Lentivirus physical titer - ELISA}

The amount of p24 HIV-1 viral capsid protein was detected using the HIV-1 p24 ELISA Kit (XpressBio, USA) according to manufacturer's instructions. Physical titer was calculated based on the assumption that approximately 2000 molecules of p24 in one physical particle of lentivirus (LP). Therefore, one LP contains $8 \times 10^{-5} \mathrm{pg}$ of p24 (2000 $\mathrm{x}$ molecular weight/Avogadro) or $1 \mathrm{ng}$ of p24 equals $1.25 \times 10^{7} \mathrm{LPs}$. A well packaged lentivirus vector will have 1 TU for every $100-1000$ LPs. A supernatants titer of $10^{6}$ $\mathrm{TU} / \mathrm{ml}$ will have $10^{8-9} \mathrm{LP} / \mathrm{ml}$ or 8 to $80 \mathrm{ng} / \mathrm{ml}$. A supernatants titer of $10^{7}$ will have 80 to $800 \mathrm{ng} / \mathrm{ml}$. 


\subsection{RNA biochemistry}

All procedures involving RNA were carried out under RNAse free conditions. RnaseZap RNAse decontamination solution (Thermo Fisher Scientific, USA) was used to decontaminate any materials that were not previously RNAse free.

\subsubsection{Northern blots}

Total RNA and nuclear and cytoplasmic RNA fractions were separated on Novex $10 \%$ or $15 \%$ TBE-urea gel (Thermo Fischer Scientific, United States), and transferred to a BrightStar Plus Positively Charged Nylon Membrane (Thermo Fischer Scientific, USA). The membrane was cross-linked chemically with $\mathrm{N}$-(3-Dimethylaminopropyl)-N'ethylcarbodiimide hydrochloride and 1-Methylimidazole (Sigma-Aldrich Merk, Germany) and hybridized with a 5' end biotinylated oligonucleotide probes that has a complementary sequence to each target (Sigma-Aldrich, Germany). Chemiluminescence signals were analysed using the Chemiluminescent Nucleic Acid Detection Module Kit (Thermo Fischer Scientific, United States) on an ECL Chemocam Imager (INTAS, Germany). Probe sequences can be found in table 7.

Table 7: Probes used for Northern blot

\begin{tabular}{ll}
\hline \multicolumn{1}{c}{ Target } & \multicolumn{1}{c}{ 5'-3'sequence } \\
\hline miR-U3 & CUACACGUUCAGAGAA \\
miR-U6 & AACGCTTCACGAATTTGC \\
tRNA-val & TGTAAGTTGGGTGCTTTG \\
\hline
\end{tabular}




\subsection{Materials}

\subsubsection{Buffers and media}

Buffers used for DNA extraction and Northern blot and bacterial media can be found in table 8.

Table 8: Buffers and bacterial media composition

\begin{tabular}{|c|c|}
\hline Solution & Composition \\
\hline Lactate broth (LB) medium & $\begin{array}{l}\text { Yeast extract }(5 \mathrm{~g} / \mathrm{L}) \\
\text { Trypton }(10 \mathrm{~g} / \mathrm{L}) \\
\mathrm{NaCl}(5 \mathrm{~g} / \mathrm{L})\end{array}$ \\
\hline LB-Agar & $\begin{array}{l}\text { Yeast extract }(5 \mathrm{~g} / \mathrm{L}) \\
\text { Trypton }(10 \mathrm{~g} / \mathrm{L}) \\
\mathrm{NaCl}(5 \mathrm{~g} / \mathrm{L}) \\
\text { Agar }(7.5 \mathrm{~g} / \mathrm{L})\end{array}$ \\
\hline SOC medium & $\begin{array}{l}0.5 \% \text { Yeast Extract } \\
2 \% \text { Tryptone } \\
10 \mathrm{mM} \mathrm{NaCl} \\
2.5 \mathrm{mM} \mathrm{KCl} \\
10 \mathrm{mM} \mathrm{MgCl} 2 \\
10 \mathrm{mM} \mathrm{MgSO} 4 \\
20 \mathrm{mM} \text { Glucose }\end{array}$ \\
\hline TAE buffer & $\begin{array}{l}40 \mathrm{mM} \text { Tris- } \mathrm{HCl} 1 \mathrm{mM} \text { EDTA } \\
20 \mathrm{mM} \text { acetic acid } \\
\text { adjust to } \mathrm{pH} 7,0\end{array}$ \\
\hline TBE running buffer & $\begin{array}{l}\text { 89mM Tris Base } \\
\text { 89mM Boric acid } \\
\text { 2mM EDTA (free acid) } \\
\text { Adjust pH to } 8.3\end{array}$ \\
\hline
\end{tabular}

\subsubsection{Chemicals}

A list of chemicals used in this thesis can be found on table 9 
Table 9: Chemicals and manufacturer information

\begin{tabular}{|c|c|}
\hline Chemicals & Manufacturer \\
\hline 2-propanol & Merck-Millipore, Germany \\
\hline Acetic acid & Carl Roth, Germany \\
\hline Agar-Agar & Carl Roth, Germany \\
\hline Agarose & Carl Roth, Germany \\
\hline Ampicillin & Carl Roth, Germany \\
\hline Boric acid & Sigma Aldrich, MO, USA \\
\hline Bovine Serum albunin & Fluka, MO, USA \\
\hline Calcium chloride (Cellpure) & Carl Roth, Germany \\
\hline Chloroform & Merck Millipore, Germany \\
\hline d'NTPs & Sigma Aldrich, MO, USA \\
\hline di Sodiumhydrogenphosphate & Carl Roth, Germany \\
\hline Diethyl pyrocaronate & Sigma Aldrich, MO, USA \\
\hline Dimethylsulfoxid & Roth, Germany \\
\hline DMSO & Carl Roth, Germany \\
\hline EDTA & Applichem, MO, USA \\
\hline Ethanol & Merck-Millipore, Germany \\
\hline Ethidiumbromide & Carl Roth, Germany \\
\hline Fetal calf serum & Gibco, MA, USA \\
\hline Geneticin & Gibco, CA, USA \\
\hline Glucose & Carl Roth, Germany \\
\hline HEPES & Carl Roth, Germany \\
\hline HPLC-Wasser & Sartorius, Germany \\
\hline Kanamycin & Applichem, MO, USA \\
\hline Loading Dye (DNA) & Thermo Fischer, MA, USA \\
\hline Magnesium chloride & Carl Roth, Germany \\
\hline Magnesium sulfate & Carl Roth, Germany \\
\hline PBS-Dulbecco & PAA, MA, USA \\
\hline Penicillin/streptomycin & PAA, MA, USA \\
\hline $\begin{array}{l}\text { Poly(ethyleneimine) PEI } \\
\text { solution }\end{array}$ & Sigma Aldrich, MO, USa \\
\hline Polyethylenglycol 8000 & Sigma Aldrich, MO, USA \\
\hline Potassium hydroxyide & Carl Roth, Germany \\
\hline Potassium chloride & Carl Roth, Germany \\
\hline Puromycin Dihydrochloride & Gibco, MA, USA \\
\hline RNase & Sigma Aldrich, MO, USA \\
\hline Sodium butyrate & Sigma Aldrich, MO, USA \\
\hline Sodium chloride & Carl Roth, Germany \\
\hline Sodium hydroxid & Carl Roth, Germany \\
\hline Sodiumsulfate & Merck, Germany \\
\hline T4 DNA Ligase & Promega, WI, USA \\
\hline Tris acetate & Carl Roth, Germany \\
\hline TRIS base & Sigma Aldrich, MO, USA \\
\hline Tris-HCl & Sigma Aldrich, MO, USA \\
\hline Trypanblue & PAA, MA, USA \\
\hline Trypsin-EDTA & PAN, MA, USA \\
\hline Trypton / Pepton & Carl Roth, Germany \\
\hline Yeast & Carl Roth, Germany \\
\hline
\end{tabular}




\subsubsection{Machines}

Table 10: Machines, models and manufacturer information

\begin{tabular}{|c|c|c|}
\hline Equipments & Model & Manufacturer \\
\hline Balance & EG 620-3NM & Kern \& Sohn GmbH, Germany \\
\hline Chemiluminescence System & ChemoCam Imager & INTAS, Germany \\
\hline Centrifuge & Heraeus Megafuge 8R & $\begin{array}{l}\text { Thermo Fisher Scientific, MA, } \\
\text { USA }\end{array}$ \\
\hline Centrifuge & Heraeus Fresco21 & $\begin{array}{l}\text { Thermo Fisher Scientific, MA, } \\
\text { USA }\end{array}$ \\
\hline $\begin{array}{l}\text { E-Gel system } \\
\text { Freezer }\left(-20^{\circ} \mathrm{C}\right)\end{array}$ & E-Gel iBase System & $\begin{array}{l}\text { Life Technologies, CA, USA } \\
\text { Bosch, Germany }\end{array}$ \\
\hline Freezer $\left(-80^{\circ} \mathrm{C}\right)$ & MDF-DU500VH-PE & Panasonic, Japan \\
\hline Freezer $\left(-150^{\circ} \mathrm{C}\right)$ & ULT7150-9-D & $\begin{array}{l}\text { Thermo Fisher Scientific, MA, } \\
\text { USA }\end{array}$ \\
\hline Flow Cytometer & LSR II Flow Cytometer & BD Bioscience, NJ, USA \\
\hline Gel documentation system & Gel iX Imager & INTAS, Germany \\
\hline Ice machine & ZBE $70-35$ & Ziegra, Germany \\
\hline Incubator & Heracell VIOS 160i & $\begin{array}{l}\text { Thermo Fisher Scientific, MA, } \\
\text { USA }\end{array}$ \\
\hline Incubator & IN75 & Memmert, Germany \\
\hline Incubator & Ecotron & Infors HT, Switzerland \\
\hline Microscope & Axio Vert. A1 & Zeiss, Germany \\
\hline PCR Thermocycler & Labcycler & Sensoquest, Germany \\
\hline PCR Thermocycler & 2720 Thermal cycler & Applied Biosystems, MA, USA \\
\hline $\mathrm{pH}$ meter & SevenCompactTM S210 & Mettler Toledo, $\mathrm{OH}$, USA \\
\hline Plate Reader & Synergy 2 & BioTek, VT, USA \\
\hline Platform Rocker & PMR-30 & Grant bio, Cambridge, UK \\
\hline Power supply & EV231 & Consort bvba, Belgium \\
\hline Real-Time PCR System & StepOneTMPlus Real-Time & Applied Biosystems, USA \\
\hline Safety Cabinet & Safe 2020 & $\begin{array}{l}\text { Thermo Fisher Scientific, MA, } \\
\text { USA }\end{array}$ \\
\hline Thermoblock & ThermoStat plus & Eppendorf, Germany \\
\hline Thermoblock & CTM & HTA-BioTec, Germany \\
\hline Tissue slicer & 51425 & Stoelting, Ireland \\
\hline Vortexer & Vortex-GenieTM 2 & Scientific Industries, NY, USA \\
\hline Water bath & WNB10 & Memmert, Germany \\
\hline
\end{tabular}

\subsubsection{Software}

Software used to produce schematic drawings and data analysis:

ChemDraw Professional 15.1 (University of Göttingen licence)

Flowing software 2

GraphPad Prism 6 (DPZ licence)

Microsoft Excel 365

Microsoft Word 365

Microsoft PowerPoint 365 
Serial Cloner 2.6

StepOnePlus Systems software

\section{Results}

\subsection{Transgene delivery tools}

The delivery of transgenic information into cells, tissues or animals is a basic requirement for genetic manipulations that in turn enables phenotypic changes in research questions, disease modelling and the development of therapies. Here, I focused on the utilization of viral vectors to carry transgenes into cells and tissues and biotechnological improvements of the tropism of lentiviral vectors and, with less priority, the efficiency of Adeno-associated vectors (AAV).

\subsubsection{LV production, titer determination and concentration}

Lentiviruses were produced as described in materials and methods (2.2.5). Usually, LV bud from the producer cell's plasma membrane, carrying a patch of its lipid bilayer and the proteins located there are subsequently released to the cell culture supernatant $(\mathrm{SN})$. The $\mathrm{SN}$, i.e. conditioned medium containing LV particles is harvested, cleared and can afterwards directly be used for transduction of target cells or titer-determination (figure 8). The concentration of the viral SN is an optional step that enables adjustments of the quantity of virus to be used, thus enabling improvement of the overall performance through the option of increased multiplicities of infection (MOI, number of recombinant LVs per target cell). There are several methods and techniques available for the LV-concentration. The biophysical method of PEG (polyethylene-glycol) precipitation is a straight-forward an easy method, but it leads to a higher amount of impurities in the concentrated virus pellet and shorter storage time. Ultracentrifugation in sucrose cushions is also very affordable and direct, but the disadvantages include i) the extensive manipulation of the viral SN, which can lead to contaminations and ii) the necessary use of a specialized equipment, i.e. an ultracentrifuge with appropriate containers for $\mathrm{S} 2$ material manipulation. For the purposes of this study, the concentration method of choice was commercially available centrifugation tubes with appropriate molecular weight exclusion filters (e.g. Vivaspin - Sartorius). It is a more cost-intensive, but easy and reliable method leading to a pure LV-solution with appr. 100-fold increased LV concentrations in average. 


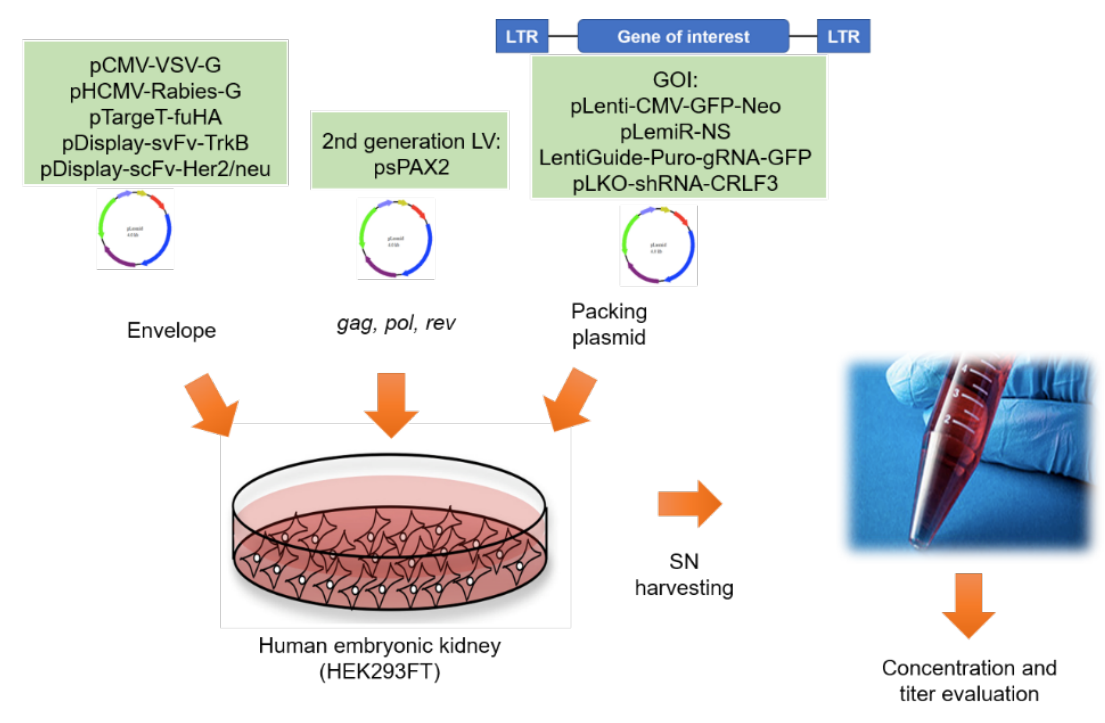

Figure 8. Second generation lentivirus production workflow. LV are produced by transfection of a producer cell line (HEK293FT) with three separate plasmids containing 1) Envelope glycoprotein (pCMV-VSV-G / pHCMV-Rabies-G), fusogenic molecule (pTargeT-fuHA) and/or targeting molecule (pDisplay-scFv-TrkB / pDisplaysvFv-Her2/neu); 2) HIV-1 structural components gag, pol, rev (psPAX2) and 3) a packing plasmid containing a gene of interest flanked by viral LTR regions. The LV tropism can be altered by utilizing different envelope plasmids. In this study VSV-G and Rabies-G originated from envelope plasmids provided by addgene.org. Constructs to alter LV tropism were generated in house for co-expression of single-chain antibodies and fusogenic molecule (see next topic). Viral particles are secreted into medium supernatant which is harvested for clearance, concentration and titer evaluation. Packing plasmids for GFP (pLenti-CMV-GFP-Neo) and RFP (pLemiR-NS) expression were obtained from addgene.org. An shRNA construct (pLKO-shRNACRLF3) and a sgRNA construct (lentiGuide-Puro-sgRNA-GFP) were generated in house.

The assessment of the number of viral particles produced was done by tittering of the viral SN. The amounts of HIV-1 capsid protein p24 was detected by ELISA assay and in addition the physical titer was calculated in transducing units per volume $(\mathrm{TU} / \mathrm{mL})$. For LV carrying GFP as GOI, a functional titer could also be calculated by utilizing a serial dilution of viral $\mathrm{SN}$ to transduce cells, which were later analysed by flow cytometry (FACS). The titer is calculated using the percentage of fluorescent cells, the volume of $\mathrm{SN}$ added and the number of cells at the moment of transduction. 


\subsubsection{Pseudotyping and re-targeting LV}

Recombinant Lentiviral vectors are potent gene delivery tools for both clinical and research purposes. Genetic engineering of HIV-1 viruses gave rise to a versatile delivery tool that safely targets cells of choice by manipulation of expression of glycoproteins on the viral envelope, in a process called pseudotyping. However, there is still a lack of targeting specificity that can be reached by conventional manipulation of such molecules. Increasing the specificity of viral vectors is desirable to decrease the required amounts of viruses while at the same time being used to reduce the chances of cell toxicity or activation of an immune response in animal models or human patients. Figure 9 shows a schematic view of the pseudotyping and re-targeting strategy of LV covered in this thesis. The drawings show models for viral particles and the molecules inserted on the viral envelope for altering the tropism.

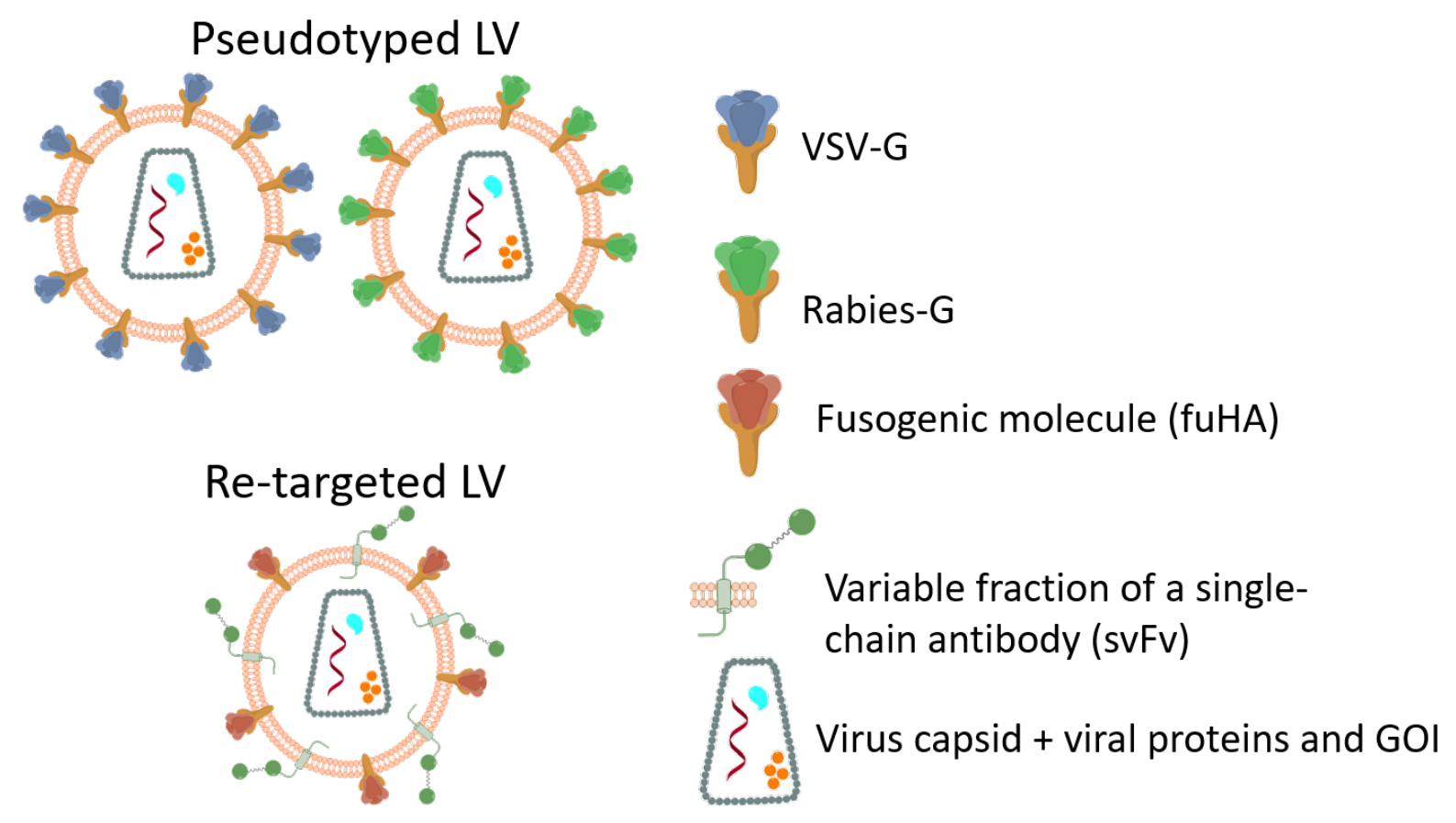

Figure 9. Models of pseudotyped and re-targeted LV. Pseudotyped viruses carry glycoproteins prevenient from other virus species to alter their tropism. In this thesis the vesicular stomatitis virus glycoprotein (VSV-G) and Rabies virus glycoprotein (Rabies-G) were produced. Re-targeted viruses have their tropism altered by expression of other molecules on the viral envelope. Re-targeted viruses coexpressing the variable fraction of a single-chain antibody (scFv) and a fusogenic molecule (fuHA) were produced to target specific ligands. 


\subsubsection{Pseudotyped LV successfully express transgenes in mammalian target cell lines}

In this thesis, HIV-1 based LV particles were produced and pseudotyped with, among others, vesicular stomatitis virus glycoprotein (VSV-G), generating recombinant viruses with a broad range of transduction and high levels of transgene expression (73,3\% $\pm 5,4 \%$ of fluorescent HEK293 cells). These viruses served as controls for the other pseudotyped and retargeted viruses and transduction efficiencies were compared (see figure 10). The transgene or gene of interest (GOI) carried by the viral particles were either green fluorescent protein (GFP) or red fluorescent protein (RFP). This way, the transduction patterns could be analyzed by microscopy and fluorescence activated cell sorting (FACS).
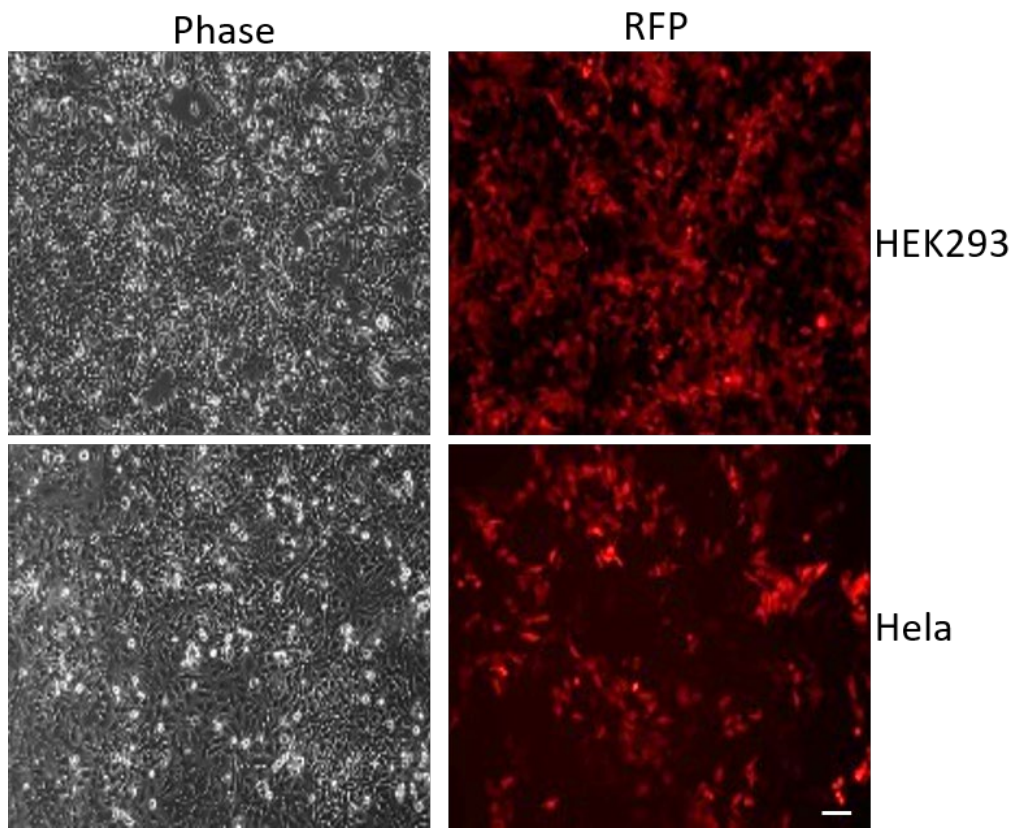

Figure 10. LV-VSV-G transduction pattern in HEK293 and Hela cells. Cells were transduced with $150 \mathrm{MOI}$ (150 viral particles per cell). $72 \mathrm{~h}$ after transduction cells were analysed under epifluorescence microscope for RFP expression and FACS. In average around $73,3 \% \pm 5,4 \%$ of HEK293 cells were fluorescent and $65,1 \% \pm 3,3 \%$ Hela showed expression of transgene. Scale bar: $100 \mu \mathrm{M}$. 
Rabies virus is a neurotropic virus that infects peripheral neuronal cells and is transported retrogradely to the central nervous system (Gluska et al., 2014). The tropism, binding and fusion of these viruses is mediated by their glycoprotein (RabiesG) which targets nicotinic acetylcholine receptors (nAchR) (Lafon, 2005). In order to produce LV with narrowed tropism towards nervous tissue, HIV-1 based LV were pseudotyped with Rabies- $G$ and their transduction patterns were investigated in figure 11. Human neuroblastoma derived differentiated cells (SH-SY5Y, see figure 18) were utilized as a nervous tissue like model. Although the transduction efficiency of these viruses was lower than the LV-VSV-G $(27,6 \% \pm 4,7 \%$ of fluorescent HEK293 cells against $73,3 \% \pm 5,4 \%$ ), the viral particles were able to transduce cell lines from origins other than nervous tissue such as cervical cancer derived Hela and human embryonic kidney HEK293. A summary of transduction efficiencies measured as percentage of fluorescent cells can be found in table 11.
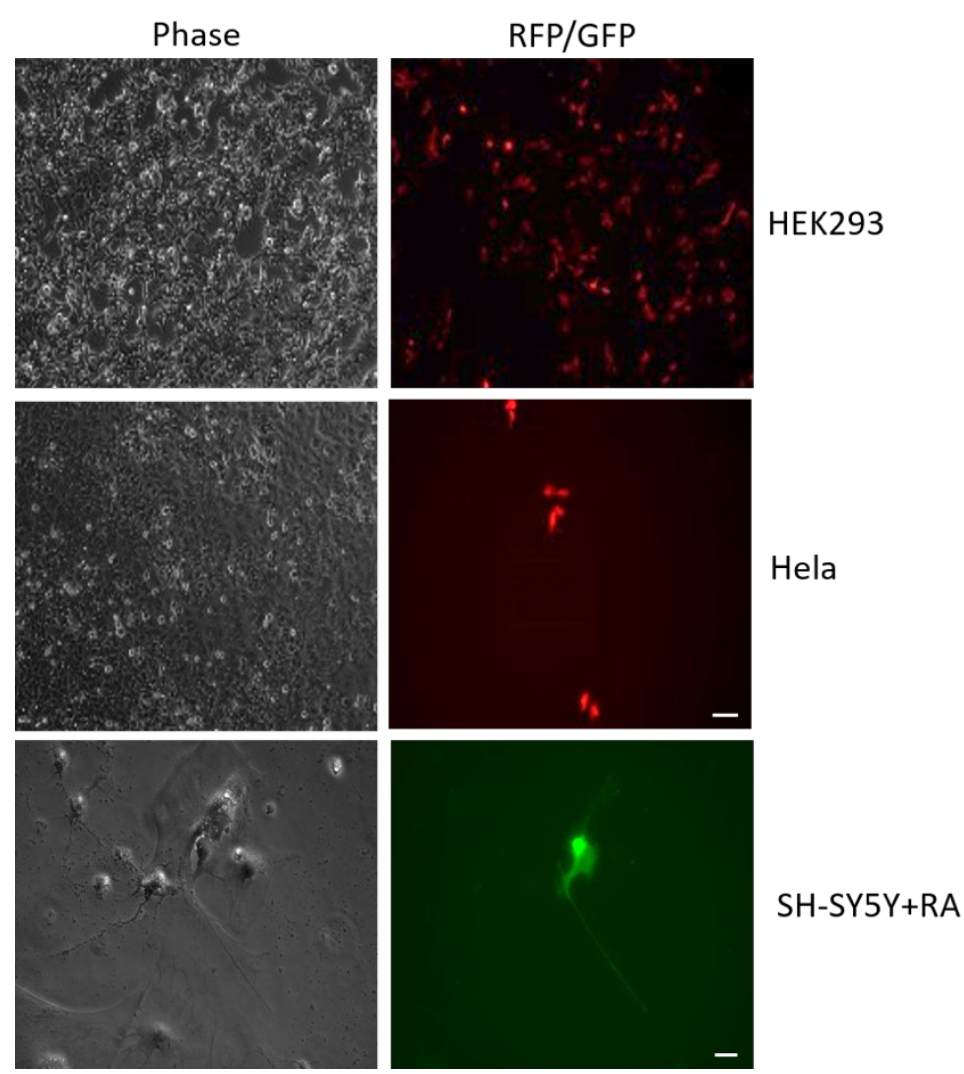

Figure 11. LV-Rabies-G transduction pattern in HEK293, Hela and differentiated SH-SY5Y cells. Cells were transduced with $150 \mathrm{MOI}$ (150 viral particles per cell). $72 \mathrm{~h}$ after transduction cells were analysed under epifluorescence microscope for RFP/GFP expression and by FACS. In average around 27,6\% \pm 4,7\% HEK293 cells, 17,3\% \pm $3,0 \%$ Hela cells and $11,1 \% \pm 3,1 \%$ SH-SY $5 Y+R A$ cells were fluorescent. Scale bar: upper images $100 \mu \mathrm{M}$, lower image $20 \mu \mathrm{M}$. 
Table 11: Transduction efficiency of pseudotyped LV

\begin{tabular}{lll}
\hline Cell line & \multicolumn{2}{l}{ Lentiviruses used for transduction } \\
\hline & LV-VSV-G & LV-Rabies-G \\
\hline HEK293 & $73,3 \% \pm 5,4 \%$ & $27,6 \% \pm 4,7 \%$ \\
Hela & $65,1 \% \pm 3,3 \%$ & $17,3 \% \pm 3,0 \%$ \\
SH-SY5Y+RA & $55,2 \% \pm 2,1 \%$ & $11,1 \% \pm 3,1 \%$ \\
\hline
\end{tabular}

\subsubsection{Pseudotyped LV leads to successful transgene expression in rat brain dissociated culture}

Lentiviruses are especially suited for use in neurosciences for they can infect nondividing cells like neuronal cells. Thereby LV-VSV-G and LV-Rabies-G were tested on rat brain dissociates cultures and their transduction pattern was analyzed by microscopy. LV-VSV-G led to an average of $52.2 \%$ of transduced cells (manual counting), while LV-Rabies-G transduced around $9,6 \%$ of the cells in culture (figure 12). Virus were added after 13 DIV and cultures could be kept for at least 14 days after transduction without significant signs of cell degradation in both transduced and control wells. 


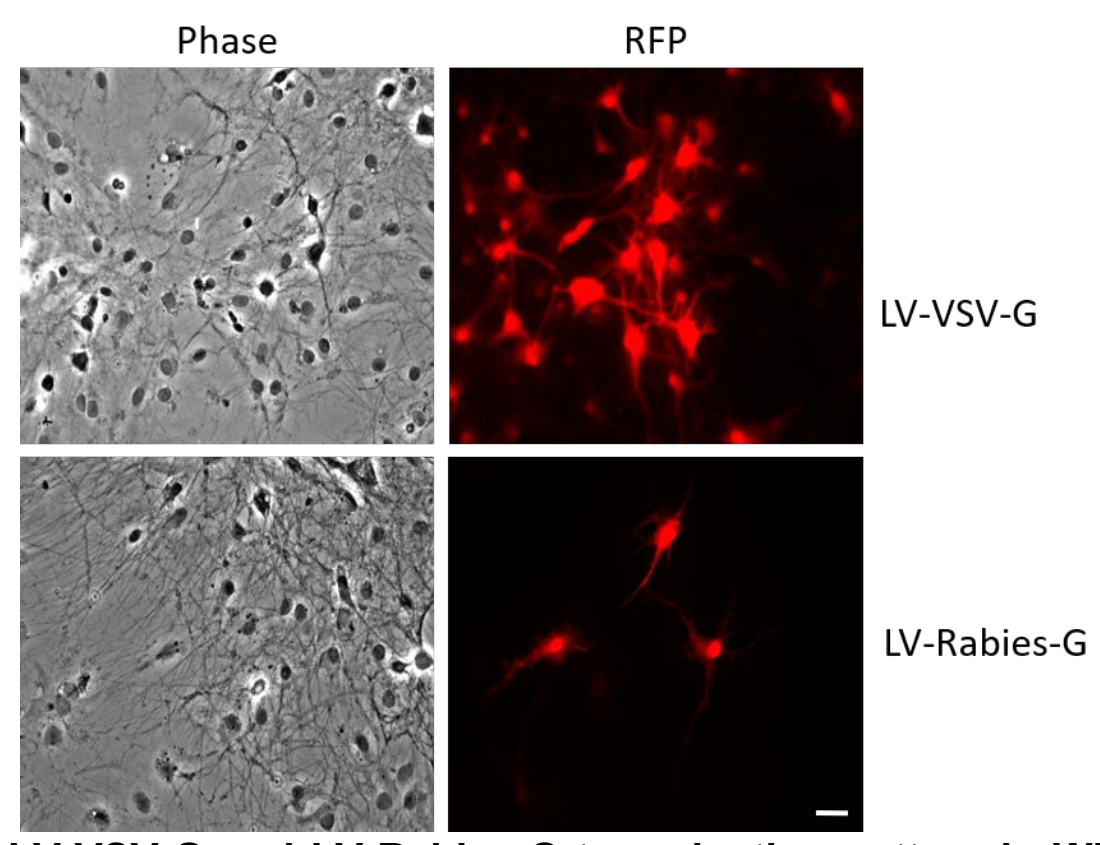

Figure 12. LV-VSV-G and LV-Rabies-G transduction pattern in Wistar rat brain dissociated culture. Virus were added after $13 \mathrm{DIV} .72 \mathrm{~h}$ after transduction cells were analysed under epifluorescence microscope for RFP expression. LV-VSV-G treated cultures expressed the transgene in around $52.2 \%$ of the cells, while LV-Rabies-G treated cells were $9.6 \%$ fluorescent. No signs of cytotoxicity were observed on treated cells when compared to non-treated controls for at least 14 days after transduction. Scale bar: $20 \mu \mathrm{M}$.

\subsubsection{Pseudotyped LV leads to successful transgene expression in ex vivo non-human primates organotypic brain slices}

Advancing an extra step regarding the complexity of experimental models, cortical brain slices from a non-human primate species (Macaca fascicularis) were prepared and kept alive in culture dishes as an ex vivo experimental model. Lentiviruses were added directly on top of the cultured slices and successful delivery of RFP was qualitatively assessed after 13 days in vitro (DIV) as shown in figure 13. The slices were kept for at least 20 DIV with no signs of increased degradation on treated slices when compared to non-treated slices. The identity of the cells was not checked but morphology indicates glial cells to be the most successful transduced given the size and shape of fluorescent cells. 


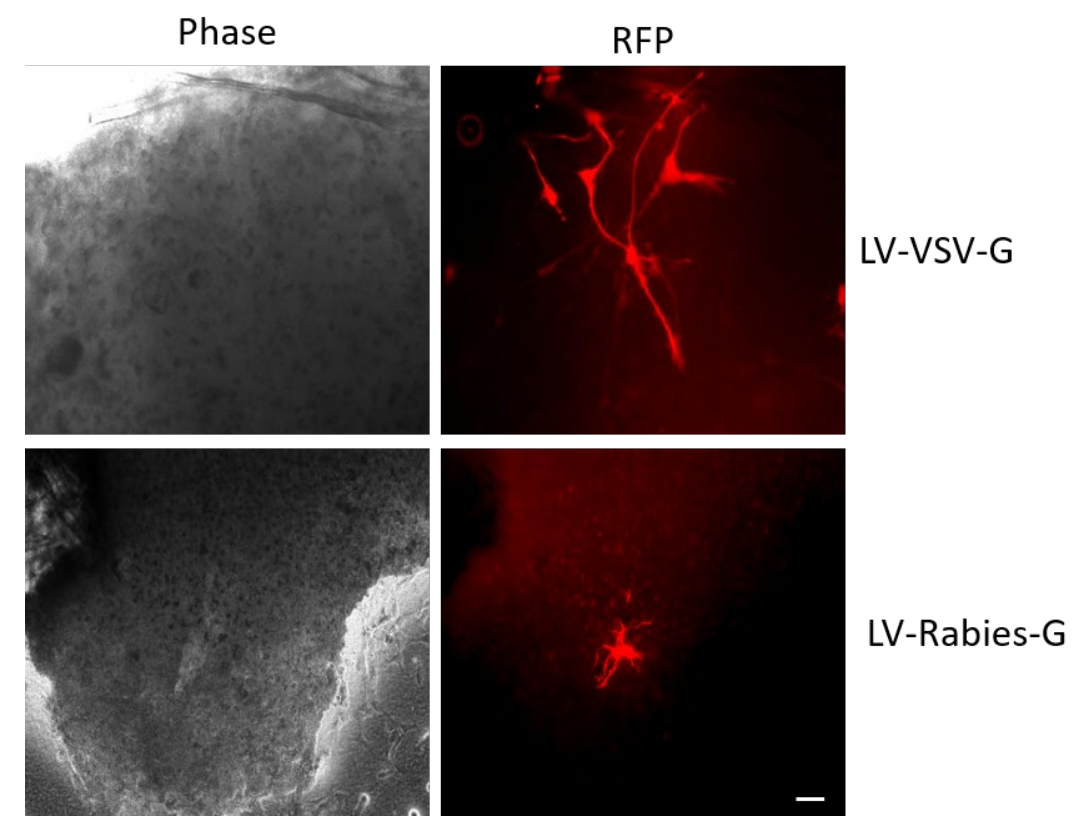

Figure 13. LV-VSV-G and LV-Rabies-G transduction pattern in Macaca fascicularis organotypic brain slices. Brain slices were kept on a permeable membrane in such a way that the slice had access to the culture medium and atmospheric gases. Slices were transduced on 10 DIV. $72 \mathrm{~h}$ after transduction cells were analysed under epifluorescence microscope for RFP expression. Given the nature of the material the quantification of percentage of fluorescent cells is difficult but qualitative assessment show a higher efficiency of LV-VSV-G. No differences in tissue degradation were observed on treated slices compared to the controls for at least 7 days after transduction. Scale bar: $100 \mu \mathrm{M}$.

\subsubsection{Re-targeted LV: narrowing viral tropism by expression of single chain antibodies and fusogenic molecule}

Yang and colleagues (Yang et al., 2006), (Lei et al., 2009), (Lei et al., 2010) have worked on a different approach towards modifying the molecules on LV envelope in order to increase specificity of transduction. They used the variable fraction of a single chain antibody (scFv) for their high binding specificity. Furthermore, the reduced size of these molecules allowed for the fusion with a transmembrane protein for anchorage on the viral envelope. However, this chimeric protein alone is not able to drive fusion of the viral envelope with the host cell membrane, a fundamental step on the delivery of the transgene. Their approach involved driving fusion by co-expression of a binding 
defective viral glycoprotein mutated to preserve its fusogenic property. In this study the same rational was followed. Two re-targeted LV were produced targeting different molecules. In both viruses the fusogenic molecule was a modified hemagglutinin (HA) from the influenza virus. As shown in figure 14, three point mutations were inserted on the binding segment of the molecule in order to refrain it from its biding activity. This mutated or fusogenic HA (fuHA) was then co-expressed with two different svFv:

$1^{\text {st }}$ ) scFv-TrkB: the tyrosine kinase receptor (TrkB) is a receptor for brain-derived neurotrophic factor (BDNF) and it is known to be highly expressed in nervous tissue (Huang and Reichardt, 2003). By producing LV bearing a specific scFv for TrkB, the working hypothesis was that the tropism of LV would be narrowed towards nervous tissue exposing TrkB. For research and clinical applications, a neurotropic LV is valuable because it can deliver transgenes in a safer manner in such a delicate system as the central nervous system.

$2^{\text {nd }}$ scFv-Her2/neu: human epidermal growth factor receptor 2, also known as Her2/neu is an oncogene (Coussens et al., 1985) known to be overexpressed in a variety of breast cancers, nowadays being used as a marker of the progression of the disease and potential therapeutic target (Mitri et al., 2012). The advent of genetic manipulation tools such as silencing RNA (siRNA) and genome editing tools such as the CRISPR-Cas9 system brought new light onto potential new therapies for cancer by allowing the inhibition of the expression of proto-oncogenes and activating the expression of tumor suppressor genes. Therefore, delivery tools that are highly specific for cancerous cells are highly desirable. 


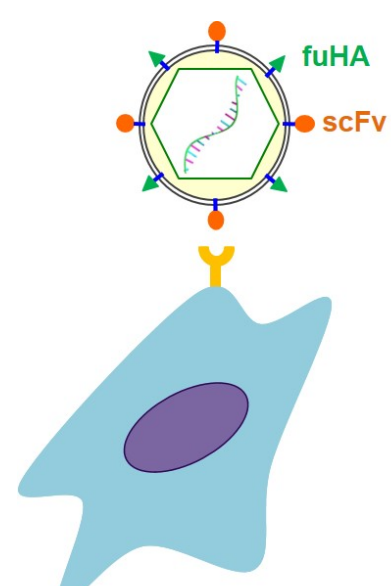

Target cell
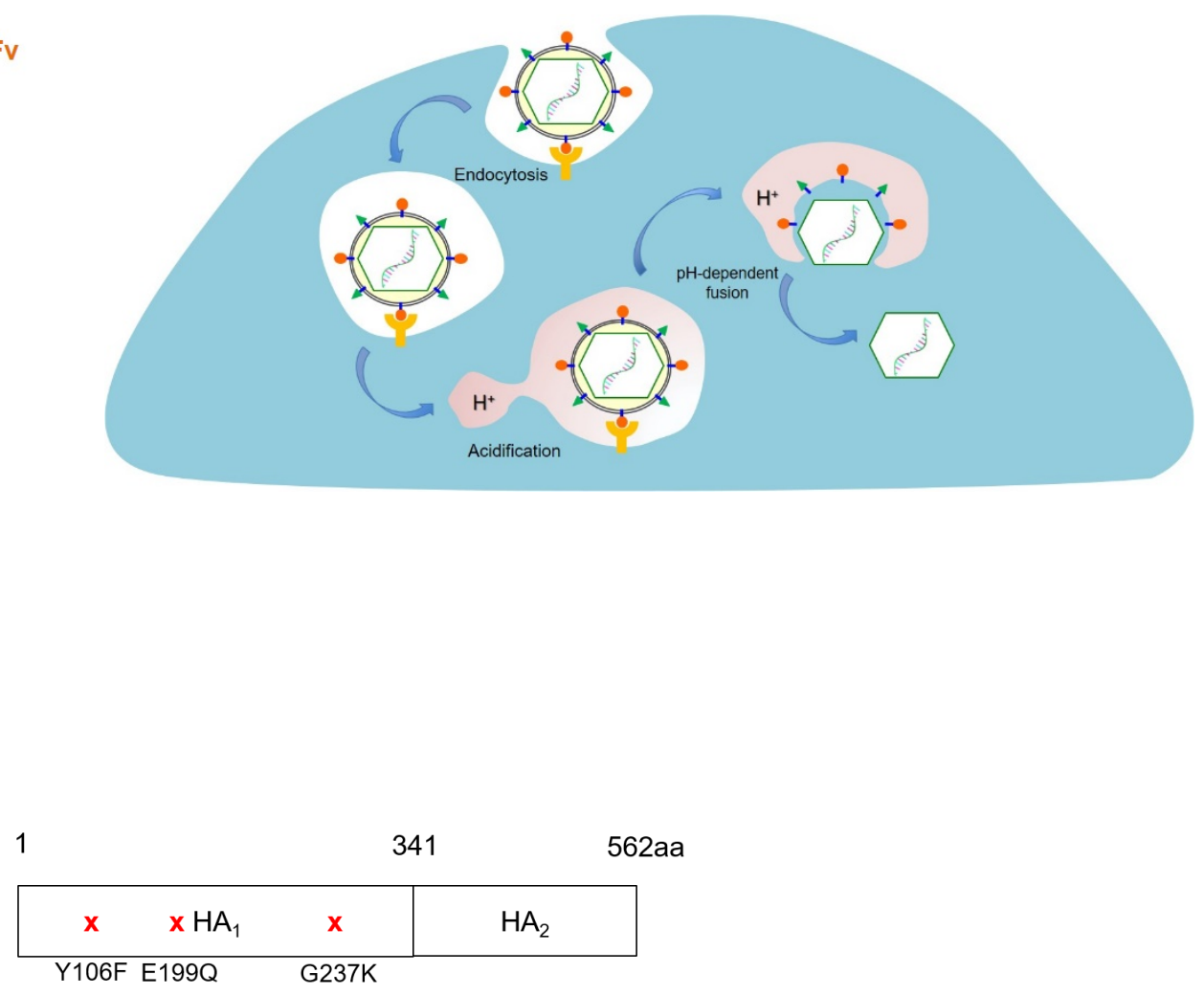

Fusogenic hemagglutinin - fuHA

Figure 14. Schematic view of proposed mode of action of fusogenic molecule. Re-targeted LV co-expressing a targeting molecule (single-chain antibody - scFv in green) and a fusogenic molecule to drive fusion (fusogenic hemagglutinin - fuHA in red) on the envelope recognizes a target molecule on the cell membrane (upper panel, left). After binding and endocytosis, the fusogenic molecule will promote fusion of the viral envelope and release of viral capsid upon acidification of endosome. Lower panel: Fusogenic molecule was generated by insertion of three point-mutations (Y106F, E199Q, G237K) on the binding domain of hemagglutinin from influenza virus, which prevents it from binding with host cell. The fusion activity is not disrupted. $\mathrm{HA}_{1}$ : binding domain; $\mathrm{HA}_{2}$ : fusion domain. Adapted from (Yang et al., 2006) 
For the expression of scFv's on the cell membrane and later incorporation into viral envelope, this molecule was fused with a Platelet-derived growth factor receptor transmembrane domain (PDGFR-TM) construct contained in a plasmid commercially available ( $p$ Display - Invitrogen, USA). This construct is specific for guiding expression of proteins on outer cell membranes and contains among others a myc tag for protein detection (figure 15). svFv-TrkB and svFv-Her2/neu were cloned into the vector creating a chimeric PDGFR-svFv protein for expression on the cell membrane. In order to determine whether the ScFv construct was indeed being expressed on the outer membrane surface an immunoassay was developed:

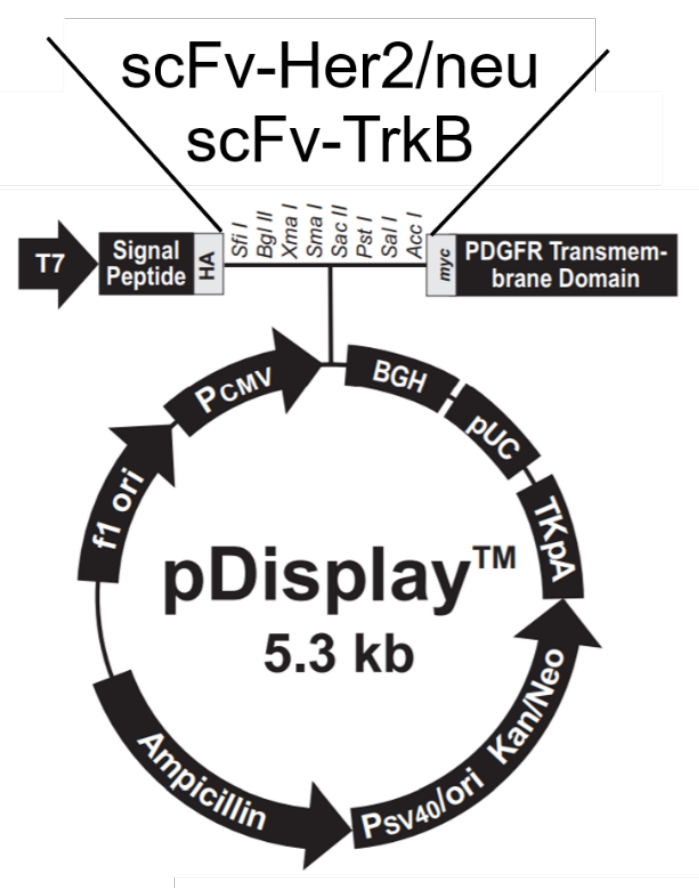

Figure 15. Construct for expression of molecules on mammalian cell membranes. The commercially available pDisplay system for display of proteins on the outer cell membrane contains a Platelet-derived growth factor receptor transmembrane domain (PDGFR-TM) for anchoring proteins to the membrane, HA tag and myc tag for protein detection. scFv targeting Her2/neu and TrkB were cloned into in the multiple cloning site according to manufacturer's instructions creating chimeric PDGFR-scFv proteins. Source: pDisplay vector Catalog no. V660-20 Invitrogen. (Agholme et al., 2010) 
HEK293 cells were transfected with pDisplay empty, pDisplay-scFv-TrkB and pDisplay-scFv-Her2/neu. 72h later cells were fixed with paraformaldehyde, unspecific epitopes were blocked with BSA and then incubated with primary anti-myc tag antibody. An appropriate secondary antibody conjugated with Alexafluor 488 was used and fluorescence was analysed by FACS. Figure 16 shows that there is a striking increase in average fluorescence on the transfected cells in comparison to wt cells. The constructs containing scFv also showed a slightly higher average fluorescence.

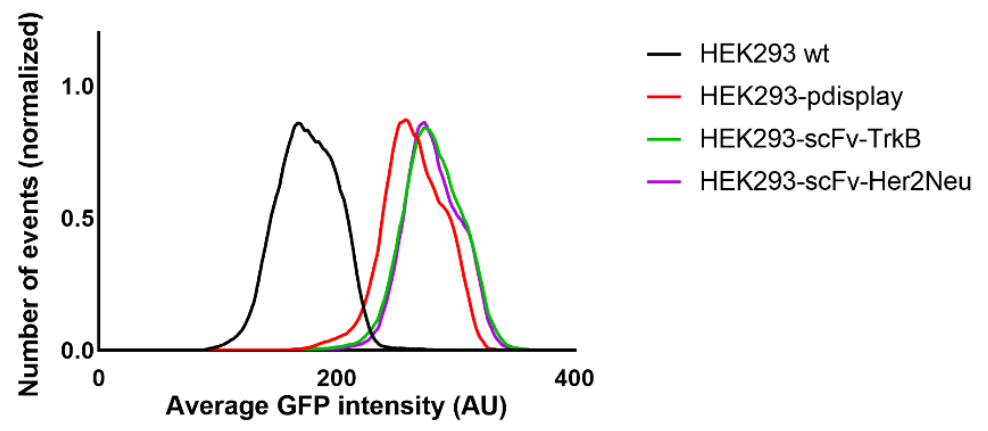

Figure 16. Histogram of immunoassay for detection of protein on the outer cell membrane in HEK293 cells. Cells expressing pDisplay constructs and wt cells were treated for staining of myc tagged proteins with Alexa 488 conjugated antibody. Only proteins expressed on the outer cell membrane could be detected because the cells were not permeabilized. Average fluorescence intensity was measured by FACS. Histograms show a much higher average fluorescence intensity on cells expressing pDisplay in comparison with the wt (black line). Cells expressing pDisplay fused with a svFv show slightly higher fluorescence. 


\subsubsection{LV-scFv-TrkB: targeting nervous tissue}

Lentiviruses bearing a scFv-TrkB and a fuHA were tested in different cells lines. A LVfuHA carrying only the fusogenic molecule was used as a negative control, once it is not expected to drive fusion of virus and host cell. To check whether our cell lines expressed the TrkB receptor, a PCR and $\mathrm{qPCR}$ using $\beta 2 \mathrm{M}$ as housekeeping gene were performed and the electrophoresis gel as well as the relative expression of TrkB are shown in figure 17. The higher amounts of the receptor were detected in differentiated SH-SY5Y. These cells, upon incubation with retinoic acid (RA) differentiate into mature neuronal-like cells including their morphology (Påhlman et al., 1995), (Agholme et al., 2010) (see figure 18). Therefore, the re-targeted viruses were tested on these cells first, as shown in figure 19. Although with low efficiency, LV-scFvTrkB were able to drive expression of the GOI.

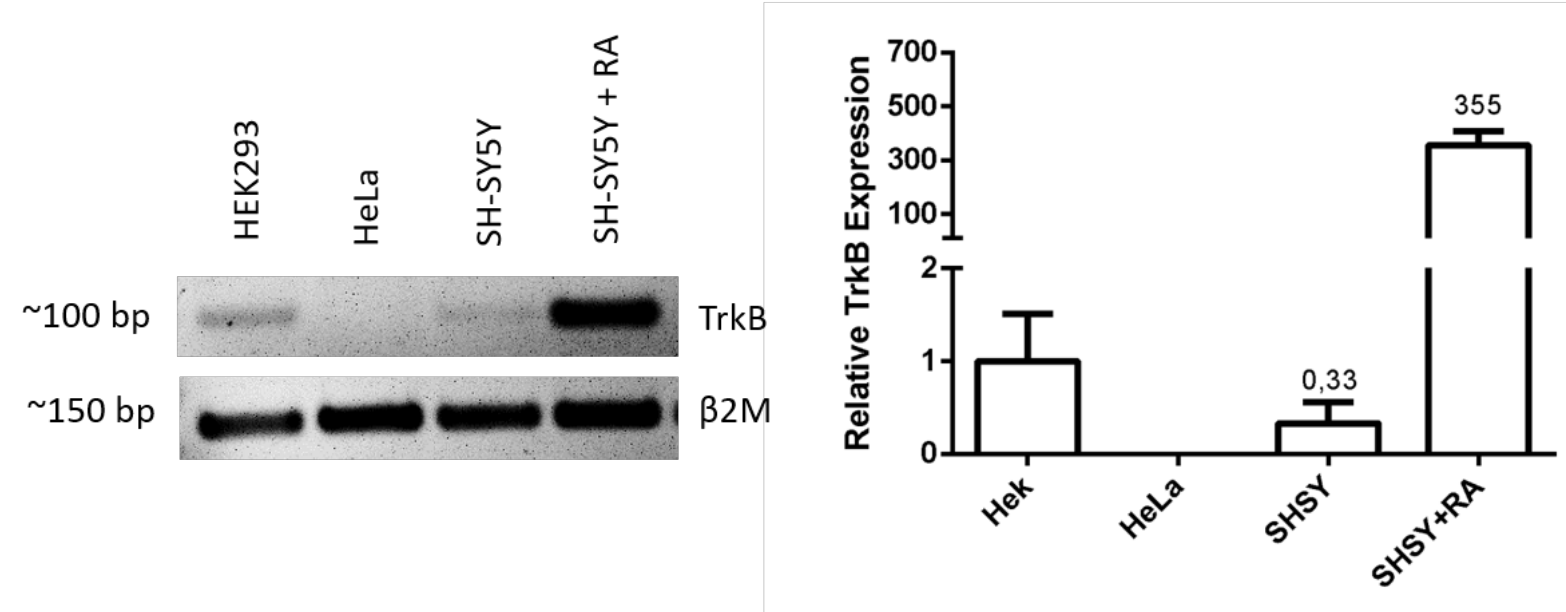

Figure 17. TrkB expression detection by PCR and qPCR. Expression of TrkB receptor in various cell lines were detected by PCR (left panel and quantified by qPCR (right panel). Observe the steep increase in TrkB expression upon differentiation in SH-SY5Y cells (355-fold increase when compared to HEK296 wt). Hela cells show neglectable expression and therefore could be used as a negative control when targeting TrkB. $\beta 2 \mathrm{M}$ was used as housekeeping gene. Error bars represent SEM.

To access the specificity of these viruses, other cell lines showing low expression of TrkB were also transduced, including Hela and HEK293. Surprisingly, these cells also showed fluorescence (see figure 20). 


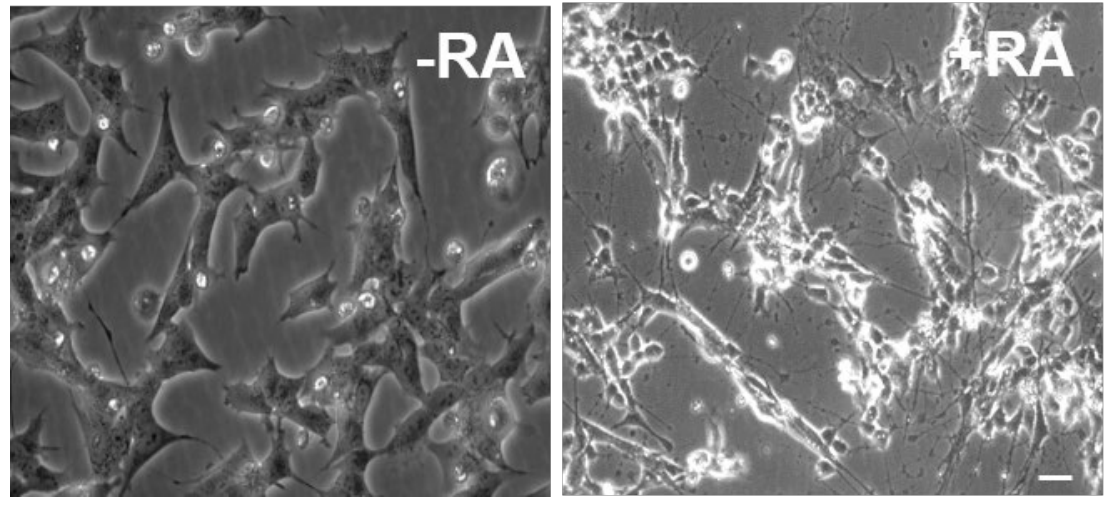

Figure 18. Neuroblastoma derived SH-SY5Y cells morphology upon differentiation. SH-SY5Y cells can be differentiated into mature neuron-like cells by incubation with retinoic acid (RA). 10 $\mathrm{MM}$ RA for $72 \mathrm{~h}$ leads to cells with longer, thinner and more abundant processes. Differentiated cells express neuronal markers such as NeuN.

Phase
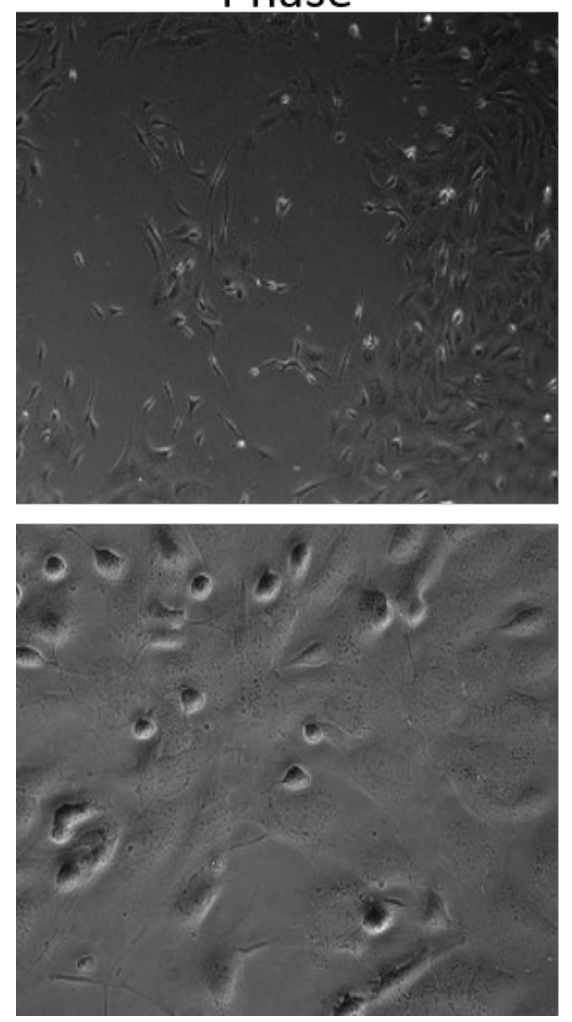

RFP
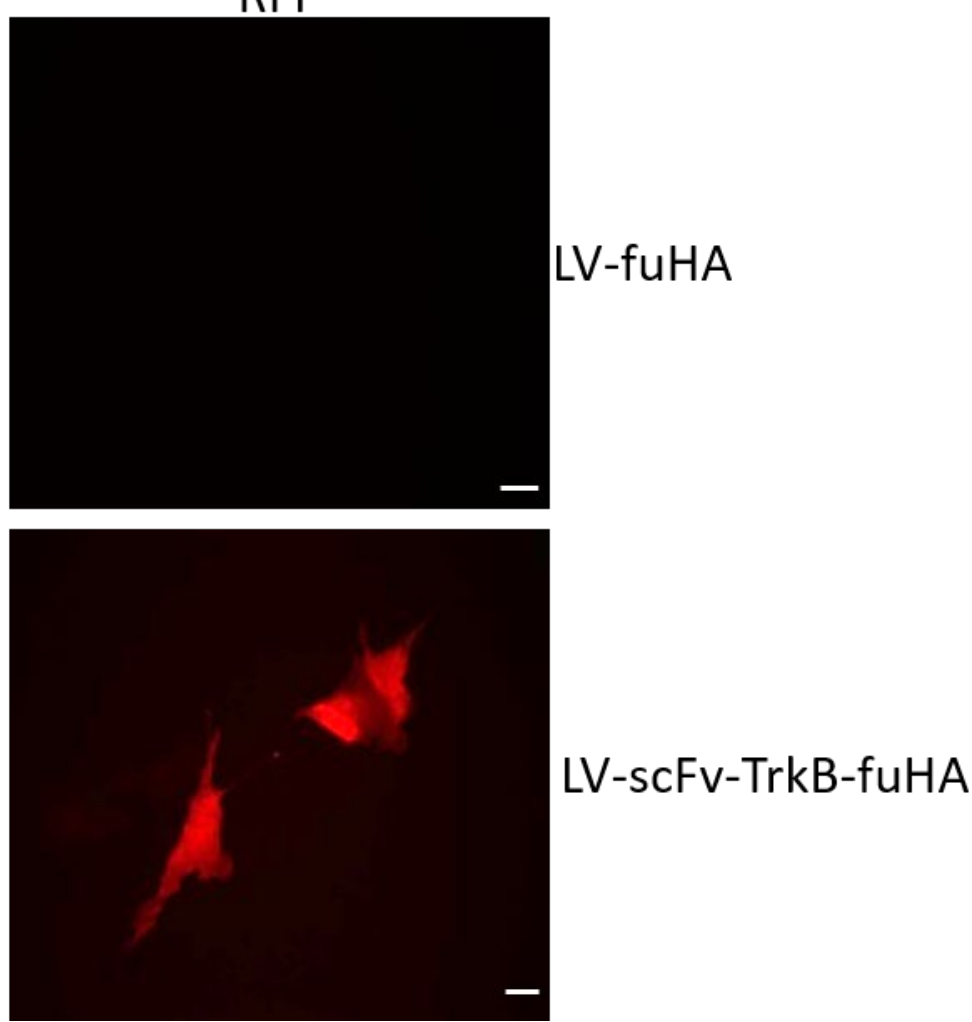

Figure 19. LV-fuHA and LV-scFv-TrkB-fuHA transduction pattern in differentiated SH-SY5Y. As expected fuHA alone do not lead to transgene expression. LV-scFvTrkB-fuHA leads to low efficiency expression. $72 \mathrm{~h}$ after transduction cells were analised under epifluorescence microscope for RFP intensity. Scale bar: upper image: $100 \mu \mathrm{M}$, lower image $20 \mu \mathrm{M}$. 

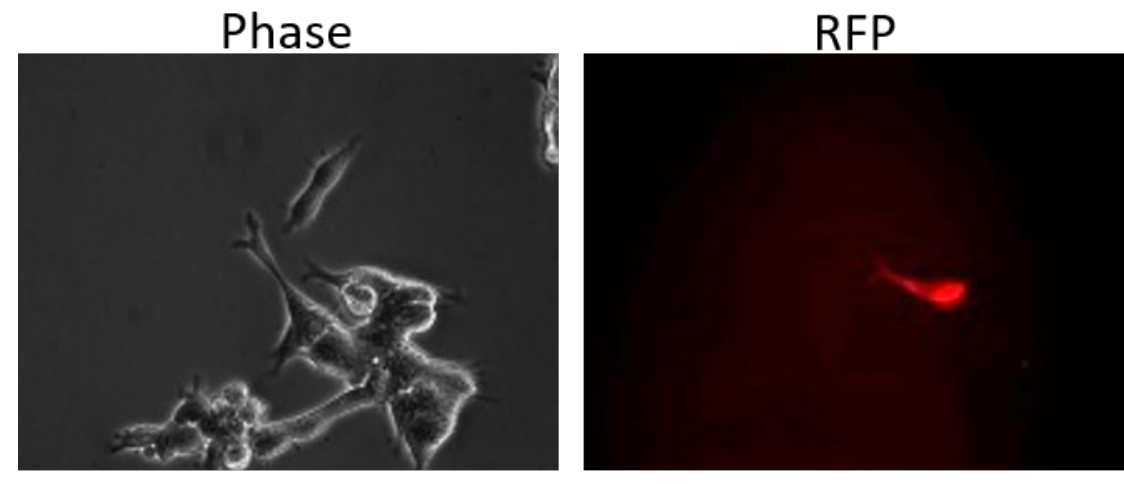

HEK293
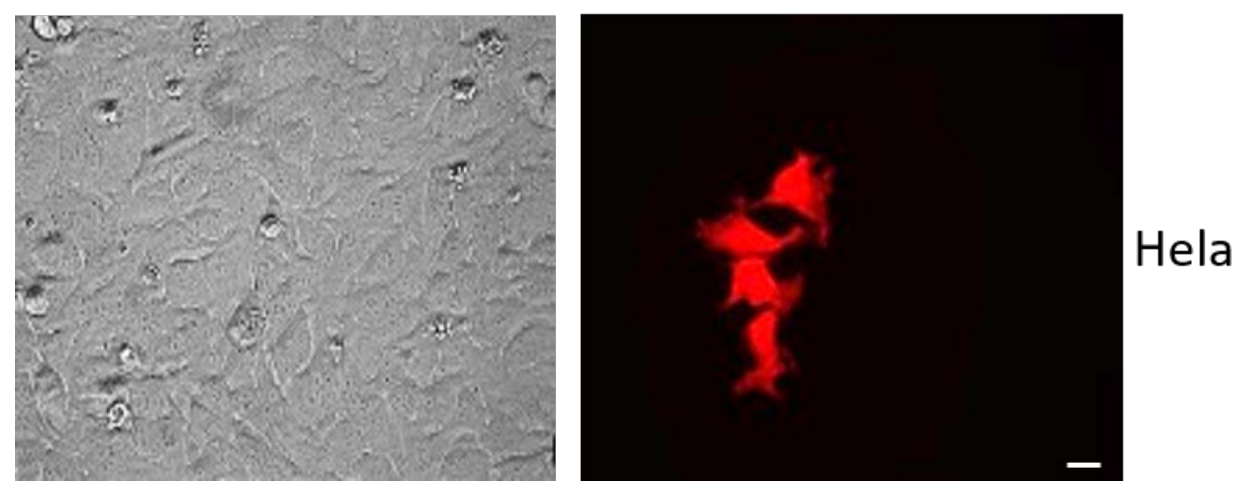

Figure 20. LV-scFv-TrkB-fuHA transduction pattern in HEK293 and Hela. Though these cell lines show low expression of TrkB receptor (see figure 17), LV-ScFv-TrkBfuHA lead to expression of RFP in a few cells. $72 \mathrm{~h}$ after transduction cells were analised under epifluorescence microscope for RFP intensity. Scale bar: $20 \mu \mathrm{M}$.

\subsubsection{LV-scFv-Her2/neu: targeting breast cancer cells}

As described before, LV carrying scFv-Her2/neu and fuHA were produced. The expression levels or Her2/neu in target cell lines were detected by GPCR as shown in figure 21. A high Her2/neu expression cell line SKBR3 (breast cancer) as well as low expression HEK293 were transduced. Figure 22 show the transduction patterns on these cell lines. Interestingly, all cell lines tested expressed the transgene and unexpectedly the control virus LV-fuHA also lead expression in HEK293 and SKBR3. 


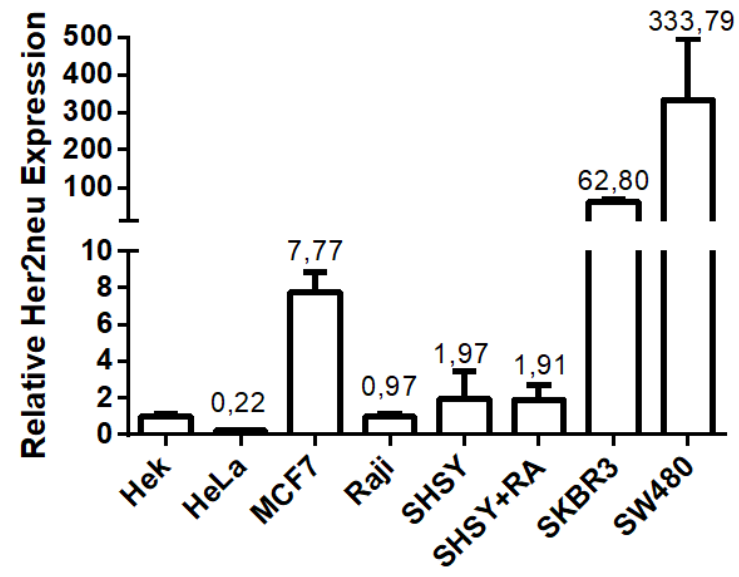

Figure 21. Her2/neu expression detection by qPCR in several cell lines. Higher amounts of Her2/neu are expressed in MCF7, SKBR3 and SW480, all cancer cell lines. $\beta 2 \mathrm{M}$ was used as housekeeping gene. Error bars represent SEM.

SKBR3
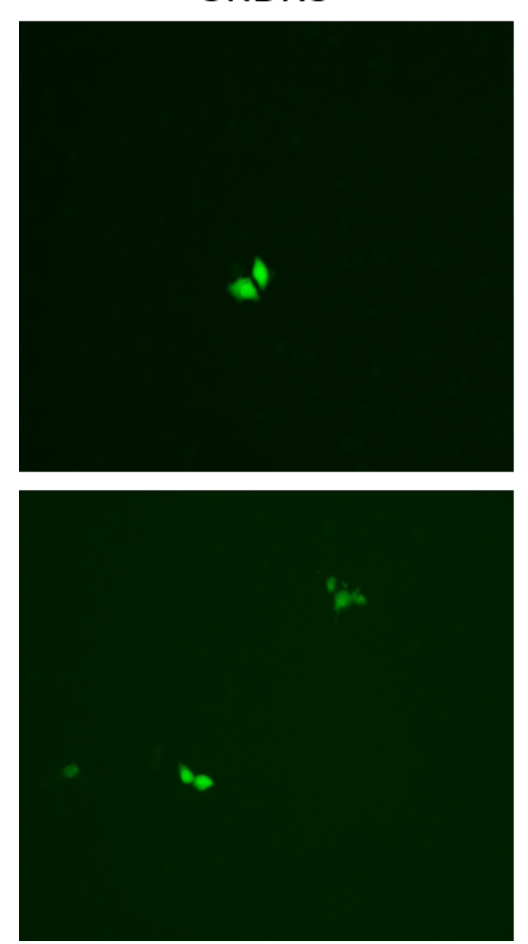

HEK293

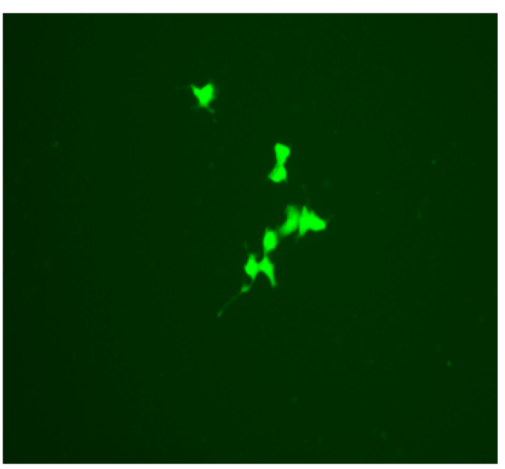

LV-scFv-Her2/neu-fuHA

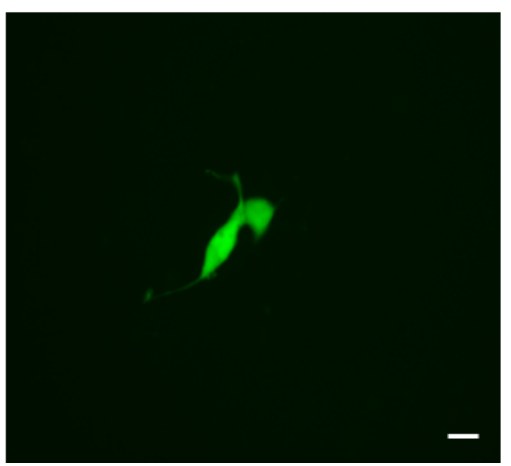

LV-fuHA

Figure 22. LV-Her2/neu-fuHA transduction pattern in SKBR3 and HEK293. LVScFv-Her2/neu-fuHA lead to expression of GFP with low efficiency. Surprisingly LVfuHA also leads to expression of transgene. $72 \mathrm{~h}$ after transduction cells were analysed under epifluorescence microscope for GFP intensity. Scale bar: $20 \mu \mathrm{M}$. 


\subsection{Improving the efficiency of viral vectors}

Besides specificity, efficiency is also a quality desired when it comes to gene delivery tools. The higher the efficiency, the lower amounts of viruses can be used leading to less potential risks to the target organism or cell.

\subsubsection{The tetraspanin CD9 and LV}

A study in which I am a contributing author (Böker et al., 2018) showed that the coexpression of a membrane protein with VSV-G on the viral envelope resulted in LV that were more efficient in delivering the transgene as assessed by FACS. The tetraspanin CD9 is a membrane protein that is known to be involved in several cell processes such as adhesion, proliferation (Hemler, 2005) and in facilitating fusion of the sperm and egg during fecundation (Miyado et al., 2000). The LV-VSV-G-CD9 viruses promoted a faster and higher expression of the GOI when compared to LV-VSV-G (figure 23). The viral titers however were not affected by CD9 expression. 

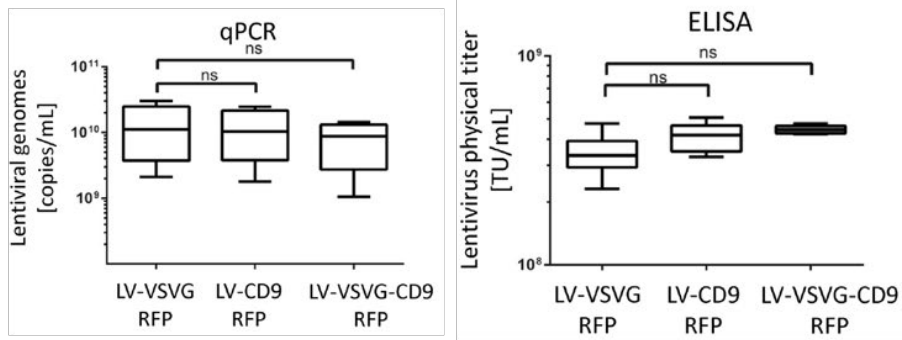

LV-VSV-G-CD9

$20 \mathrm{~h}$

$40 \mathrm{~h}$

$64 \mathrm{~h}$

$84 \mathrm{~h}$

$108 \mathrm{~h}$

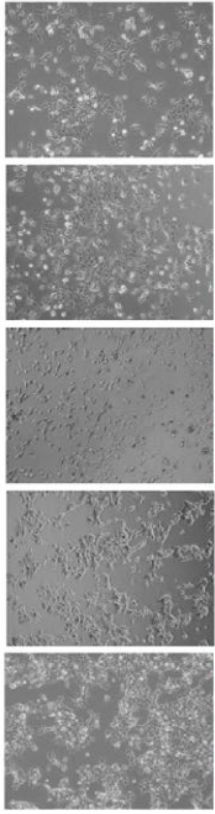

Phase
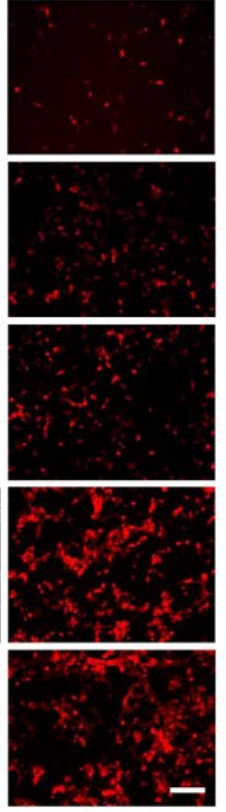

RFP

LV-VSV-G

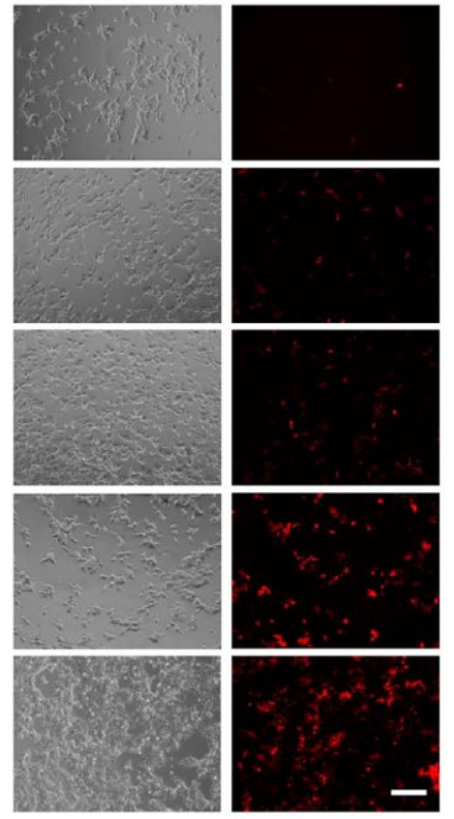

Phase
LV efficiency HEK293 cells

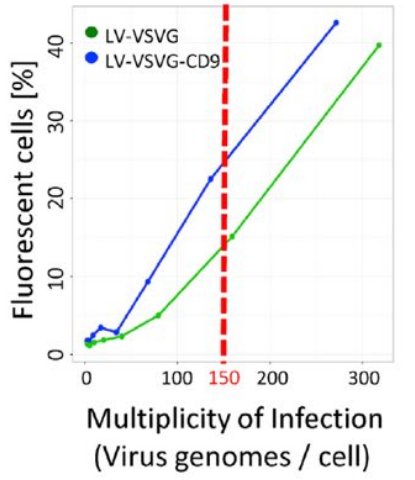

Figure 23. CD9 improves LV efficiency. The CD9 tetraspanin was co-expressed with VSV-G on the viral envelope generating LV-VSV-G-CD9. The transduction patterns and viral titer were compared to the control LV-VSV-G. Co-expression of CD9 did not influence on viral titer as assessed by physical titer (ELISA) and genomic titer (upper panel). LV-VSV-G-CD9 lead to faster and improved expression of RFP as assessed by microscopy in HEK293 cells at different time points (lower left panel). Percentage of fluorescent cells using different MOI by FACS analysis show higher efficiency of LVVSV-G-CD9 (lower right panel). Error bars show SD. Scale bar 200 $\mu$ M. Source: (Böker et al., 2018). 


\subsubsection{The tetraspanin CD9 and LV-Rabies-G}

To test whether co-expression of the CD9 tetraspanin and Rabies-G would have a positive influence on LV efficiency, LV-Rabies-G-CD9 was produced and its transduction patterns were compared to those of LV-Rabies-G. Same MOI of both LV were added to four different cell lines including HEK293, SH-SY5Y and hard-totransfect suspension cell lines Jurkat (T-cell line) and Raji (B-cell line). The physical titers were calculated by ELISA (figure 24). Transduction patterns were analysed by microscopy and FACS (figure 25). There was no significant difference on viral amounts produced when CD9 was co-expressed. The viral efficiency did not change significantly among the cell lines tested.

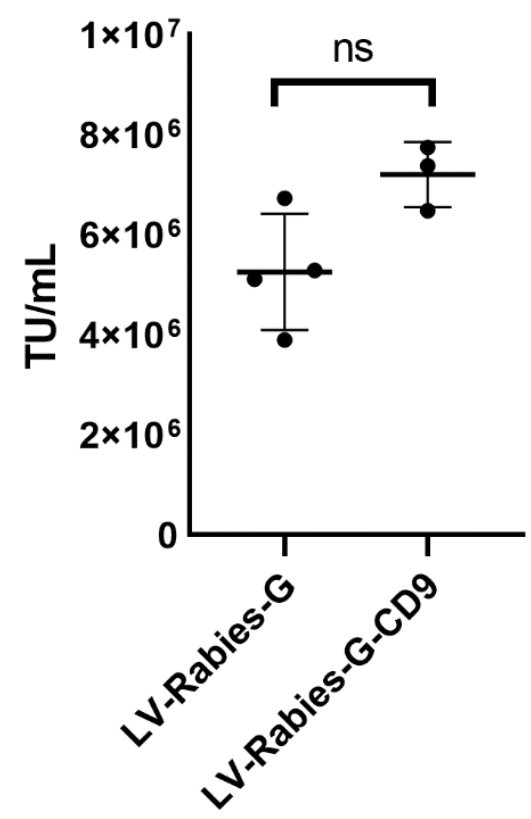

Figure 24. Physical titer comparison LV-Rabies-G vs LV-Rabies-G-CD9. Physical titer of LV-Rabies-G and LV-Rabies-G-CD9 was measured by HIV-1 p24 protein quantification in ELISA and calculated as transducive units per $\mathrm{mL}(\mathrm{TU} / \mathrm{mL})$. There was no significant difference on the number of viral particles produced in CD9 expressing producer cell lines when four technical replicas were analysed. 


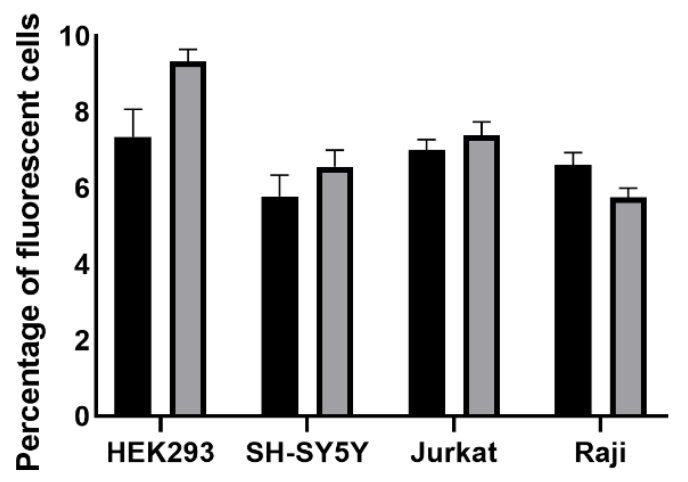

LV-Rabies-G

ㅁ LV-Rabies-G-CD9

LV-Rabies-G
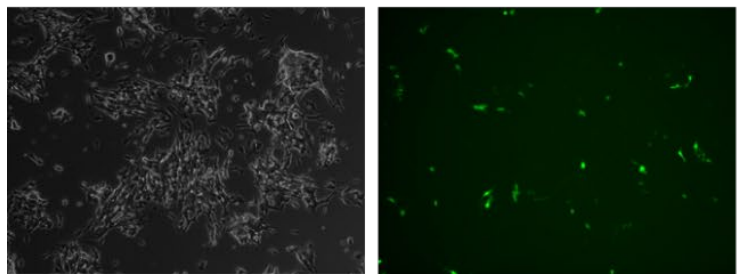

LV-Rabies-G-CD9
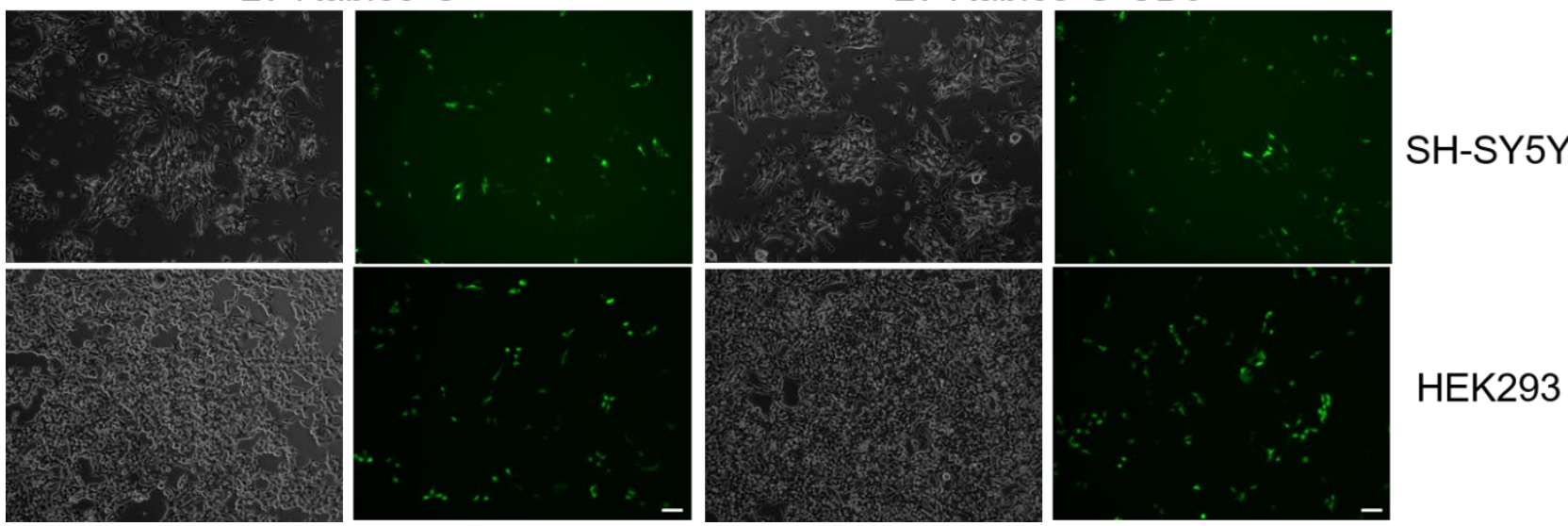

Figure 25. Transduction pattern and fluorescence quantification of LV-Rabies-G and LV-Rabies-G-CD9 treated cells. HEK293, SH-SY5Y, Jurkat and Raji cells were transduced with $150 \mathrm{MOI}$ LV-Rabies-G and LV-Rabies-G-CD9 and percentage of fluorescent cells were quantified by FACS (upper panel). Although both viruses were functional, there was no significant difference in the number of transduced cells when CD9 was present. Lower panel shows transduction patter on HEK293 and SH-SY5Y. Scale bar $100 \mu \mathrm{m}$. 


\subsubsection{The tetraspanin CD9 and exosome associated Adeno-associated virus}

Although AAV are non-enveloped viruses, studies showed that the association of these viruses with extracellular vesicles of endosomal origin, called exosomes had beneficial effects on AAV transduction efficiency (Maguire et al., 2012). Exosomes are small extracellular vesicles (30-100nM) secreted by virtually all mammalian cells. When associated to AAV (exo-AAV) it was hypothesized that these particles could transduce target cells more efficiently and the natural tropism of AAV could be altered by manipulation of molecules expressed on exosomes membrane.

On the course of Lara Schiller's project we sought to further proof whether exosomes had in fact a positive effect on AAV transduction efficiency and extend the concept of beneficial impact of CD9 on viral efficiency by studying CD9-enriched exo-AAVs transduction patterns. A summary of the findings is shown in figure 26. In brief, CD9 overexpression on AAV producer cells increases the number of exosomes secreted, which lead to a higher amount of exosome associated AAV. The CD9 exo-AAVs were in average $26 \%$ more efficient in transducing HEK293 cells when compared to wt exoAAV. 

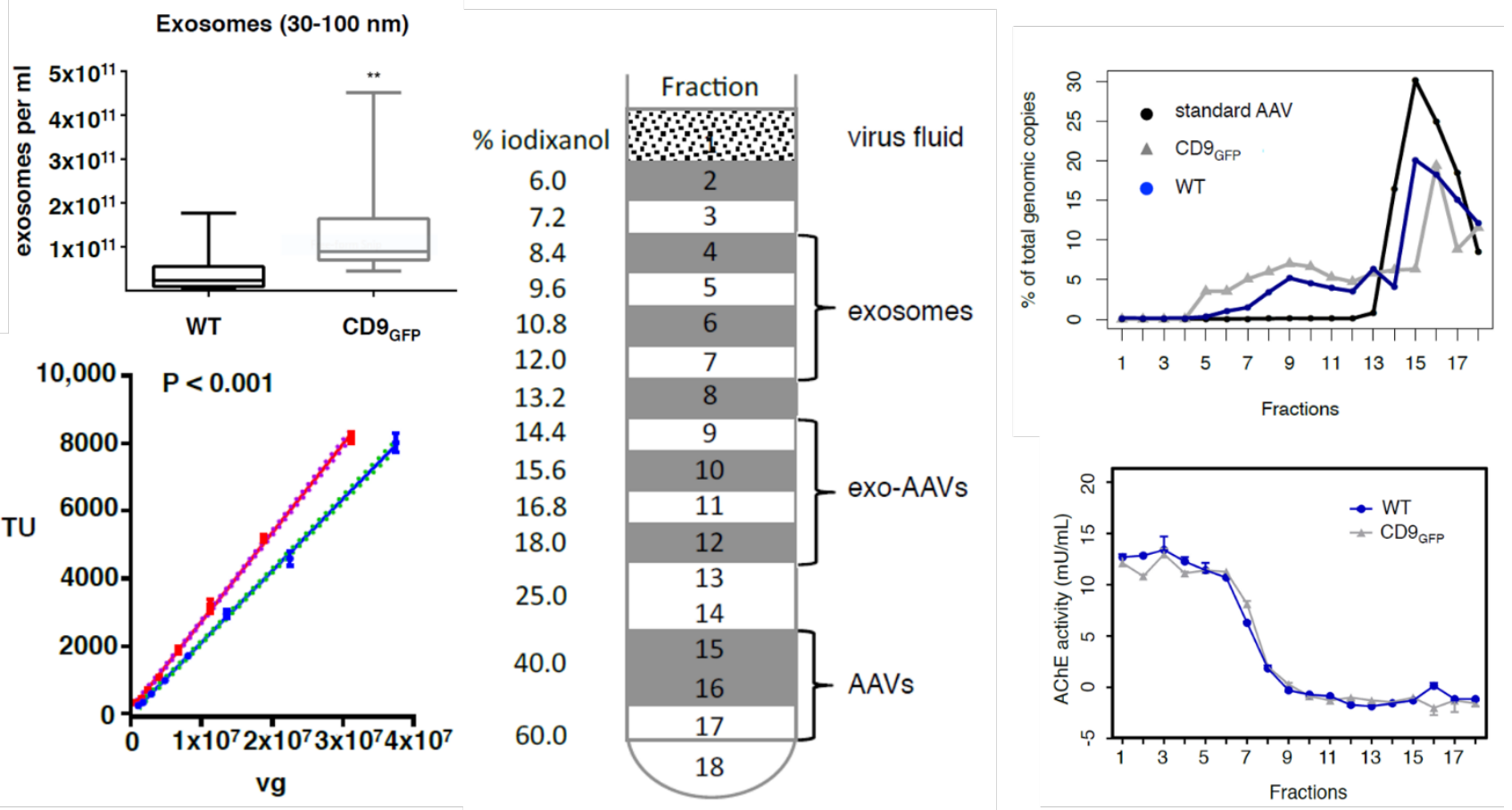

Figure 26. CD9 boosts exosome production and exo-AAV efficiency. AAvs were produced in wt and CD9 overexpressing producer cell lines. Total amount of exosomes was quantified in conditioned media from wt and CD9 cells. Upper left panel shows an increased production of exosomes by high CD9 cells. ${ }^{* *} p<0.01$. Error bars show SD. Pellets obtained after centrifugation of conditioned media at $100.000 \times \mathrm{xg}$ were resuspended and separated in iodixanol density gradient. 18 fractions were prepared (center panel). AAV and exosome content were analysed in the fractions by qPCR and acetylcholinesterase activity assay respectively. High CD9 cells produced increased amounts of exo-AAV as shows by higher expression of AAV genomic copies in exosome enriched fractions 4-13 (right panel). Comparison of genomic titer and functional titer show that CD9 exo-AAV were in average $26 \%$ more efficient in transducing cells when compared to wt exo-AAV. The higher slope of the red line indicates that the same amount of exo-AAV (as calculated by genomic titer) leads to higher number of transduced cells (higher calculated TU) when CD9 is present. Source: (Schiller et al., 2018).

\subsection{Genetic manipulation by utilization of modified viral vectors}

Modified viral vectors that have different tropisms and are more efficient when compared to classical viral particles were successfully produced and characterized in different in vitro and ex vivo models as shown above. The next sections will refer to practical applications of the generated viral tools in order to deliver genetic manipulation components and address scientific questions such as genome editing 
with CRISPR-Cas9 system, the use of an RNAi system to unfold a possible role of a cytokine-receptor like molecule in cell protection and investigation of a hypothesized role of the U3 snoRNA as a source of functional miRNA.

\subsubsection{Genetic manipulation at genome level: the CRISPR system}

The CRISPR-Cas9 system is a genome editing technique that has been en vogue for the past decade. Derived from a bacterial archaic immune system, the system has been adapted for use in mammalian cells where it can be used for gene expression disruption or activation. The broad applications of the system make it an important and potentially powerful tool for the treatment of genetic disorders such as cancer and neurodegenerative diseases.

As one of the many applications of the LV tools afore mentioned, LV carrying CRISPRCas9 system components were produced and tested in different cell lines. HEK293 and $\mathrm{SH}-\mathrm{SY} 5 Y$ stabling expressing GFP and Cas9 protein were generated in two steps:

$\left.1^{\text {st }}\right)$ Transduction with LV-VSV-G-GFP: $150 \mathrm{MOI}$ were added to wt cells. $72 \mathrm{~h}$ later selection of GFP expressing cells was started with geneticin. The optimal amount of antibiotic for selection was found to be $1 \mathrm{mg} / \mathrm{mL}$ for HEK293 and $800 \mu \mathrm{g} / \mathrm{mL}$ for SHSY5Y.

$\left.2^{\text {nd }}\right)$ Transduction with LV-VSV-G-lentiCRISPRv2: for expression of Cas9, fabricated in the same procedure as above. After $72 \mathrm{~h}$ cells were selected with $0,5 \mu \mathrm{g} / \mathrm{mL}$ Puromycin. After three rounds of splitting, cells were ready to be used.

The HEK293-GFP-Cas9 and SH-SY5Y-GFP-Cas9 cells were then transduced with LVVGV-G-sgRNA-GFP. The viruses transduced for the expression of a guide RNA specific for GFP. In association with the Cas9 protein, the Cas9-sgRNA complex should lead to a double strand break (DSB) in the GFP gene and overall lower GFP expression. As analysed by FACS, figure 27 show reduction in the average fluorescence intensity in both cell lines tested, which can be observed by the shift a population of GFP expressing cells towards the lower GFP intensities area in the chart (red line). 

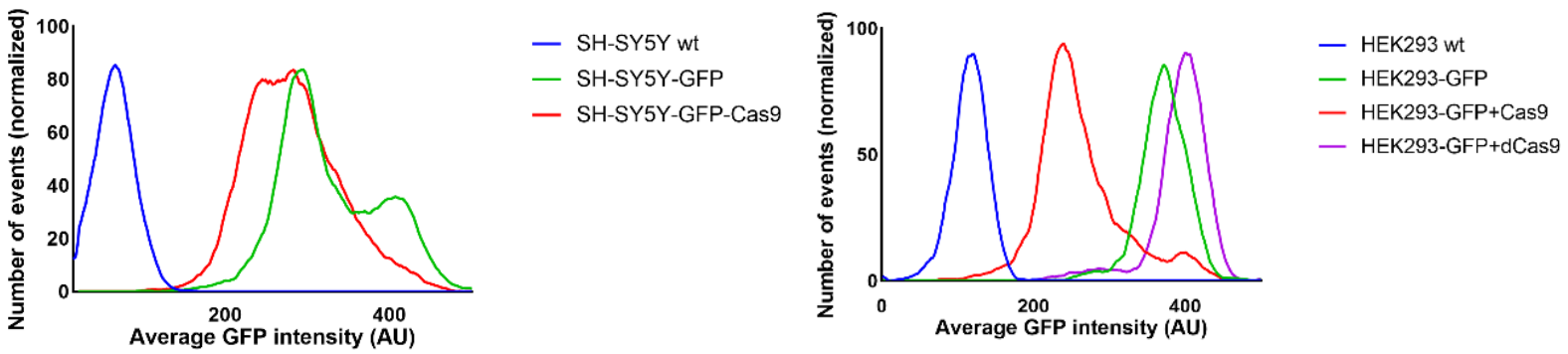

Figure 27. GFP expression disruption by CRISPR-Cas9 in HEK293 and SH-SY5Y. Cells stabling expressing GFP and Cas9 were treated with LV carrying a guide RNA for GFP. Observe the decreased average fluorescence intensity on cells expressing Cas9. Additionally, HEK 293 cells stabling expressing an endonuclease deficient Cas9 (dCas9) show no significant decrease in fluorescence intensity, indicating that no effective DSB occurred.

A HEK293-GFP-dCas9 cell line was also generated as mentioned before as a control. These cells express an endonuclease deficient Cas9 (dCas9) that is utilized in CRISPR interference and CRISPR activation systems (see section 1.3.3.1-2). This molecule can bind to the DNA strand through association with sgRNA but do not lead to DSB. The purple line on the histogram in figure 27 show that the average GFP expression levels on the dCas9 expressing cells is like those of the HEK293-GFP, indicating that the system works together with the LV tool.

\subsubsection{Genetic manipulation at the mRNA level: gene silencing through RNA interference}

Genetic manipulation can be achieved through targeting different steps of gene expression. As described above the CRISPR-Cas9 system targets the very first step of gene expression by targeting the genome itself, altering the transcription of DNA to RNA. One can also disrupt gene expression by targeting a later step of the process. Short hairpin RNA (shRNA) target mRNA molecules specifically through complementarity to its target sequence (Paddison, 2002). Target mRNA activity is then repressed by association with RNA-induced silencing complex (RISC) in a process called RNA interference (RNAi).

This system can also be coupled with the LV tools for delivery of shRNA constructs. In this study LV-shRNA were utilized for gene expression repression in HEK293 cells. 
These experiments were carried out in collaboration with Nina Hahn and the group of the Dept. of Cellular Neurobiology from the Schwann-Schleiden Research Center lead by Dr. Ralf Heinrich in Göttingen. One of the scientific questions is whether a cytokine receptor-like factor (CRLF3) can lead to neuroprotection by interaction with erythropoietin (Epo). Similar effects have been documented by his group in invertebrates (Hahn et al., 2017) and the next step is to assess whether the same process is conserved in mammalians.

Manipulation of expression of the molecule of interest (CRLF3) becomes important when one intends to evaluate its role in cell physiology. Overexpression and gene expression experiments were performed:

1) Overexpression of CRLF3: HEK293 cells were transfected with the construct containing the human orthologue of CRLF3 pHCMV-CRLF3

2) Gene repression: Addgene.org offers a suite of constructs and protocols for production of LV containing shRNA constructs (pLKO.1 TRC-Cloning Vector). Therefore LV-VSV-G-shRNA-CRLF3 was produced based on this protocol in order to disrupt CRLF3 expression.

The resulting alteration in CRLF3 expression was investigated by qPCR in figure 28 . Overexpression lead to a 94-fold increase in CRLF3 expression when compared to wt cells. shRNA decreased the expression of CRLF3 mRNA by $80 \%$. 

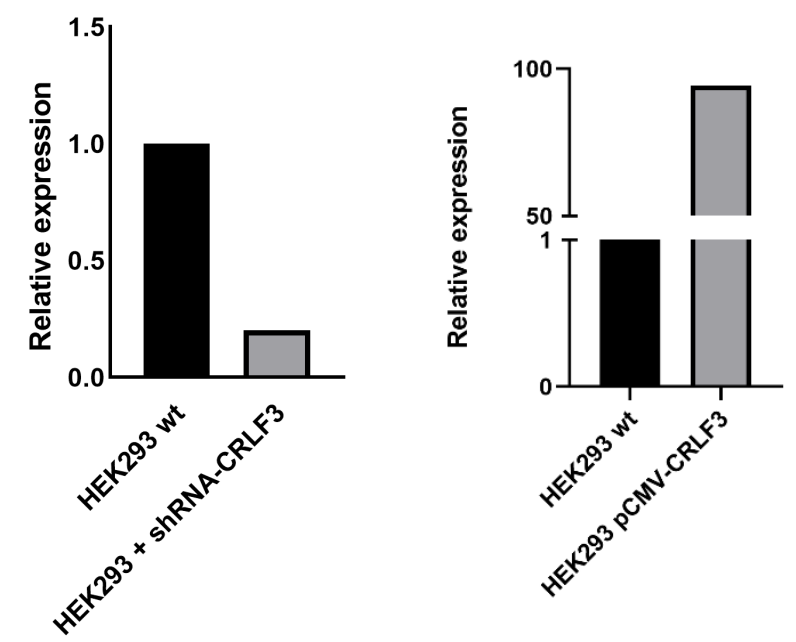

Figure 28. Relative expression of CRLF3 in HEK293 cells as assessed by qPCR. On the left panel observe an $80 \%$ reduction in CRLF3 expression upon treatment with LV-VSV-G-shRNA-CRLF3. On the right panel cells were transfected with a construct containing a cassette expression for CRLF3 under the control of CMV promoter. There was a 94-fold increase in CRLF3 expression.

Since the main question is the role of the molecule in neuroprotection, neuroblastoma cells were exposed to harmful stimuli and as a first step the CRLF3 expression levels were checked. SH-SY5Y and differentiated cells were exposed to $24 \mathrm{~h}$ hypoxic conditions with $\mathrm{O}_{2}$ tension below $1 \%$. Figure 29 shows that expression levels of CRLF3 increase in differentiated cells by $62 \%$, while wt type cells exposed to hypoxia showed $62 \%$ decreased expression. Differentiated cells exposed to hypoxia have an even more striking decrease in expression of $82 \%$. 


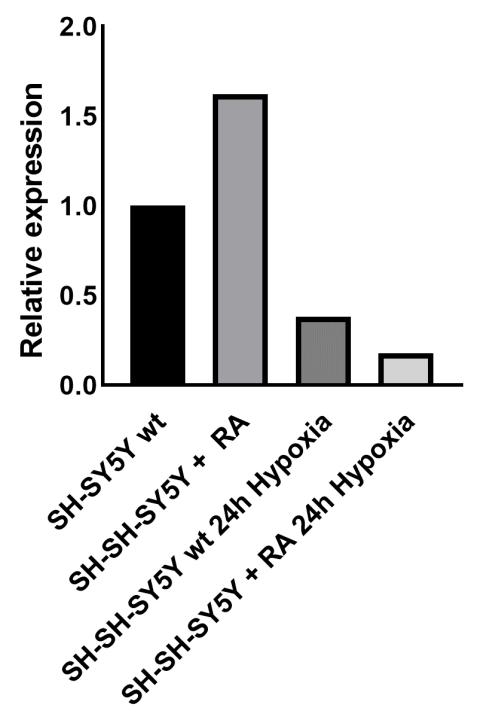

Figure 29. Relative expression of CRLF3 in SH-SY5Y and differentiated SH-SY5Y under hypoxia as assessed by qPCR. Cells were incubated in controlled atmosphere containing less than $1 \% \mathrm{O}_{2}$ for $24 \mathrm{~h}$. Differentiation leads to increase in CRLF3 expression by $62 \%$. Wildtype cells under hypoxia decreased CRLF3 expression by $62 \%$. Differentiated cells under hypoxia had an even more accentuated decrease of $82 \%$.

Besides HEK293 and neuroblastoma, the basal CRLF3 expression levels were also quantified in different mammalian cell lines such as Hela, SKBR3 and MCF7 (also a breast cancer line). See figure 30. CRLF3 levels were significantly lower in cancer cell lines such as cervical cancer Hela and breast cancer SKBR3 and MCF7 when compared to HEK293 and SH-SY5Y, an interesting finding considering the postulated role of CRLF3 in cell protection. 


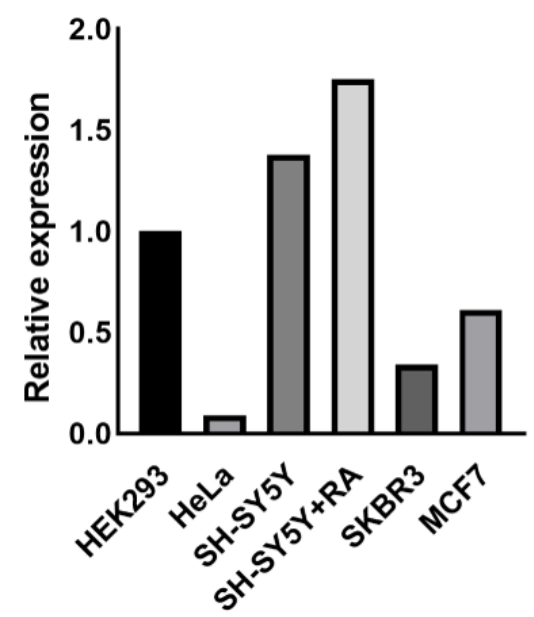

Figure 30. Expression of CRLF3 in different cell lines measured by qPCR. Relative quantification of CRLF3 expression in mammalian cell lines was quantified by qPCR. Expression of CRLF3 in cancer cell lines such as Hela, SKBR3 and MCF7 is significantly lower when compared to HEK293 or SH-SY5Y. CRLF3 deregulation may be related to the general disrupted state of cancer cells. GAPDH expression level was used as a control.

\subsubsection{Genetic manipulation at the post-transcriptional level: snoRNA U3 as a source of microRNA}

In order to check whether the 5 'domain of U3 is a source of miRNA probes complementary to U3 $5^{\prime}$ domain were utilized in qPCR optimized for detection of miRNA (miRcury kit - QIAGEN). HCT116 cells (colorectal carcinoma) lacking components of miRNA processing pathways (Dicer, Drosha, XPO5) (Kim et al., 2016) had their miRNA-U3 contents analysed and miRNA 34-a (a low functional miRNA) and U6 (a small nuclear RNA that participates in the processing of pre-mRNA in the nucleus) were used as controls. Figure 31 shows the relative quantification of three independent measurements. When Drosha is absent (nuclear processing) the yield of U3 derived miRNA is significantly higher, indicating that its processing is Drosha independent. On the other hand, when Dicer is absent (cytoplasmic processing) there is no expression of miRNA-U3, indicating that $U 3$ is processed by Dicer in the cytoplasm. 


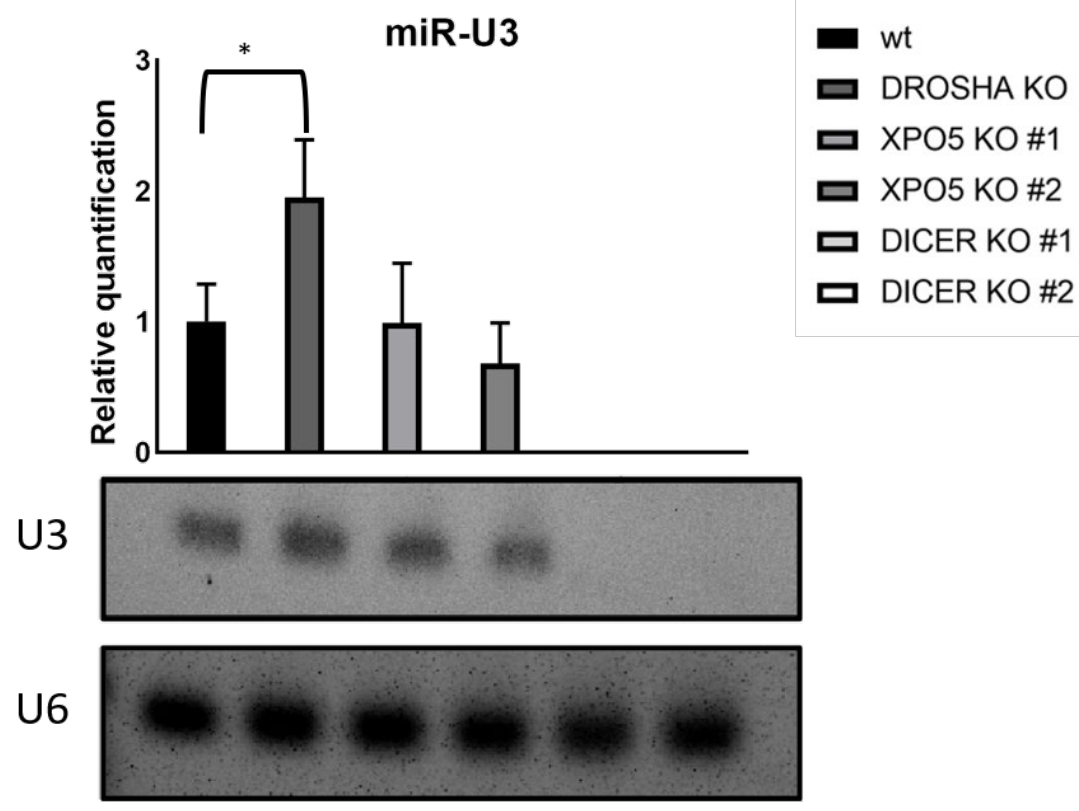

Figure 31. Expression of miR-U3 measured by qPCR. Relative expression quantification was achieved by qPCR using probes complementary to the U3 5 'domain. The qPCR amplification products were then electrophoretically separated in an agarose gel and the bands were observed. There is a significant increase in miRU3 expression when Drosha is absent. Furthermore, there is no detectable expression of miR-U3 when DICER is absent. These results indicate that U3 is processed independent of Drosha and is processed in the cytoplasm by Dicer. U6 expression was used for normalization. Error bars indicate SEM. Statistical analysis by 2way ANOVA. $\mathrm{p}=0.0021$.

To access the cellular localization of the mature $\mathrm{U} 3$, cells were fractionated, RNA was isolated to obtain nuclear and cytoplasmic fractions and the RNA was electrophoretic separated and blotted for posterior hybridization with probes for U3, U6 as a nuclear marker and Val-tRNA as a cytoplasmic marker. In figure 32 the northern blot show presence of U3 in the cytoplasm and slightly higher amounts when Dicer is absent. Expression levels of U3 were also checked by qPCR in the different fractions. 


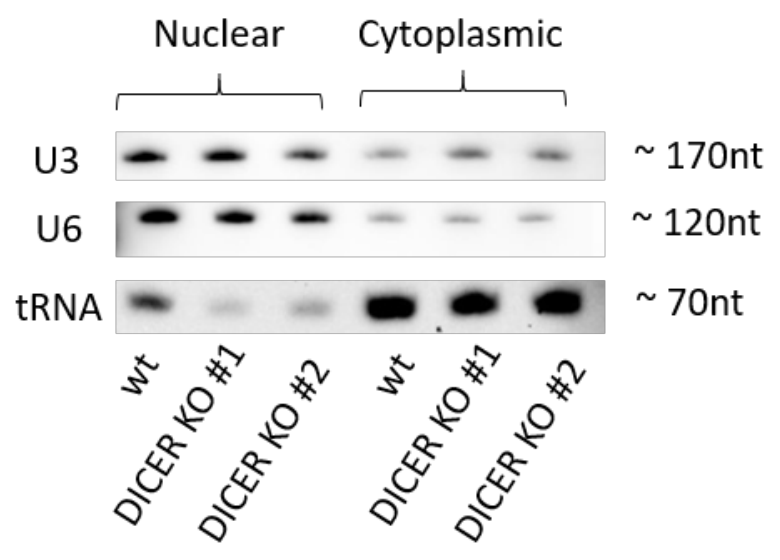

Figure 32. Northern blot of nuclear and cytoplasmic expression of U3. Cells were fractionated and RNA collected from nuclear and cytoplasmic fractions. RNA was separated on a gel and transferred to a membrane for posterior hybridization with probes for detection of U3, U6 and Val-tRNA. U6 is known to remain in the nucleus. The presence of it on the cytoplasmic fraction indicate possible leaking on the fractionation process. Val-tRNA as a cytoplasmic marker. Observe the slightly higher amounts of U3 on the cytoplasmic fraction of Dicer KO cells.

The ratio of expression on the cytoplasm over nuclear expression $(\mathrm{c} / \mathrm{n})$ was calculated and indicates that in the absence of Dicer there is an increased amount of U3 in the cytoplasm, corroborating the previous findings and the theory that $\mathrm{U} 3$ indeed migrate to the cytoplasm and is further processed by Dicer (Figure 33).

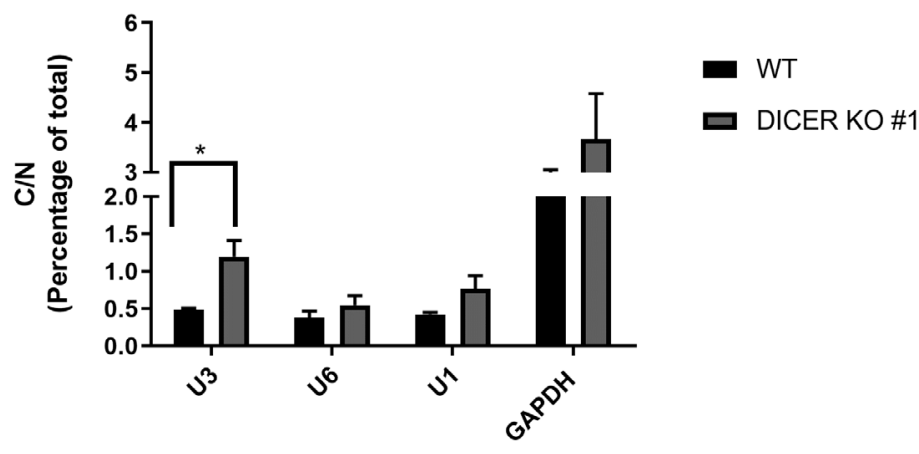

Figure 33. Expression of U3 in nuclear and cytoplasmic fractions measured by qPCR. Expression of U3 was measured in RNA nuclear and cytoplasmic fractions. The ratio cytoplasm/nucleo relative quantification was calculated. A significant increase in $\mathrm{c} / \mathrm{n}$ on Dicer KO cells corroborate the findings in the northern blots and indicates that U3 is present in higher amounts in the cytoplasm in the absence of Dicer. Error bars indicate SEM. $p=0.0307$. 


\section{Discussion}

\subsection{Lentiviruses as gene delivery tools}

Lentiviruses are a potent and versatile delivery tool for transgene expression. They have a higher packing capacity when compared to other viral vectors such as adenoassociated viruses (AAV), allowing for delivery of longer genetic sequences. Furthermore, LV leads to a stable, long term transgene expression once the delivered $\mathrm{GOI}$ integrates into the cell host genome. The ability of these vectors to infect nondividing cells make them extremely useful tools for use in neurosciences (Naldini et al., 1996).

However, like any other delivery systems, LV also present disadvantages, such as the fact that the transgene is incorporated into the host genome in a random manner, which can lead to interference in normal cell function and increase the risks of oncogeneses (Hacein-Bey-Abina et al., 2003), (Ott et al., 2006), (Schwarzwaelder et al., 2007). Nonintegrating LV are an alternative to avoid potential harmful effects of random viral genome integration and such system have been used successfully for transient GOI expression in muscle (Apolonia et al., 2007), primary stem cells, hematopoietic and lymphoid cells (Nightingale et al., 2006).

LV delivery systems utilized in research are based on HIV backbone, what generate concerns regarding immune response for in vivo applications and general safety for use in patients and safety measures during the production of the viral particles. Nonetheless, several safety precautions have been taken along the years to make sure the viral particles produced are safe. The expression cassettes utilized nowadays are stripped from any non-essential components from the wildtype HIV (almost $95 \%$ of original HIV genome is out) (Naldini et al., 1996). The second-generation lentiviral production system utilised a vector expressing the three structural HIV-1 genes gag, pol and rev. On third-generation systems the rev gene is separated on its own vector for the expression of the viral components in separated expression cassettes adds an additional layer of safety decreasing the chances of recombination. This system requires the transfection of at least four plasmids for LV production, namely the two plasmids containing viral genes, a packing plasmid and an envelope plasmid for 
pseudotyping. That can decrease transfection efficiency and viral production. For the purposes of this thesis we used a second-generation LV production method. The gag, pol and rev genes are encoded by the same plasmid (psPAX2). That allows for a better titer since the number of plasmids to be transfected is lower. We chose this system because our re-targeting approach already requires an additional plasmid to be transfected: targeting and fusogenic molecule.

The viral particles produced nowadays are also replication deficient, meaning that they do not deliver additional viral replication sequences (Zufferey et al., 1998).

Perhaps the most striking feature of LV is the fact that the tropism of the viral particles can be determined by the molecules that are expressed on the producer cell membrane. This allows for the manipulation of the tropism of the viruses by exogenous expression of targeting molecules of interest by the producer cell lines in a process called pseudotyping. In order to broaden the tropism of LV in general the expression of a glycoprotein originally expressed by a vesicular stomatitis virus (VSV-G) is used to replace the original HIV targeting glycoproteins (Aiken, 1997), (Amado and Chen, 1999). This molecule confers the produced viral particles the ability to infect a variety of mammalian cells increasing the efficiency of transgene expression significantly, with low specificity.

\subsection{Advantages of $L V$ in research and gene therapy applications}

Researchers have been using and improving the LV system for years now. It is a validated tool for effective transgene delivery for several reasons:

- Easy production: viral particles are secreted into SN, facilitating harvesting and purification for in vivo applications;

- Safety: although unlike AAVs the LV system is based on a pathogenic virus, the advent of replication deficient LV and third generation production methods makes the system safe enough for use in clinics;

- The packing capacity of around $8.5 \mathrm{~kb}$ makes LV the tool of choice for the delivery of components of very popular cell biology manipulation tools, such as the CRISPR system and opsins for optogenetics;

- The number of viral particles necessary for efficient use in organisms is relatively small when compared to other viral vectors: $10^{8} \mathrm{TU} / \mathrm{mL}$ versus $10^{12}$ $\mathrm{TU} / \mathrm{mL}$ in the case of AAV; 
- Changing the tropism of the viruses is achieved by manipulating expression of molecules on viral envelope;

- Low immunogenicity and lack of previous immunity, (Shaw and Cornetta, 2014);

- LV are validated tools for use in non-human primates (Dissen et al., 2009). These animal models are invaluable (and expensive) tools that require extra thought when it comes to genetic manipulation, especially in the field of neurosciences.

Several clinical trials that used LV as delivery tool reported no cytotoxicity in patients (Levine et al., 2006), (Thompson et al., 2016), (Palfi et al., 2014), (Palfi et al., 2018).

\subsection{Lentiviral production}

\subsubsection{Lentiviral safety remarks}

HIV-1 based LV are considered level S2 lab safety risk because of the potential production of recombinant viruses and potential harmful effects of GOI integration. Safety protocols must be followed when manipulating LV, what can be a disadvantage of the system:

1. Not every research institute can operate an S2 facility for viral production, storage and manipulation;

2. The handling and inoculation of LV also requires specialized facilities and trained personnel.

However, when safety protocols are followed properly and second or third generation production systems are chosen, LV are a consistent tool for gene delivery.

\subsubsection{Lentiviral titering methods}

Regarding the titering methods I used in this study, a few points come to attention:

- Physical titering by detection of viral proteins through immunoenzymatically assays can offer an overestimation of the real viral count. ELISA assays are extremely sensitive and there is no way to know for sure whether the protein being detected is a part of a full capsid or a defective capsid. The method is advantageous though because it is relatively easy to perform and very specific; 
- Functional titer measured by percentage of fluorescent cells on FACS is a very good way of knowing the functionality of produced viruses. Unfortunately, it usually offers an underestimation of the actual viral count because a single cell can be transduced by a single virus or many viral particles. Another disadvantage of the method is the fact that one can only titer LV that contains fluorescent proteins as $\mathrm{GOI}$, which limits the application of the method for other purposes;

- Genomic titering is another interesting option and a way of complementing the other methods mentioned above. The disadvantage again is an overestimation of viral functionality.

Figure 34 shows the differences of viral amounts obtained in $T U / \mathrm{mL}$ when using functional titration by FACS and physical titration with ELISA. The chart depicts titering of three independent LV production batches. For this study we decided to perform functional titering whenever the GOI was a fluorescent protein. For other applications such as production of shRNA and sgRNA carrying viruses physical titering was necessary.

For an overview on lentiviral titering techniques see (Geraerts et al., 2006). 


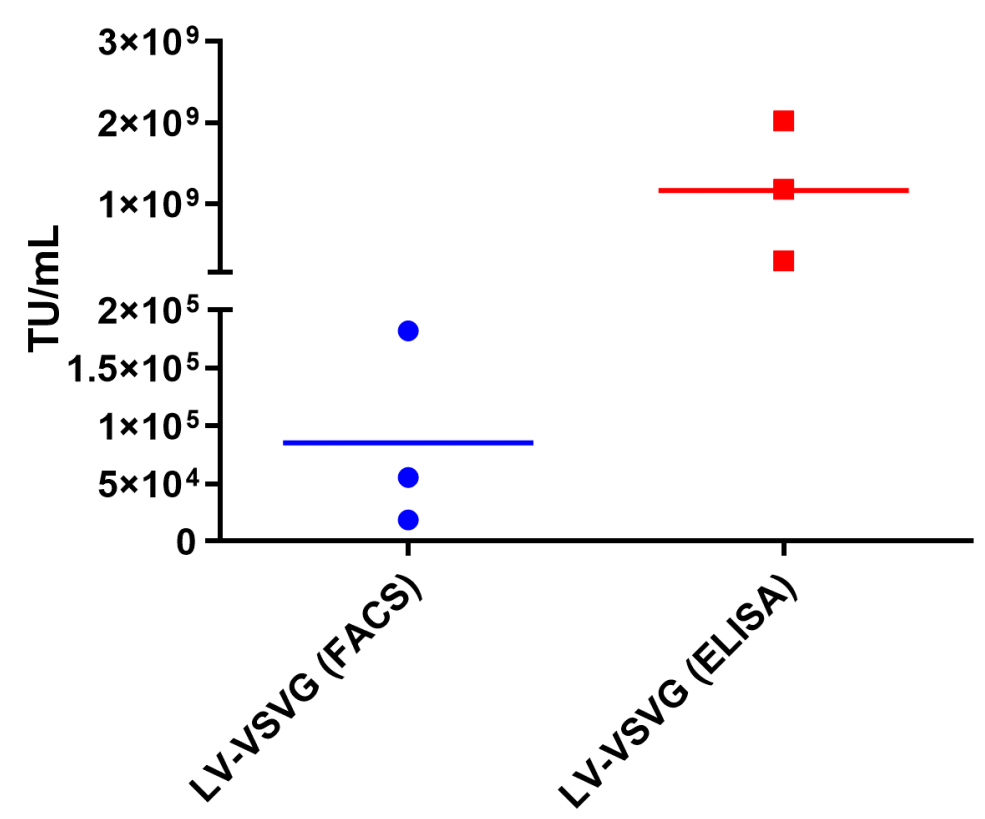

Figure 34. Comparison of two titration methods for LV. Functional titer calculated by number of fluorescent cells by (FACS) tend to underestimate viral count while physical titer (ELISA) tend to overestimate it. Each dot represents a different batch of LV production. Each batch was titered by FACS and ELISA, viral amounts were calculated as transducive units per $\mathrm{mL}(\mathrm{TU} / \mathrm{mL})$ and the values were plotted.

\subsubsection{Lentiviral concentration methods}

The concentration techniques I used in this study also pose advantages and disadvantages as mentioned before (see section 3.1.1). The most straightforward concentration method I came across in the literature is the polyethylene glycol (PEG) precipitation. The fact that one only need to incubate their viral samples overnight and pellet the precipitate on an average benchtop centrifuge is a big advantage over ultracentrifugation (too laborious and demands specific equipment) and molecular weight exclusion filtration (much more expensive). The disadvantage is the fact that PEG precipitate absolutely any vesicle on the $\mathrm{SN}$, making the final viral suspension "impure" and not suitable for in vivo application, for example. I also found long-term storage to be poor since batches of viruses concentrated with this method were not functional after a few months, even when stored under standard conditions at $-80^{\circ} \mathrm{C}$.

Ultracentrifugation in sucrose cushion proved to be challenging for the extensive manipulation of viral SN and appropriate ultracentrifuge containers. Contamination of 
viral samples occurred much more often in viral batches concentrated in this way. For most of the experiments in this thesis, I concentrated viral SN with the use of centricons containing molecular weight filters (see section 2.2.6). The viral preparations remained stable for at least 18 months at $-80^{\circ} \mathrm{C}$.

\subsection{Pseudotyped and re-targeted LV efficiency}

As described in sections 3.1.6-8, re-targeted viruses carrying a fusogenic molecule (fuHA) and an scFv (scFv-TrkB / scFv-Her2/neu) lead to low efficiency transgene expression. A few possible reasons for that are:

- During LV production all necessary plasmids are transfected at the same time on producer HEK293FT cells. It is logical to assume that some constructs will be expressed sooner than others. Perhaps the trafficking of the chimeric svFvPDGFR-TM is slow due to fused svFv not being a natural membrane protein. The expression and trafficking of the mutated hemagglutinin could also be impaired due to the modifications introduced;

- The reduced size of the scFv molecule $(\sim 27 \mathrm{kDa})$ could also be a factor specially when one considers that the hemagglutinin $(\sim 66 \mathrm{kDa})$ molecule is quite large in comparison. That could be a factor interfering on the biding capability of the scFv;

- Other members of my work group successfully used a scFv-Her2/neu for virus like particle (VLP) re-targeting. I assume that the efficient use of the molecule for LV application is a matter of optimization of transfection protocols and cloning of the scFv into the pDisplay vector.

Furthermore, as shown in figure 22, in some cases viruses bearing only a fusogenic protein could transduce cells in culture. I can speculate that perhaps the mutations introduced in HA were not completely effective. The risk of cross- contamination or sample mix up also must be kept in mind.

Another reason for low efficiency re-targeted LV is the fact that he hemagglutinin molecule is natively inactive. Several studies suggest it needs to be activated in order to promote efficient fusion (Chaipan et al., 2009) and that the low $\mathrm{pH}$ of endosomes in the cytoplasm is supposed to promote HA activation (Gray and Tamm, 1998), (Reed et al., 2010), (Reed et al., 2010), (see figure 14). Other studies suggest that pH drop alone is not enough to change the conformational status of the molecule and make it 
active. In the influenza wt virus hemagglutinin is co-expressed with molecules of Neuraminidase, which will facilitate the necessary conformational changes in HA (Porotto et al., 2012), (Bose et al., 2012). Other studies suggest that hemagglutinin can be activated by partial cleavage with the enzyme trypsin (Chaipan et al., 2009). Perhaps co-expression of a neuraminidase molecule on re-targeted viral envelope to mimic influenza virus fusion function could lead to higher efficiency viruses.

An option to try and improve re-targeted viruses would be the use of a fusogenic molecule other than fuHA. Studies suggest the use of Sindbis virus glycoprotein (Lei et al., 2009) and glycoproteins from Henipavirus genus (Khetawat and Broder, 2010) among others as fusogenic molecules.

There are also ways of improving virus efficiency such as the use of certain chemicals during viral production and transduction.

In this study I used a protocol that incorporate an 8h incubation with sodium butyrate with the intent to boost the protein expression by the producer cell line. This chemical is believed to be a non-specific histone deacetylase (HDAC) inhibitor, therefore improving the accessibility of some genomic areas to polymerase complexes (Chen et al., 1997), (Govindarajan et al., 2011). Since we mostly produced LV carrying fluorescent reporters, we could analyse transfection efficiency during viral production and could observe a boost in fluorescence intensity on transfected cells after incubation with sodium butyrate.

The use of cationic polymers like polybrene during cell transduction is also a validated way of increase the efficiency of viral transduction (Davis et al., 2002). The claimed mechanism is the decrease of repulsion charges between the cell membrane and the viral envelope, facilitating viral-cell biding. However, the method is not without flaws for studies suggest cytotoxicity mesenchymal stem cells (Lin et al., 2011).

\subsubsection{The influence of the tetraspanin CD9 on LV efficiency}

In 2018 we published a study in which there is evidence of improved LV upon coexpression of CD9 and VSV-G on lentiviral envelope (figure 23) (Böker et al., 2018). There are some possible explanations for that:

- Since CD9 alone was also shown to be able to promote binding and fusion of LV to the host cell (see Böker et al., 2018, figure 5), it is logic to assume that 
co-expression of CD9 with other targeting molecules would have a synergistic effect;

- The postulated role of CD9 in cell adhesion (Reyes et al., 2018), (Leung et al., 2011) could make up for a somewhat more "adherent" viral envelope, increasing virus-cell binding successes.

As an extension of that study, we sought to assess the impact of CD9 on Rabies-G pseudotyped LV. We produced LV-Rabies-G and LV-Rabies-G-CD9, determined physical titer and analysed the transduction patterns on four different cell lines. Figure 24 shows four technical replicas of ELISA tittering comparing both viruses. There was no significant change in the number of virus produced, as observed on LV-VSV-GCD9. However, unlike previously observed there was no quantifiable change on the transduction patterns of LV-Rabies-G-CD9 when compared to LV-Rabies-G (figure 25). So far two different batches of LV-Rabies-G-CD9 were produced and tested. The first one led to inconclusive results (very low transduction efficiency). Transduction patterns were analysed $72 \mathrm{~h}$ after addition of $150 \mathrm{MOI}$ LV. Perhaps the amounts of virus used for transduction need to be optimized, or the synergistic effect of CD9+Rabies-G takes longer to happen.

As future steps on working with improving LV, I would like to go deeper in the investigation of the effects of the CD9 molecule on viral efficiency. I would propose using the CD9 tetraspanin as an anchor for an ScFv rather than the PDGFR from pDisplay vector. Perhaps there will also be a synergistic effect there while the expression of a chimeric CD9 protein could mask its inherent targeting property.

\subsection{Genetic manipulation tools}

In this study we focused on the development of targeted tools for gene delivery that are more specific and efficient. We produced pseudotyped LV that were able to deliver fluorescent reporters. Here we show applications of different genetic manipulation tools that can be used in combination with our LV system.

\subsubsection{Gene expression manipulation with the CRISPR-Cas9 system}

Since its discovery in 1993 till its adaptation for use in eukaryotes 20 years later by Zhang and collaborators (Cong et al., 2013), the CRISPR system is nowadays a very promising tool for gene therapy. 
Researchers worldwide have been working to improve the system and get rid of its disadvantages, such as the off-target effects and the potential immune response triggered by the Cas 9 in humans. For an overview on improvements and new applications of the CRISPR system see (Adli, 2018).

The ability of manipulating the genes on a genomic level open several possibilities specially regarding genetic disorders. Being able to correct a gene that is malfunctioning, either by disrupting or enhancing its expression shines a new light into the lives of patients that otherwise are condemned to an incurable genetic disease.

For the research area the possibilities are also astonishing. Changing a cell fate by manipulating a pool of genes at the same time open many exciting possibilities. Some of these possibilities are also frightening, as proofed by the recent announcement of the first CRISPR babies created by a Chinese scientist. It opens new ethical and philosophical discussions for the next generation of scientists, me included.

In this thesis I was able to utilise the classical CRISPR-Cas9 system to disrupt GFP expression on GFP expressing HEK293 and SH-SY5Y (figure 27). We produced LVVSV-G carrying components of the system to produce cell lines stabling expressing Cas9 (HEK293-Cas9 and SH-SY5Y-Cas9) and dCas9 (HEK293-dCas9) and sgRNA expression construct to disrupt GFP expression in Cas9 cells.

The CRISPRi and CRISPRa systems are cleaver and useful developments of the technology. CRISPRi in particular is an interesting approach on gene expression knocking-down (Gilbert et al., 2014), (Gilbert et al., 2013), (Qi et al., 2013) that leads to a lowered expression of a target mRNA rather than a modulation of mRNA activity like the RNAi systems, what is handy when studying function of new molecules.

In the future I would test the CRISPRi system to disrupt the expression of CRLF3 as an additional gene expression repression method together with RNAi system.

\subsubsection{RNAi application to uncover the function of CRLF3}

The cytokine receptor-like factor 3 is a mysterious molecule that we showed is expressed in several cell lines, including neuroblastoma and is scarcely expressed in breast and cervical cancer derived cell lines (figure 30).

The group of Dr. Ralf Heinrich already unravelled an important role of the orthologue of this receptor in invertebrates: neuroprotection upon interaction with erythropoietin. 
That is quite an important role for a molecule we barely know anything about its orthologue in mammalians.

The fact that it plays a role in cell protection and it appears to be down-regulated in cancer cell lines brings the question if this is a kind of defence mechanism of the cell upon harmful physiological changes caused by cancerous stimuli. A lower number of receptors would lead to higher chances of apoptosis and consequent elimination of the cancerous cell. However, they survive and proliferate better than normal cells.

It is a very interesting scientific question to investigate whether the effects observed in invertebrates are translated to mammalian cells. If that holds true, we can be on the verge of uncovering a new potential therapeutic target for diseases that cause neurodegeneration and cancer. There can also be ways we can use our new understanding of this molecule to develop treatments to prevent and treat brain injuries such as brain ischemia and trauma.

In this study we show that we can successfully manipulate the expression of CRLF3 using our LV tool and shRNA constructs. The next step is issuing what happens to cells under harmful stimuli when the expression of the receptor changes. For that we need to establish an efficient way of quantifying cellular damage so we can analyse the influence of Epo and its interaction with CRLF3 under harmful stimuli such as hypoxia and chemical damage.

\subsubsection{Genetic manipulation at a post-transcriptional level: untangling the biology of a snoRNA}

The field of RNA biology is one of the most exciting and full of possibilities in molecular biology in my opinion. New classes of RNA are discovered quite often, and their function remains a mystery or turn out to be fascinating new tools that open unexpected technologies, e.g. RNA interference or genome editing with the CRISPR/Cas9 system.

Gone is the time that science considered non-coding RNA (ncRNA) cellular garbage. We learn more every day about the importance of these volatile molecules and their intricate regulatory functions and complex interactions (Karapetyan et al., 2013), (Vance and Ponting, 2014), (Quan et al., 2017).

During this study I had the opportunity to scratch the surface of this giant iceberg that covers the complete knowledge of RNA biology. 
The U3 snoRNA is not less mysterious. Before thought to be exclusively in the nucleus where it performed its function at early rRNA cleavage (Cléry et al., 2007), studies showed that this molecule could leave the nucleus and give origin to miRNA (Ender et al., 2008), (Brameier et al., 2011).

Dr. Nicolás Lemus during his PhD studies analysed NGS data from RNA-protein and RNA-RNA interactions, he showed that $\mathrm{U} 3$ was possibly interacting with protein miRNA processing machinery such as the cytosolic Dicer. On that course also a possible mRNA target (SNX27) for miR-U3 was identified. Using a newly developed flowcytometry based technique to analyse miRNA activity at single cell level, it was also observed that U3 behaves like a low functional miRNA (figure 7) (Lemus-Diaz, 2017). In this study I showed my small contribution to this project. By isolating RNA from nuclei and cytoplasm of cells lacking Dicer, we could show that U3 is indeed also present in the cytoplasm and in higher amounts when Dicer is depleted (figure 31). By utilizing an LNA-miRNA q PCR detection kit we could detect miR-U3 and show that possibly its biogenesis is Drosha independent, once it's still expressed even in higher amounts in cells that lack this protein in the nuclei (figure 32 and 33). We also show that when Dicer is not present, miR-U3 expression is also absent, which reinforces the theory that U3 interacts with Dicer like a classical miRNA.

For the future we still need to confirm the Dicer interaction by rescuing its expression in Dicer-KO cells (Kanellopoulou et al., 2005), (JnBaptiste et al., 2017) and observe whether the effects on miR-U3 expression are reverted.

\subsection{Conclusions}

In this thesis, I demonstrate the successful establishment of the techniques to pseudotype and re-target HIV-1 based LV that can deliver a variety of $\mathrm{GOI}$ to a variety of mammalian cell lines, dissociated neuronal cultures and organotypic non-human primates brain slices:

- Fluorescent reporters

- Genome editing tools (Cas9, dCas9, sgRNA);

- shRNA 
I also showed here that combining the genome manipulation techniques and the delivery tools I have mastered during this project and used these to investigate the function of a receptor that might turn out to be a potential target for cancer and neuro therapies. Furthermore, I contributed substantially in a study that demonstrates how snoRNAs can derive functional miRNA and the project summarizing the biochemical and cell biological characterization of the U3 snoRNA-derived miRNA is prepared for publication. 


\section{References}

Adli, M. (2018). The CRISPR tool kit for genome editing and beyond. Nature Communications 9, 1911.

Agholme, L., Lindström, T., Kågedal, K., Marcusson, J., and Hallbeck, M. (2010). An In Vitro Model for Neuroscience: Differentiation of SH-SY5Y Cells into Cells with Morphological and Biochemical Characteristics of Mature Neurons. Journal of Alzheimer's Disease 20, 1069-1082.

Aiken, C. (1997). Pseudotyping human immunodeficiency virus type 1 (HIV-1) by the glycoprotein of vesicular stomatitis virus targets HIV-1 entry to an endocytic pathway and suppresses both the requirement for Nef and the sensitivity to cyclosporin $A$. J. Virol. 71, 5871-5877.

Ali, S.H., and DeCaprio, J.A. (2001). Cellular transformation by SV40 large T antigen: interaction with host proteins. Semin. Cancer Biol. 11, 15-23.

Amado, R.G., and Chen, I.S.Y. (1999). Lentiviral Vectors--the Promise of Gene Therapy Within Reach? Science 285, 674-676.

Apolonia, L., Waddington, S.N., Fernandes, C., Ward, N.J., Bouma, G., Blundell, M.P., Thrasher, A.J., Collins, M.K., and Philpott, N.J. (2007). Stable gene transfer to muscle using non-integrating lentiviral vectors. Mol. Ther. 15, 1947-1954.

Bachellerie, J.-P., Cavaillé, J., and Hüttenhofer, A. (2002). The expanding snoRNA world. Biochimie 84, 775-790.

Bartel, D.P. (2004). MicroRNAs: Genomics, Biogenesis, Mechanism, and Function. Cell 116, 281-297.

Blaese, R.M., Culver, K.W., Miller, A.D., Carter, C.S., Fleisher, T., Clerici, M., Shearer, G., Chang, L., Chiang, Y., Tolstoshev, P., et al. (1995). T Lymphocyte-Directed Gene Therapy for ADA- SCID: Initial Trial Results After 4 Years. Science 270, 475-480.

Böker, K.O., Lemus-Diaz, N., Ferreira, R.R., Schiller, L., Schneider, S., and Gruber, J. (2018). The Impact of the CD9 Tetraspanin on Lentivirus Infectivity and Exosome Secretion. Molecular Therapy 26, 634-647.

Bose, S., Zokarkar, A., Welch, B.D., Leser, G.P., Jardetzky, T.S., and Lamb, R.A. (2012). Fusion activation by a headless parainfluenza virus 5 hemagglutininneuraminidase stalk suggests a modular mechanism for triggering. PNAS 109, E2625E2634.

Brameier, M., Herwig, A., Reinhardt, R., Walter, L., and Gruber, J. (2011). Human box C/D snoRNAs with miRNA like functions: expanding the range of regulatory RNAs. Nucleic Acids Res. 39, 675-686.

Brines, M.L., Ghezzi, P., Keenan, S., Agnello, D., Lanerolle, N.C. de, Cerami, C., Itri, L.M., and Cerami, A. (2000). Erythropoietin crosses the blood-brain barrier to protect against experimental brain injury. PNAS 97, 10526-10531. 
Carter, B.J. (2004). Adeno-associated virus and the development of adeno-associated virus vectors: a historical perspective. Molecular Therapy 10, 981-989.

Cavazzana-Calvo, M. (2000). Gene Therapy of Human Severe Combined Immunodeficiency (SCID)-X1 Disease. Science 288, 669-672.

Chaipan, C., Kobasa, D., Bertram, S., Glowacka, I., Steffen, I., Solomon Tsegaye, T., Takeda, M., Bugge, T.H., Kim, S., Park, Y., et al. (2009). Proteolytic Activation of the 1918 Influenza Virus Hemagglutinin. Journal of Virology 83, 3200-3211.

Chavez, A., Scheiman, J., Vora, S., Pruitt, B.W., Tuttle, M., Iyer, E., Kiani, S., Guzman, C.D., Wiegand, D.J., Ter-Ovanesyan, D., et al. (2014). Highly-efficient Cas9-mediated transcriptional programming. BioRxiv.

Chen, W.Y., Bailey, E.C., McCune, S.L., Dong, J.-Y., and Townes, T.M. (1997). Reactivation of silenced, virally transduced genes by inhibitors of histone deacetylase. Proceedings of the National Academy of Sciences 94, 5798-5803.

Cléry, A., Senty-Ségault, V., Leclerc, F., Raué, H.A., and Branlant, C. (2007). Analysis of Sequence and Structural Features That Identify the B/C Motif of U3 Small Nucleolar RNA as the Recognition Site for the Snu13p-Rrp9p Protein Pair. Mol Cell Biol 27, 1191-1206.

Cong, L., Ran, F.A., Cox, D., Lin, S., Barretto, R., Habib, N., Hsu, P.D., Wu, X., Jiang, W., Marraffini, L.A., et al. (2013). Multiplex Genome Engineering Using CRISPR/Cas Systems. Science 339, 819-823.

Coussens, L., Yang-Feng, T.L., Liao, Y.C., Chen, E., Gray, A., McGrath, J., Seeburg, P.H., Libermann, T.A., Schlessinger, J., Francke, U., et al. (1985). Tyrosine kinase receptor with extensive homology to EGF receptor shares chromosomal location with neu oncogene. Science 230, 1132-1139.

Cullen, B.R. (2005). RNAi the natural way. Nature Genetics 37, 1163-1165.

Davis, H.E., Morgan, J.R., and Yarmush, M.L. (2002). Polybrene increases retrovirus gene transfer efficiency by enhancing receptor-independent virus adsorption on target cell membranes. Biophysical Chemistry 97, 159-172.

Deltcheva, E., Chylinski, K., Sharma, C.M., Gonzales, K., Chao, Y., Pirzada, Z.A., Eckert, M.R., Vogel, J., and Charpentier, E. (2011). CRISPR RNA maturation by transencoded small RNA and host factor RNase III. Nature 471, 602-607.

Dissen, G.A., Lomniczi, A., Neff, T.L., Hobbs, T.R., Kohama, S.G., Kroenke, C.D., Galimi, F., and Ojeda, S.R. (2009). In vivo manipulation of gene expression in nonhuman primates using lentiviral vectors as delivery vehicles. Methods 49, 70-77.

Ender, C., Krek, A., Friedländer, M.R., Beitzinger, M., Weinmann, L., Chen, W., Pfeffer, S., Rajewsky, N., and Meister, G. (2008). A human snoRNA with microRNA-like functions. Mol. Cell 32, 519-528.

Fan, X., Brun, A., and Karlsson, S. (2000). Adenoviral vector design for high-level transgene expression in primitive human hematopoietic progenitors. Gene Therapy 7, 2132-2138. 
Fire, A., Xu, S., Montgomery, M.K., Kostas, S.A., Driver, S.E., and Mello, C.C. (1998). Potent and specific genetic interference by double-stranded RNA in Caenorhabditis elegans. Nature 391, 806-811.

Fisher, J.W. (2003). Erythropoietin: Physiology and Pharmacology Update. Exp Biol Med (Maywood) 228, 1-14.

Flotte, P.I.T., Carter, C.-I.B., Conrad, C., Guggino, W., Reynolds, T., Rosenstein, B., Taylor, G., Walden, S., and Wetzel, R. (2008). A Phase I Study of an Adeno-Associated Virus-CFTR Gene Vector in Adult CF Patients with Mild Lung Disease. Johns Hopkins Children's Center, Baltimore, Maryland.

Gasiunas, G., Barrangou, R., Horvath, P., and Siksnys, V. (2012). Cas9-crRNA ribonucleoprotein complex mediates specific DNA cleavage for adaptive immunity in bacteria. Proceedings of the National Academy of Sciences 109, E2579-E2586.

Geraerts, M., Willems, S., Baekelandt, V., Debyser, Z., and Gijsbers, R. (2006). Comparison of lentiviral vector titration methods. BMC Biotechnol 6, 34 .

Gilbert, L.A., Larson, M.H., Morsut, L., Liu, Z., Brar, G.A., Torres, S.E., Stern-Ginossar, N., Brandman, O., Whitehead, E.H., Doudna, J.A., et al. (2013). CRISPR-Mediated Modular RNA-Guided Regulation of Transcription in Eukaryotes. Cell 154, 442-451.

Gilbert, L.A., Horlbeck, M.A., Adamson, B., Villalta, J.E., Chen, Y., Whitehead, E.H., Guimaraes, C., Panning, B., Ploegh, H.L., Bassik, M.C., et al. (2014). Genome-Scale CRISPR-Mediated Control of Gene Repression and Activation. Cell 159, 647-661.

Gluska, S., Zahavi, E.E., Chein, M., Gradus, T., Bauer, A., Finke, S., and Perlson, E. (2014). Rabies Virus Hijacks and Accelerates the p75NTR Retrograde Axonal Transport Machinery. PLoS Pathogens 10, e1004348.

González, F., Zhu, Z., Shi, Z.-D., Lelli, K., Verma, N., Li, Q.V., and Huangfu, D. (2014). An iCRISPR Platform for Rapid, Multiplexable, and Inducible Genome Editing in Human Pluripotent Stem Cells. Cell Stem Cell 15, 215-226.

Govindarajan, N., Agis-Balboa, R.C., Walter, J., Sananbenesi, F., and Fischer, A. (2011). Sodium Butyrate Improves Memory Function in an Alzheimer's Disease Mouse Model When Administered at an Advanced Stage of Disease Progression. Journal of Alzheimer's Disease 26, 187-197.

Gray, C., and Tamm, L.K. (1998). pH-Induced conformational changes of membranebound influenza hemagglutinin and its effect on target lipid bilayers. Protein Science 7, 2359-2373.

Hacein-Bey-Abina, S., Kalle, C.V., Schmidt, M., McCormack, M.P., Wulffraat, N., Leboulch, P., Lim, A., Osborne, C.S., Pawliuk, R., Morillon, E., et al. (2003). LMO2Associated Clonal T Cell Proliferation in Two Patients after Gene Therapy for SCIDX1. Science 302, 415-419.

Hahn, N., Knorr, D.Y., Liebig, J., Wüstefeld, L., Peters, K., Büscher, M., Bucher, G., Ehrenreich, H., and Heinrich, R. (2017). The Insect Ortholog of the Human Orphan 
Cytokine Receptor CRLF3 Is a Neuroprotective Erythropoietin Receptor. Front Mol Neurosci 10.

Hartigan-O'Connor, D., Kirk, C.J., Crawford, R., Mulé, J.J., and Chamberlain, J.S. (2001). Immune Evasion by Muscle-Specific Gene Expression in Dystrophic Muscle. Molecular Therapy 4, 525-533.

Hemler, M.E. (2005). Tetraspanin functions and associated microdomains. Nature Reviews Molecular Cell Biology 6, 801-811.

Huang, E.J., and Reichardt, L.F. (2003). Trk Receptors: Roles in Neuronal Signal Transduction. Annu. Rev. Biochem. 72, 609-642.

JnBaptiste, C.K., Gurtan, A.M., Thai, K.K., Lu, V., Bhutkar, A., Su, M.-J., Rotem, A., Jacks, T., and Sharp, P.A. (2017). Dicer loss and recovery induce an oncogenic switch driven by transcriptional activation of the oncofetal Imp1-3 family. Genes Dev. 31, 674-687.

Kanellopoulou, C., Muljo, S.A., Kung, A.L., Ganesan, S., Drapkin, R., Jenuwein, T., Livingston, D.M., and Rajewsky, K. (2005). Dicer-deficient mouse embryonic stem cells are defective in differentiation and centromeric silencing. Genes Dev. 19, 489-501.

Karapetyan, A.R., Buiting, C., Kuiper, R.A., and Coolen, M.W. (2013). Regulatory Roles for Long ncRNA and mRNA. Cancers (Basel) 5, 462-490.

Khetawat, D., and Broder, C.C. (2010). A Functional Henipavirus Envelope Glycoprotein Pseudotyped Lentivirus Assay System. Virol J 7, 312.

Kim, Y.-K., Kim, B., and Kim, V.N. (2016). Re-evaluation of the roles of DROSHA, Exportin 5 , and DICER in microRNA biogenesis. Proceedings of the National Academy of Sciences 113, E1881-E1889.

Konermann, S., Brigham, M.D., Trevino, A., Hsu, P.D., Heidenreich, M., Cong, L., Platt, R.J., Scott, D.A., Church, G.M., and Zhang, F. (2013). Optical control of mammalian endogenous transcription and epigenetic states. Nature 500, 472-476.

Konermann, S., Brigham, M.D., Trevino, A.E., Joung, J., Abudayyeh, O.O., Barcena, C., Hsu, P.D., Habib, N., Gootenberg, J.S., Nishimasu, H., et al. (2015). Genome-scale transcriptional activation by an engineered CRISPR-Cas9 complex. Nature 517, 583588.

Konishi, Y., Chui, D.H., Hirose, H., Kunishita, T., and Tabira, T. (1993). Trophic effect of erythropoietin and other hematopoietic factors on central cholinergic neurons in vitro and in vivo. Brain Res. 609, 29-35.

Kristen, A.V., Ajroud-Driss, S., Conceição, I., Gorevic, P., Kyriakides, T., and Obici, L. (2019). Patisiran, an RNAi therapeutic for the treatment of hereditary transthyretinmediated amyloidosis. Neurodegenerative Disease Management 9, 5-23.

Kutner, R.H., Zhang, X.-Y., and Reiser, J. (2009). Production, concentration and titration of pseudotyped HIV-1-based lentiviral vectors. Nature Protocols 4, 495-505. 
La Russa, M.F., and Qi, L.S. (2015). The New State of the Art: Cas9 for Gene Activation and Repression. Molecular and Cellular Biology 35, 3800-3809.

Lafon, M. (2005). Rabies virus receptors. J. Neurovirol. 11, 82-87.

Lei, Y., Joo, K.-I., and Wang, P. (2009). Engineering fusogenic molecules to achieve targeted transduction of enveloped lentiviral vectors. J Biol Eng 3, 8.

Lei, Y., Joo, K.-I., Zarzar, J., Wong, C., and Wang, P. (2010). Targeting lentiviral vector to specific cell types through surface displayed single chain antibody and fusogenic molecule. Virology Journal 7, 35.

Leist, M., Ghezzi, P., Grasso, G., Bianchi, R., Villa, P., Fratelli, M., Savino, C., Bianchi, M., Nielsen, J., Gerwien, J., et al. (2004). Derivatives of erythropoietin that are tissue protective but not erythropoietic. Science 305, 239-242.

Lemus-Diaz, N., Böker, K.O., Rodriguez-Polo, I., Mitter, M., Preis, J., Arlt, M., and Gruber, J. (2017). Dissecting miRNA gene repression on single cell level with an advanced fluorescent reporter system. Sci Rep 7.

Lemus-Diaz, N., Tamon, L., and Gruber, J. (2018). Dual Fluorescence Reporter Based Analytical Flow Cytometry for miRNA Induced Regulation in Mammalian Cells. BIOPROTOCOL 8.

Leung, K.T., Chan, K.Y.Y., Ng, P.C., Lau, T.K., Chiu, W.M., Tsang, K.S., Li, C.K., Kong, C.K.L., and Li, K. (2011). The tetraspanin CD9 regulates migration, adhesion, and homing of human cord blood CD34+ hematopoietic stem and progenitor cells. Blood 117, 1840-1850.

Levine, B.L., Humeau, L.M., Boyer, J., MacGregor, R.-R., Rebello, T., Lu, X., Binder, G.K., Slepushkin, V., Lemiale, F., Mascola, J.R., et al. (2006). Gene transfer in humans using a conditionally replicating lentiviral vector. Proc Natl Acad Sci U S A 103, 17372 17377.

Lin, P., Correa, D., Lin, Y., and Caplan, A.I. (2011). Polybrene Inhibits Human Mesenchymal Stem Cell Proliferation during Lentiviral Transduction. PLoS One 6.

Maeder, M.L., Linder, S.J., Cascio, V.M., Fu, Y., Ho, Q.H., and Joung, J.K. (2013). CRISPR RNA-guided activation of endogenous human genes. Nat Methods 10, 977979.

Maguire, C.A., Balaj, L., Sivaraman, S., Crommentuijn, M.H., Ericsson, M., MinchevaNilsson, L., Baranov, V., Gianni, D., Tannous, B.A., Sena-Esteves, M., et al. (2012). Microvesicle-associated AAV Vector as a Novel Gene Delivery System. Molecular Therapy 20, 960-971.

Mali, P., Yang, L., Esvelt, K.M., Aach, J., Guell, M., DiCarlo, J.E., Norville, J.E., and Church, G.M. (2013a). RNA-Guided Human Genome Engineering via Cas9. Science 339, 823-826.

Mali, P., Aach, J., Stranges, P.B., Esvelt, K.M., Moosburner, M., Kosuri, S., Yang, L., and Church, G.M. (2013b). CAS9 transcriptional activators for target specificity 
screening and paired nickases for cooperative genome engineering. Nature Biotechnology 31, 833-838.

Masuda, S., Okano, M., Yamagishi, K., Nagao, M., Ueda, M., and Sasaki, R. (1994). A novel site of erythropoietin production. Oxygen-dependent production in cultured rat astrocytes. J. Biol. Chem. 269, 19488-19493.

Mitri, Z., Constantine, T., and O'Regan, R. (2012). The HER2 Receptor in Breast Cancer: Pathophysiology, Clinical Use, and New Advances in Therapy. Chemother Res Pract 2012.

Miyado, K., Yamada, G., Yamada, S., Hasuwa, H., Nakamura, Y., Ryu, F., Suzuki, K., Kosai, K., Inoue, K., Ogura, A., et al. (2000). Requirement of CD9 on the Egg Plasma Membrane for Fertilization. Science 287, 321-324.

Mojica, F.J.M., Díez-Villaseñor, C., García-Martínez, J., and Soria, E. (2005). Intervening Sequences of Regularly Spaced Prokaryotic Repeats Derive from Foreign Genetic Elements. J Mol Evol 60, 174-182.

Morishita, E., Masuda, S., Nagao, M., Yasuda, Y., and Sasaki, R. (1996). Erythropoietin receptor is expressed in rat hippocampal and cerebral cortical neurons, and erythropoietin prevents in vitro glutamate-induced neuronal death. Neuroscience 76, 105-116.

Naldini, L., Blomer, U., Gallay, P., Ory, D., Mulligan, R., Gage, F.H., Verma, I.M., and Trono, D. (1996). In Vivo Gene Delivery and Stable Transduction of Nondividing Cells by a Lentiviral Vector. Science 272, 263-267.

Naso, M.F., Tomkowicz, B., Perry, W.L., and Strohl, W.R. (2017). Adeno-Associated Virus (AAV) as a Vector for Gene Therapy. BioDrugs 31, 317-334.

Nightingale, S.J., Hollis, R.P., Pepper, K.A., Petersen, D., Yu, X.-J., Yang, C., Bahner, I., and Kohn, D.B. (2006). Transient gene expression by nonintegrating lentiviral vectors. Mol. Ther. 13, 1121-1132.

Ott, M.G., Schmidt, M., Schwarzwaelder, K., Stein, S., Siler, U., Koehl, U., Glimm, H., Kühlcke, K., Schilz, A., Kunkel, H., et al. (2006). Correction of X-linked chronic granulomatous disease by gene therapy, augmented by insertional activation of MDS1-EVI1, PRDM16 or SETBP1. Nature Medicine 12, 401-409.

Paddison, P.J. (2002). Short hairpin RNAs (shRNAs) induce sequence-specific silencing in mammalian cells. Genes \& Development 16, 948-958.

Palfi, S., Gurruchaga, J.M., Ralph, G.S., Lepetit, H., Lavisse, S., Buttery, P.C., Watts, C., Miskin, J., Kelleher, M., Deeley, S., et al. (2014). Long-term safety and tolerability of ProSavin, a lentiviral vector-based gene therapy for Parkinson's disease: a dose escalation, open-label, phase 1/2 trial. Lancet 383, 1138-1146.

Palfi, S., Gurruchaga, J.M., Lepetit, H., Howard, K., Ralph, G.S., Mason, S., Gouello, G., Domenech, P., Buttery, P.C., Hantraye, P., et al. (2018). Long-Term Follow-Up of a Phase I/II Study of ProSavin, a Lentiviral Vector Gene Therapy for Parkinson's Disease. Hum Gene Ther Clin Dev 29, 148-155. 
Papadakis, E., Nicklin, S., Baker, A., and White, S. (2004). Promoters and Control Elements: Designing Expression Cassettes for Gene Therapy. Current Gene Therapy $4,89-113$.

Pastore, L., Morral, N., Zhou, H., Garcia, R., Parks, R.J., Kochanek, S., Graham, F.L., Lee, B., and Beaudet, A.L. (1999). Use of a Liver-Specific Promoter Reduces Immune Response to the Transgene in Adenoviral Vectors. Human Gene Therapy 10, 17731781.

Perez-Pinera, P., Kocak, D.D., Vockley, C.M., Adler, A.F., Kabadi, A.M., Polstein, L.R., Thakore, P.I., Glass, K.A., Ousterout, D.G., Leong, K.W., et al. (2013). RNA-guided gene activation by CRISPR-Cas9-based transcription factors. Nature Methods 10, 973-976.

Porotto, M., Salah, Z.W., Gui, L., DeVito, I., Jurgens, E.M., Lu, H., Yokoyama, C.C., Palermo, L.M., Lee, K.K., and Moscona, A. (2012). Regulation of Paramyxovirus Fusion Activation: the Hemagglutinin-Neuraminidase Protein Stabilizes the Fusion Protein in a Pretriggered State. Journal of Virology 86, 12838-12848.

Pourcel, C., Salvignol, G., and Vergnaud, G. (2005). CRISPR elements in Yersinia pestis acquire new repeats by preferential uptake of bacteriophage DNA, and provide additional tools for evolutionary studies. Microbiology 151, 653-663.

Qi, L.S., Larson, M.H., Gilbert, L.A., Doudna, J.A., Weissman, J.S., Arkin, A.P., and Lim, W.A. (2013). Repurposing CRISPR as an RNA-Guided Platform for SequenceSpecific Control of Gene Expression. Cell 152, 1173-1183.

Quan, Z., Zheng, D., and Qing, H. (2017). Regulatory Roles of Long Non-Coding RNAs in the Central Nervous System and Associated Neurodegenerative Diseases. Front. Cell. Neurosci. 11.

Racay, P. (2002). Genetically modified animals and human medicine. Bratisl Lek Listy 103, 121-126.

Ramezani, A., Hawley, T.S., and Hawley, R.G. (2000). Lentiviral Vectors for Enhanced Gene Expression in Human Hematopoietic Cells. Molecular Therapy 2, 458-469.

Reed, M.L., Bridges, O.A., Seiler, P., Kim, J.-K., Yen, H.-L., Salomon, R., Govorkova, E.A., Webster, R.G., and Russell, C.J. (2010). The pH of Activation of the Hemagglutinin Protein Regulates H5N1 Influenza Virus Pathogenicity and Transmissibility in Ducks. Journal of Virology 84, 1527-1535.

Reyes, R., Cardeñes, B., Machado-Pineda, Y., and Cabañas, C. (2018). Tetraspanin CD9: A Key Regulator of Cell Adhesion in the Immune System. Front Immunol 9.

Sanjana, N.E., Shalem, O., and Zhang, F. (2014). Improved vectors and genome-wide libraries for CRISPR screening. Nature Methods 11, 783-784.

Sakanaka, M., Wen, T.-C., Matsuda, S., Masuda, S., Morishita, E., Nagao, M., and Sasaki, R. (1998). In vivo evidence that erythropoietin protects neurons from ischemic damage. PNAS 95, 4635-4640. 
Schiller, L.T., Lemus-Diaz, N., Rinaldi Ferreira, R., Böker, K.O., and Gruber, J. (2018). Enhanced Production of Exosome-Associated AAV by Overexpression of the Tetraspanin CD9. Mol Ther Methods Clin Dev 9, 278-287.

Schwarzwaelder, K., Howe, S.J., Schmidt, M., Brugman, M.H., Deichmann, A., Glimm, H., Schmidt, S., Prinz, C., Wissler, M., King, D.J.S., et al. (2007). Gammaretrovirusmediated correction of SCID-X1 is associated with skewed vector integration site distribution in vivo. J. Clin. Invest. 117, 2241-2249.

Sena-Esteves, M., Tebbets, J.C., Steffens, S., Crombleholme, T., and Flake, A.W. (2004). Optimized large-scale production of high titer lentivirus vector pseudotypes. Journal of Virological Methods 122, 131-139.

Shaw, A., and Cornetta, K. (2014). Design and Potential of Non-Integrating Lentiviral Vectors. Biomedicines 2, 14-35.

Sheridan, C. (2011). Gene therapy finds its niche. Nature Biotechnology 29, 121-128.

Stroes, E.S., Nierman, M.C., Meulenberg, J.J., Franssen, R., Twisk, J., Henny, C.P., Maas, M.M., Zwinderman, A.H., Ross, C., Aronica, E., et al. (2008). Intramuscular Administration of AAV1-Lipoprotein Lipase S447X Lowers Triglycerides in Lipoprotein Lipase-Deficient Patients. Arteriosclerosis, Thrombosis, and Vascular Biology 28, 2303-2304.

Stewart, S.A. (2003). Lentivirus-delivered stable gene silencing by RNAi in primary cells. RNA 9, 493-501.

Tanenbaum, M.E., Gilbert, L.A., Qi, L.S., Weissman, J.S., and Vale, R.D. (2014). A Protein-Tagging System for Signal Amplification in Gene Expression and Fluorescence Imaging. Cell 159, 635-646.

Thompson, A.A., Kwiatkowski, J., Rasko, J., Hongeng, S., Schiller, G.J., Anurathapan, U., Cavazzana, M., Ho, P.J., Kalle, C. von, Kletzel, M., et al. (2016). Lentiglobin Gene Therapy for Transfusion-Dependent $\beta$-Thalassemia: Update from the Northstar Hgb204 Phase 1/2 Clinical Study. Blood 128, 1175-1175.

Vance, K.W., and Ponting, C.P. (2014). Transcriptional regulatory functions of nuclear long noncoding RNAs. Trends in Genetics 30, 348-355.

Watkins, N.J., Lemm, I., and Lührmann, R. (2007). Involvement of Nuclear Import and Export Factors in U8 Box C/D snoRNP Biogenesis. Molecular and Cellular Biology 27, 7018-7027.

Weeratna, R., Wu, T., Efler, S., Zhang, L., and Davis, H. (2001). Designing gene therapy vectors: avoiding immune responses by using tissue-specific promoters. Gene Therapy 8, 1872-1878.

Yang, L., Bailey, L., Baltimore, D., and Wang, P. (2006). Targeting lentiviral vectors to specific cell types in vivo. Proceedings of the National Academy of Sciences 103, 11479-11484. 
Yoo, A.S., Sun, A.X., Li, L., Shcheglovitov, A., Portmann, T., Li, Y., Lee-Messer, C., Dolmetsch, R.E., Tsien, R.W., and Crabtree, G.R. (2011). MicroRNA-mediated conversion of human fibroblasts to neurons. Nature 476, 228-231.

Zufferey, R., Dull, T., Mandel, R.J., Bukovsky, A., Quiroz, D., Naldini, L., and Trono, D. (1998). Self-Inactivating Lentivirus Vector for Safe and Efficient In Vivo Gene Delivery. J. VIROL. 72, 8.

\section{Appendix}

\subsection{Plasmid maps: constructs generated in this thesis}
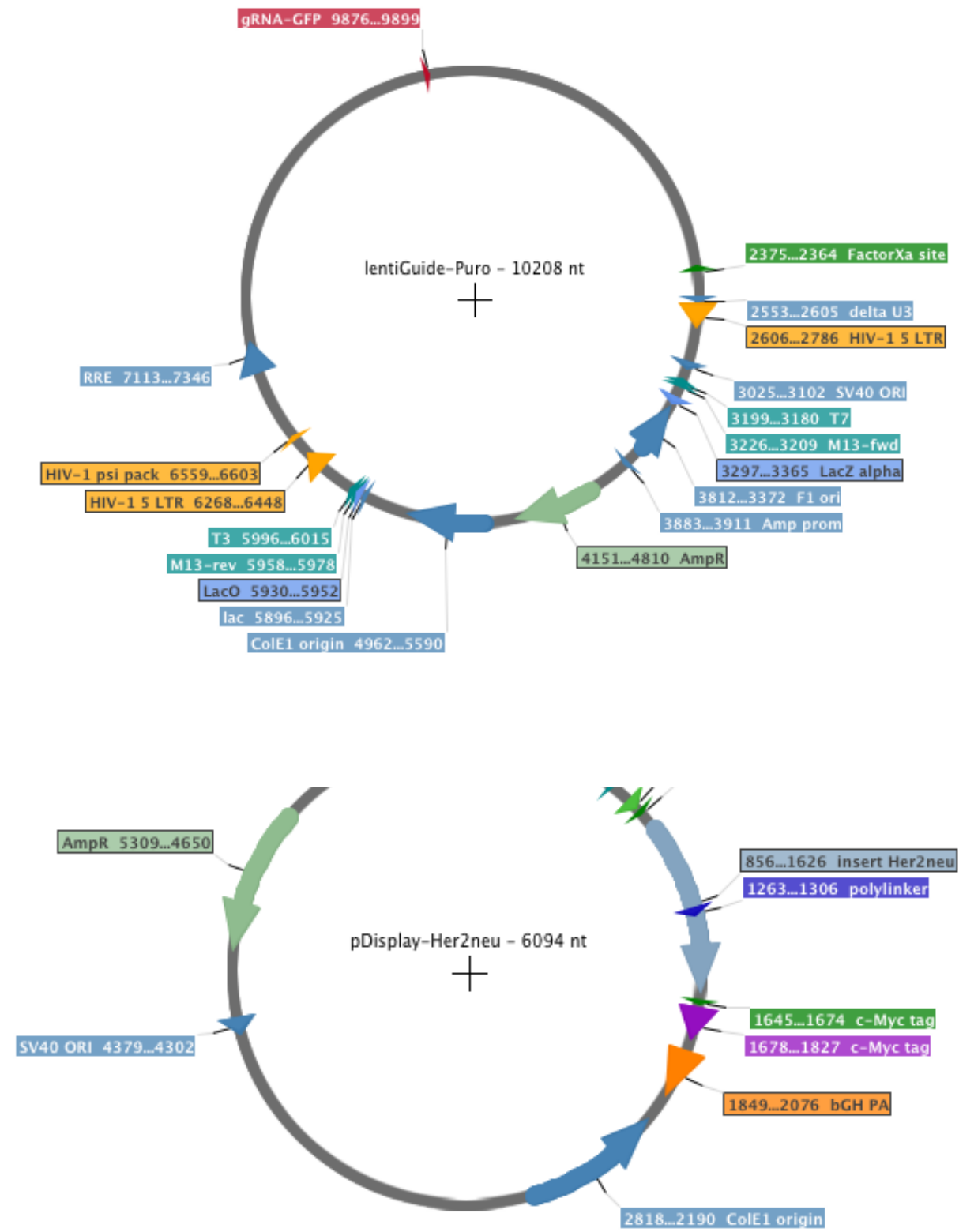


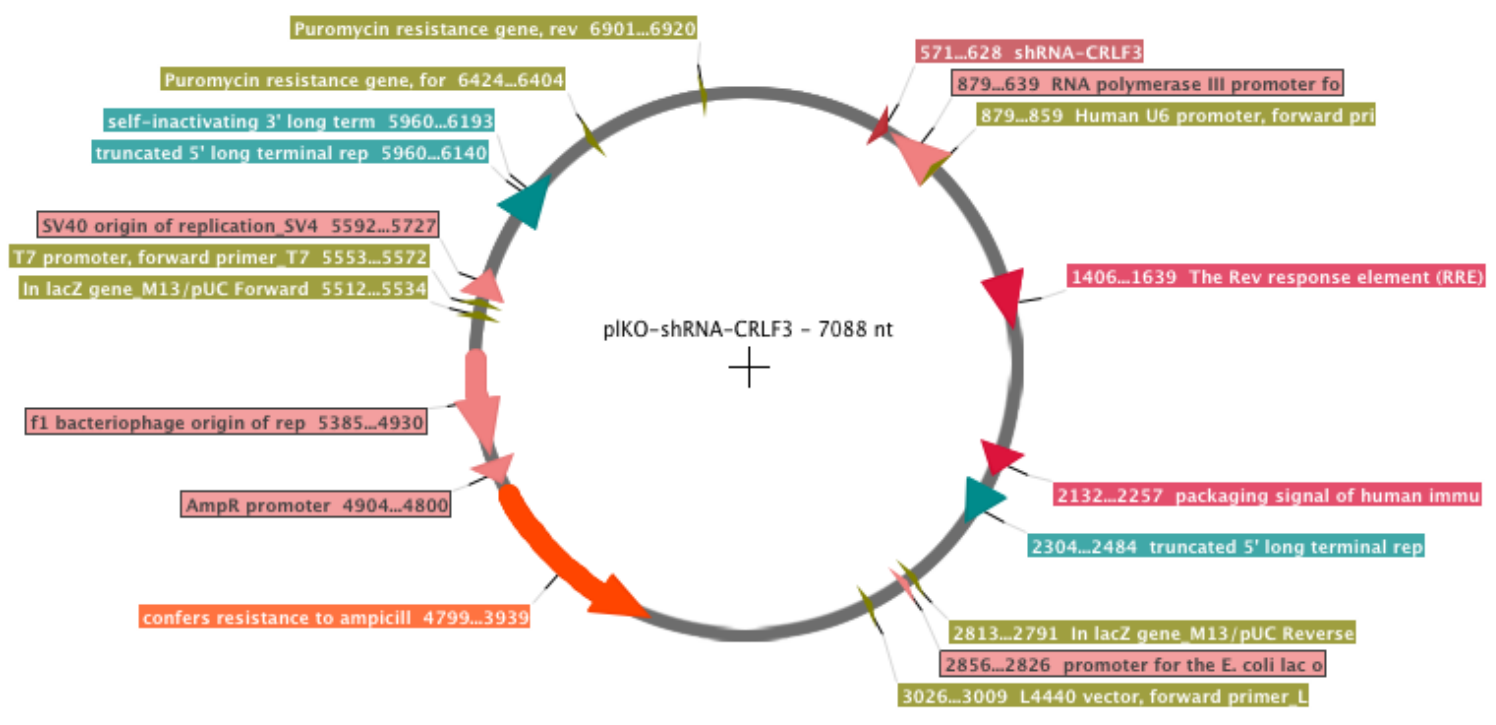


5.2. Plasmid maps: constructs obtained from depositors at addgene.org

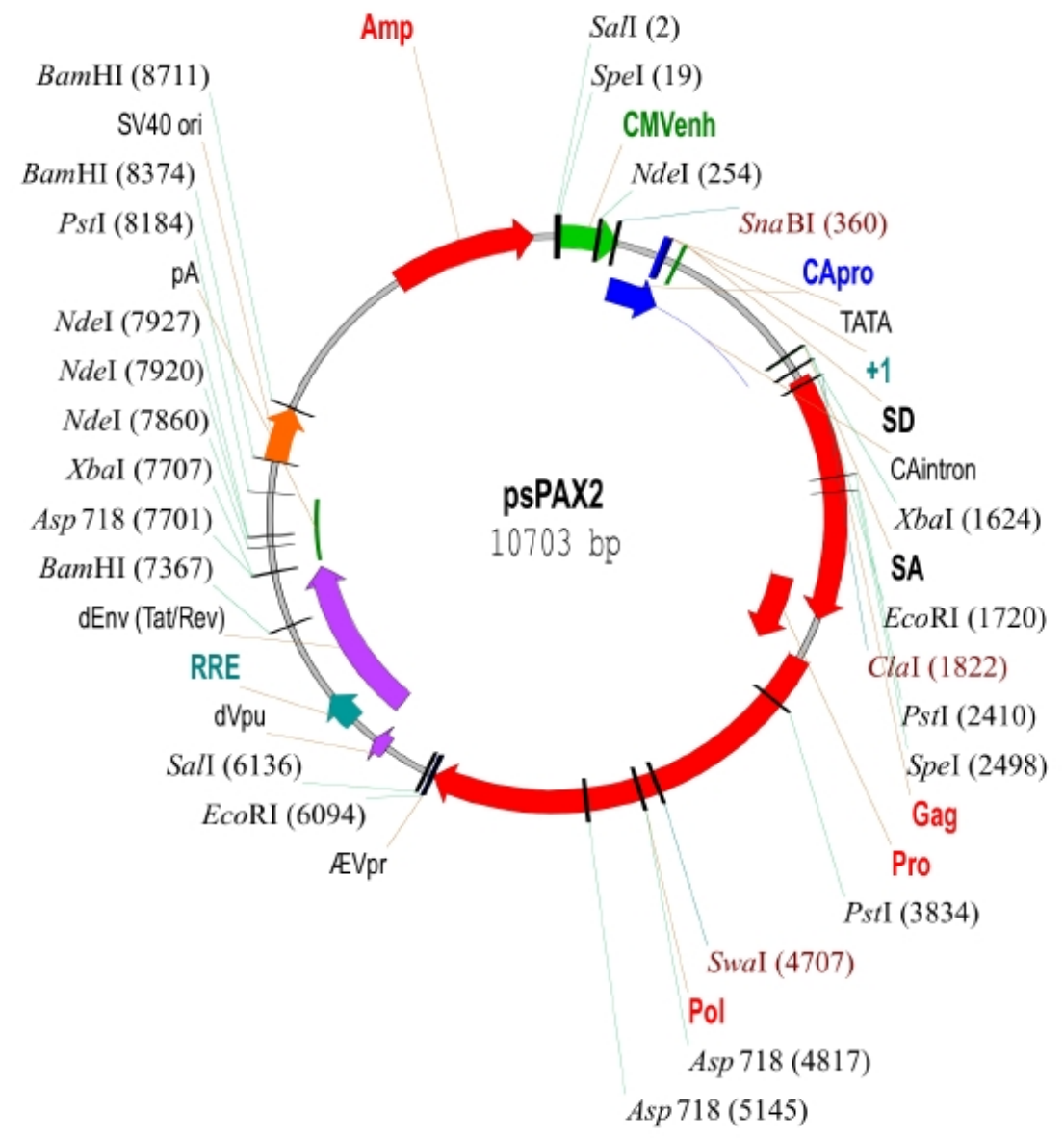




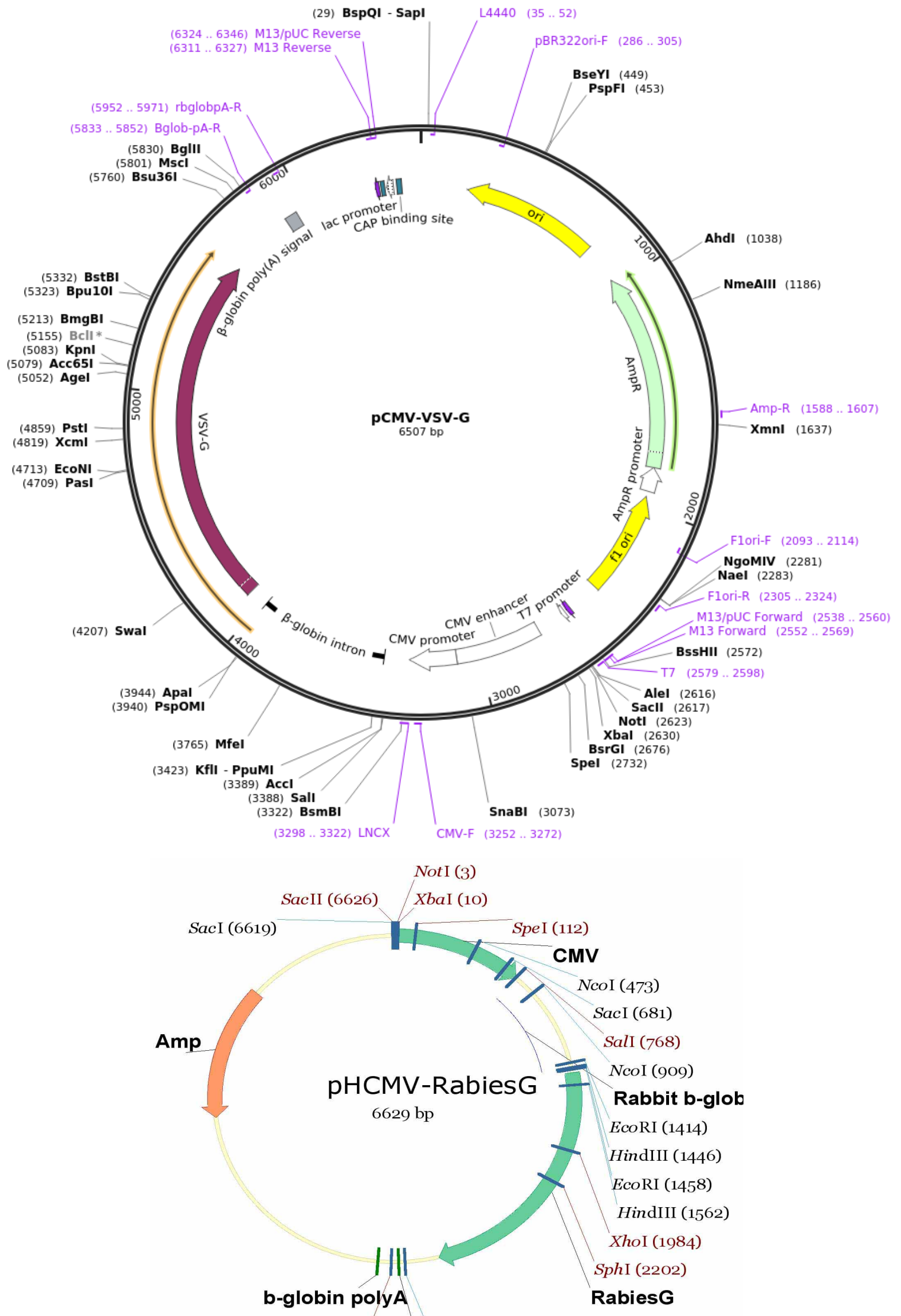

BglII (3331) EcoRI (3251)

b-globin polyA 


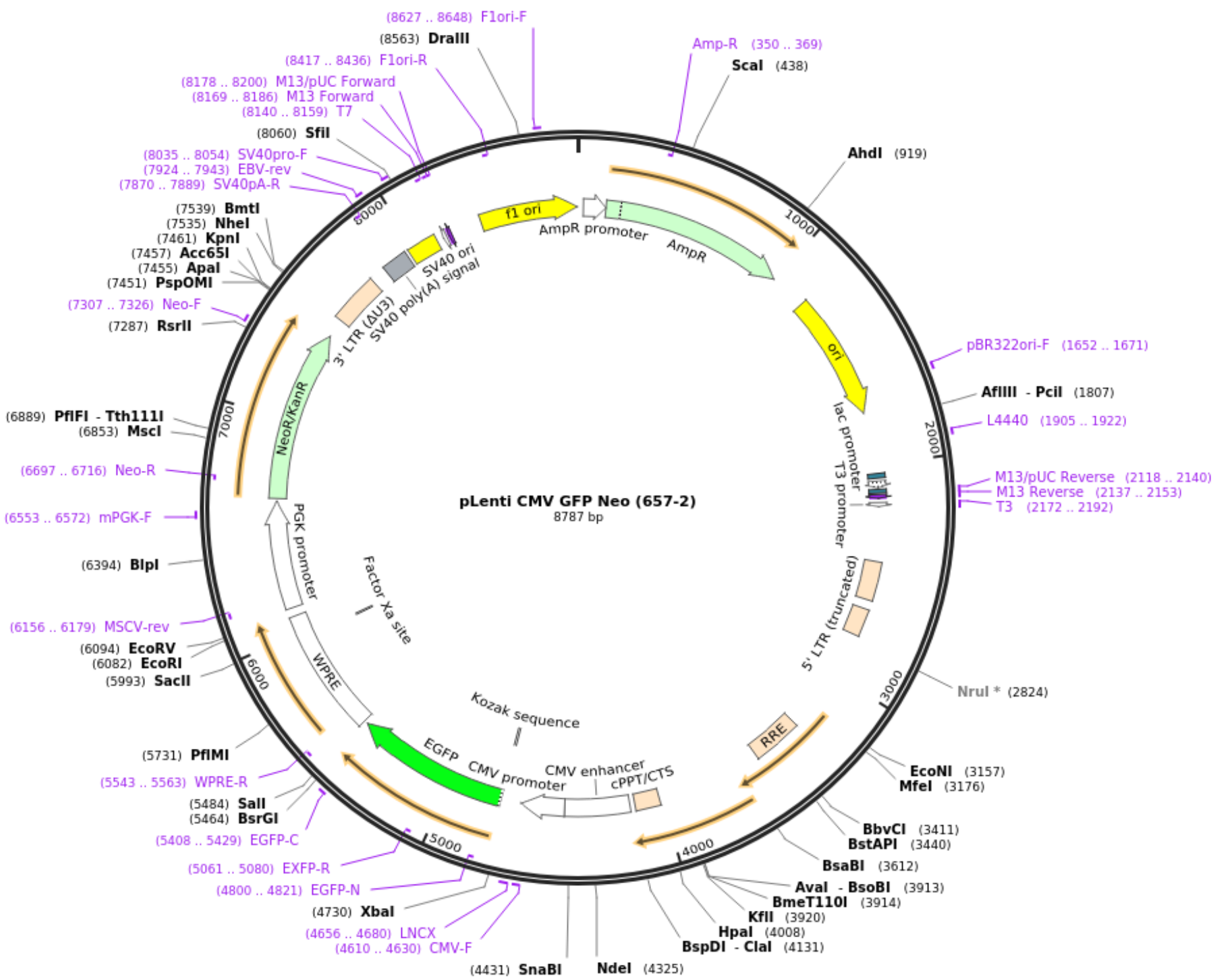




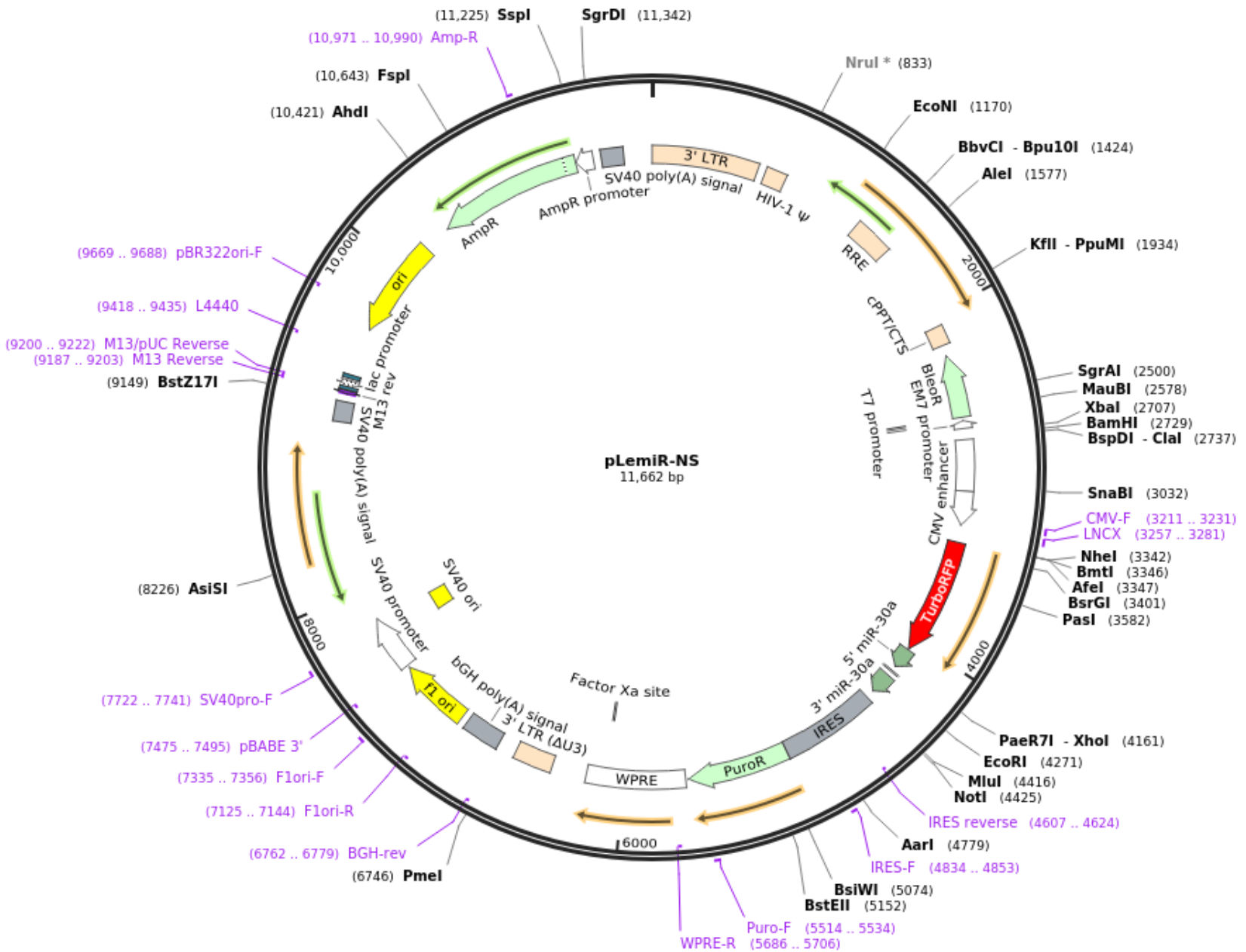




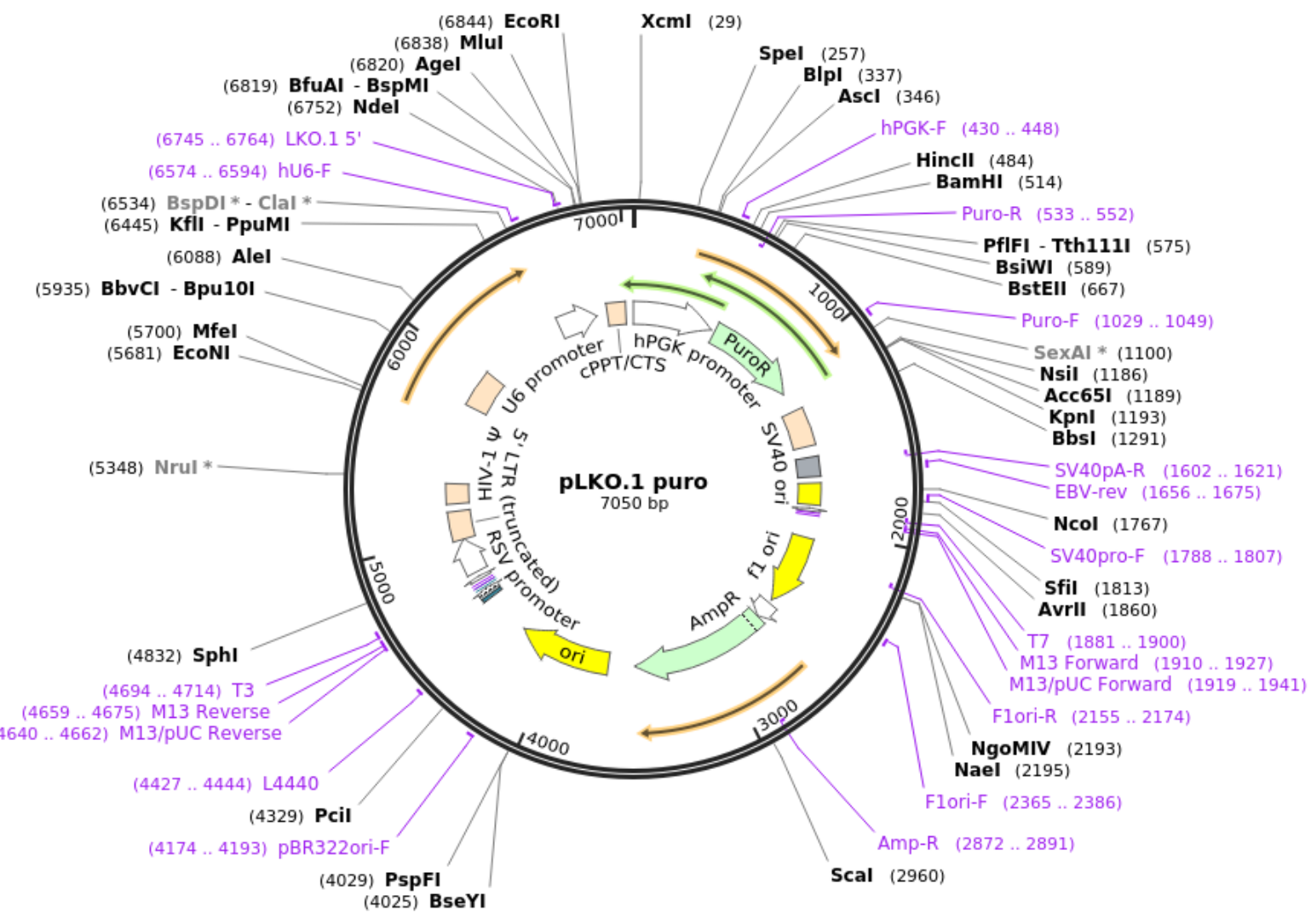




\subsection{Plasmid maps: constructs obtained from other sources}

For more information on plasmid purposes and origin see tables 4 and 5 .
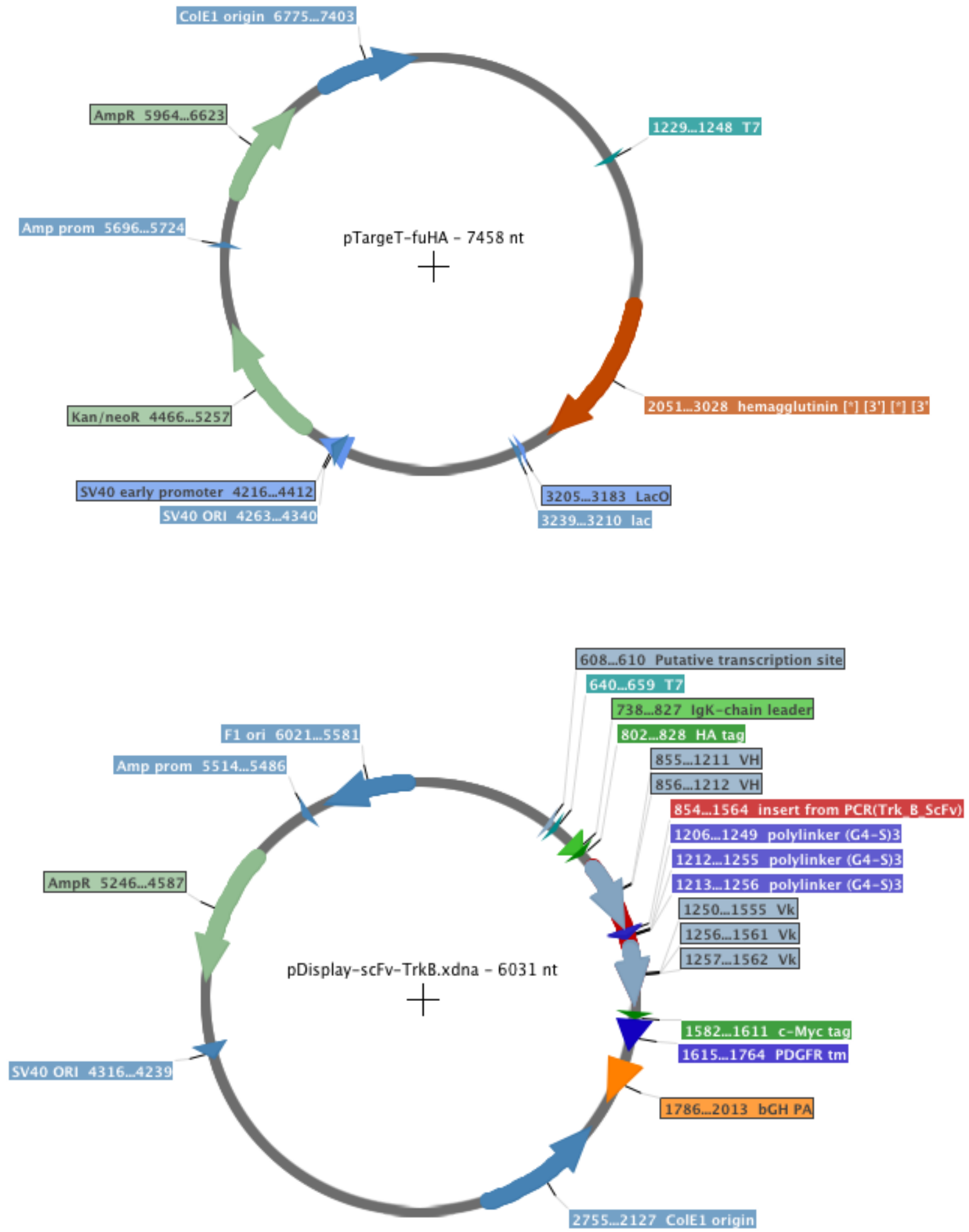


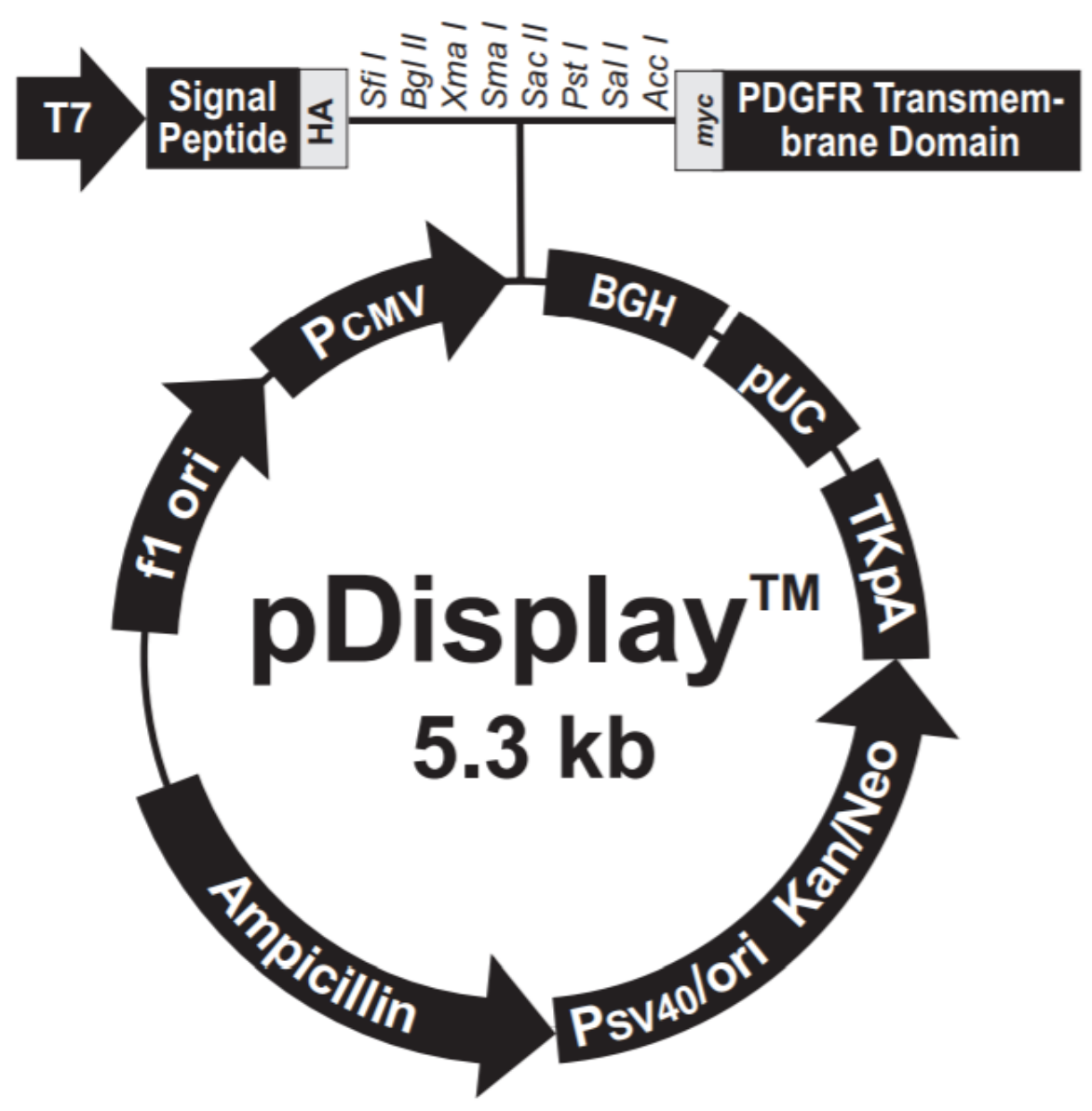




\section{Publications}

K. Böker, N. Lemus-Diaz, R. Rinaldi Ferreira, L. Schiller, S. Schneider, and J. Gruber. "The impact of the cd9 tetraspanin on lentivirus infectivity and exosome secretion." Molecular Therapy, 2017.

L. Schiller, N. Lemus-Diaz, R. Rinaldi Ferreira, K. Böker and J. Gruber. "Enhanced production of exosome-associated AAV by over-expression of the tetraspanin CD9." Molecular Therapy Methods \& Clinical Development, 2018.

Lemus-Diaz N, Rinaldi Ferreira R, Bohnsack KE, Gruber J, Bohnsack MT. The human box C/D snoRNA U3 is a miRNA source and miR-U3 regulates expression of sortin nexin 27. Nucleic Acids Research, Volume 48, Issue 14, 20 August 2020, Pages 80748089, https://doi.org/10.1093/nar/gkaa549 